\title{
Towards and inclusive society : health care for people with intellectual disability
}

Citation for published version (APA):

Wullink, M. (2010). Towards and inclusive society : health care for people with intellectual disability. [Doctoral Thesis, Maastricht University]. Datawyse / Universitaire Pers Maastricht. https://doi.org/10.26481/dis.20100331mw

Document status and date:

Published: 01/01/2010

DOI:

10.26481/dis.20100331mw

Document Version:

Publisher's PDF, also known as Version of record

\section{Please check the document version of this publication:}

- A submitted manuscript is the version of the article upon submission and before peer-review. There can be important differences between the submitted version and the official published version of record.

People interested in the research are advised to contact the author for the final version of the publication, or visit the DOI to the publisher's website.

- The final author version and the galley proof are versions of the publication after peer review.

- The final published version features the final layout of the paper including the volume, issue and page numbers.

Link to publication

\footnotetext{
General rights rights.

- You may freely distribute the URL identifying the publication in the public portal. please follow below link for the End User Agreement:

www.umlib.nl/taverne-license

Take down policy

If you believe that this document breaches copyright please contact us at:

repository@maastrichtuniversity.nl

providing details and we will investigate your claim.
}

Copyright and moral rights for the publications made accessible in the public portal are retained by the authors and/or other copyright owners and it is a condition of accessing publications that users recognise and abide by the legal requirements associated with these

- Users may download and print one copy of any publication from the public portal for the purpose of private study or research.

- You may not further distribute the material or use it for any profit-making activity or commercial gain

If the publication is distributed under the terms of Article $25 \mathrm{fa}$ of the Dutch Copyright Act, indicated by the "Taverne" license above, 


\section{TOWARDS}

\section{AN \\ INCLUSIVE SOCIETY}

health care for people with intellectual disability 
(C) 2010 Magda Wullink, Maastricht

Illustration: Vivian Heijckers (www.miemert.com)

Layout: Tiny Wouters

Production: Datawyse | Universitaire Pers Maastricht

ISBN: 978-90-5278-925-5

The studies presented in this dissertation were funded by grants from the Ministry of Health, Welfare and Sports (grant number 97-06-009), the Netherlands Organisation for Health Research and Development (ZonMw; grant numbers 1335.0018 and 1335.0029) and the Limburg provincial authorities (grant number 2002/36802 SA/0200191) and were conducted under the auspices of the School for Public Health and Primary Care (Caphri) at the Department of General Practice, Maastricht University, The Netherlands. 


\section{TOWARDS}

\section{AN \\ INCLUSIVE SOCIETY}

\section{health care for people with intellectual disability}

\section{PROEFSCHRIFT}

ter verkrijging van de graad van doctor aan de Universiteit Maastricht, op gezag van de Rector Magnificus, Prof. mr. G.P.M.F. Mols, volgens het besluit van het College van Decanen, in het openbaar te verdedigen op woensdag 31 maart 2010 om 14.00 uur

door

Magdalena Wullink geboren te Leiden

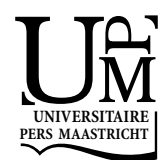




\section{Promotores:}

Prof. dr. G.J. Dinant

Prof. dr. J.F.M. Metsemakers

Prof. dr. H.M.J.van Schrojenstein Lantman - de Valk

(Radboud Universiteit Nijmegen)

\section{Beoordelingscommissie:}

Prof. dr. H.F.J.M. Crebolder, voorzitter

Prof. dr. L.M.G. Curfs

Prof. dr. H.M. Evenhuis (Erasmus Universiteit Rotterdam)

Prof. dr. E. Schadé (Universiteit van Amsterdam)

Dr. T. van der Weijden 
Opgedragen aan de nagedachtenis van Elisabeth Samson (1715-1771), een vrije, zwarte vrouw in het $18^{e}$-eeuwse Suriname

(Cynthia Mc Leod, 1996) 



\section{Table of Contents}

List of abbreviations $\quad 9$

$\begin{array}{ll}\text { Preface } & 10\end{array}$

$\begin{array}{lll}\text { Chapter } 1 & \text { General introduction } & 11\end{array}$

Chapter 2 The prevalence of intellectual disability in Limburg, 21 the Netherlands

Chapter 3 Prevalence of people with intellectual disability in the Netherlands

Chapter 4 Improving the transfer of care to general practice for people with intellectual disability: development of a guideline

Chapter 5 Changing care for people with intellectual disability: an individual educational programme for daily general practice

Chapter 6 Autonomy in relation to health among people with intellectual disability: a literature review

Chapter 7 Supporting health-related autonomy among people with intellectual disability: contributions of physicians and consultants in Victoria (Australia)

Chapter 8 Doctor-patient communication with people with intellectual disability

Chapter 9 General discussion

Summary

Samenvatting

List of publications

Dankwoord

Curriculum vitae 



\section{List of abbreviations}

$\begin{array}{ll}\text { AAMR } & \text { American Association on Mental Retardation } \\ \text { AWBZ } & \text { Exceptional Medical Expenses Act } \\ \text { CHAP } & \text { Comprehensive Health Assessment Programme } \\ \text { CDC } & \text { Centre for Disease Control } \\ \text { CDDHV } & \text { Centre of Developmental Disability Health Victoria } \\ \text { CP } & \text { consultant psychiatrist } \\ \text { CS } & \text { communication specialist } \\ \text { GP } & \text { general practitioner } \\ \text { GPHIS } & \text { General Practitioner Health Information System } \\ \text { GPR } & \text { general practitioner registrar } \\ \text { HRC } & \text { Human Relations Consultant } \\ \text { ICD } & \text { International Classification of Diseases } \\ \text { ICPC } & \text { International Classification of Primary Care } \\ \text { ID } & \text { intellectual disability } \\ \text { IDP } & \text { intellectual disability physician } \\ \text { LHV } & \text { Dutch Association of General Practitioners } \\ \text { NHG } & \text { Dutch College of General Practitioners } \\ \text { NVAVG } & \text { Dutch College of Intellectual Disability Physicians } \\ \text { P85 } & \text { Mental retardation ICPC code } \\ \text { PHR } & \text { Personal Health Record } \\ \text { PIN } & \text { Program for Individual Postgraduate Education } \\ \text { PR } & \text { psychiatrist registrar } \\ \text { RNH } & \text { Registration Network for Family Practices of the Maastricht } \\ & \text { University } \\ \text { SCP } & \text { Social and Cultural Planning Office } \\ \text { SSDI } & \text { Social Security Disability Insurance } \\ \text { ZonMw } & \text { Netherlands Organisation for Health Research and } \\ & \text { Development } \\ & \end{array}$




\section{Preface}

Almost every day, as I used my anatomy/physiology books as a teacher, I wondered how the authors knew all the things that they wrote in these books. This made my interest in science grow. One day, I decided to go to university again, wanting to know what research is.

For my Master's thesis, in the final year of the Movement Sciences programme, I decided to do a full research study, from start to finish. The subject was 'Walking exercises for patients with claudicatio intermittens'. I liked the work, my coaches and the participants, solving the problems, doing analyses, writing down the results and presenting these to fellow students and conference participants. The next step was clear: to get to the bottom of research, I had to write a PhD thesis.

In my upbringing, my parents valued highly on caring for other people, which fits in with the subject of my PhD thesis. I already had a keen interest in improving health care for disabled people. I felt that improvements were needed, and now, after my research projects, I know for sure that improvements have to be made. 


\section{Chapter $\mathbf{1}$}

General introduction 



\section{How it started}

Research into health care for people with Intellectual Disability (ID) at the Maastricht University Department of General Practice began with the start of the University's Registration Network for Family Practices (RNH, Metsemakers et al., 1992). The huge volumes of electronically stored GP data could be reliably used for all kinds of studies. Within this database, van Schrojenstein Lantman-de Valk et al. (1997 \& 2000) were able to study data of people with ID included in the $\mathrm{RNH}$, revealing the numbers of people with ID in the database and the prevalence of complaints. Subsequently, our research group, 'Health care for people with ID', studied the health problems reported by people with ID, and the prescriptions provided to them, in the second Dutch National Survey of General Practice (van Schrojenstein Lantman-de Valk et al., 2004 \& Straetmans et al., 2007). Later on, the Maastricht research group became a participant in the POMONA I and II studies, large European studies to identify health indicators for people with ID and to collect health indicator data on a sample of people with ID from 14 European Union Member States. The pioneers of this research project were Noonan Walsh, Kerr and van Schrojenstein Lantman-de Valk (POMONA, 2009). My thesis reports on another project of the Maastricht research group. The research group is incorporated in the Governor Kremers Centre, a collaborative centre of the Maastricht School for Public Health and Primary Care (Caphri) and the Research Institute for Growth and Development (Grow), which has initiated a broad range of studies. Some recent subjects include the quality of freedom restrictions (Abma et al., 2008), melatonin for chronic insomnia in Angelman syndrome (Braam et al., 2008), preference for water-related items in Angelman syndrome, Down syndrome and nonspecific intellectual disability (Didden et al., 2008), dopaminergic transmission (Evers et al., 2008) and identifying the weight status of people with ID (Verstraelen et al., 2009).

\section{Prevalence and transfer of care}

In recent decades, the paradigm concerning care for people with ID has changed from a medical to a community orientation (Nirje, 1969 \& Department of Health of the UK, 2001). People with ID were given more opportunities to move to homes in the community, instead of living with relatives or in residential care facilities, which were often closed communities situated far away from the activities of the general 
community. As early as the 1970 and 1980 , countries like Scandinavia, the UK and Australia had started to close down institutions; people with ID started living in the community and they often moved back to the region where they had spent their youth. It was not until the 1990 s that the Dutch government decided to follow this trend and adopted normalisation (Nirje, 1969) and inclusion of people with ID in the community (Department of Health of the UK, 2001). This change in the Dutch government's policy in the 1990 s resulted in around 5,000 people with ID moving from residential care facilities to supported accommodations in the community (Statistics Netherlands, 2007). The capacity of these accommodations ranges from 2-3 persons with ID to more than 20.

The Dutch government's policy change also required up-to-date prevalence data on people with ID, as the most recent data were from 1986 (Maas et al., 1988). These data related to people with ID aged 4-70 years and living in residential care facilities. Our research group was the first in the Netherlands to calculate the overall numbers of people with ID using a combination of data from ID care facilities and the RNH general practice database (Metsemakers et al., 1992). The use of the GP database for this purpose was innovative.

As people with ID started to move into the community, the organisation of health care needed to change too. General practitioners (GPs) were expected to take care of the people with ID who had recently moved into their catchment area, as the distance to the residential care facility and the ID physicians (IDPs) became too large to guarantee acute care (van Schrojenstein Lantman-de Valk, 2006; Wullink et al., 2007). However, GPs were not yet fully prepared for these tasks. Before the closing down of residential care facilities at the end of the last century, 10-15 persons with mild/moderate ID would be registered within a typical general practice (van Schrojenstein Lantman-de Valk et al., 1997), which would have an average total of 2350 registered patients (Dutch Association of General Practitioners, 2009). What was new to the GPs was not only the influx of more patients with ID, but also that of people with severe/profound ID, who often have more complex or multiple health problems (Klerk, 2002). In addition, GPs had to familiarise themselves with the treatment of adult persons with ID, whereas they had previously known persons with ID mostly from their birth until they moved into residential or supported care.

IDPs and GPs working in residential care facilities could no longer provide care for people with ID, who might now sometimes live tens of kilometres away from these facilities. This distance required the design of collaboration protocols between GPs, their practice assistants, IDPs, 
pharmacists and support workers for acute, chronic and complex medical care and delivery of medication; in other words, a chain of health care had to be developed.

Since the 1990s, individualisation and participation of people with ID have been the guiding principles in care provision. This has led to new approaches in care, e.g. by using individual and flexible planning of care and support in consultation with clients (Kebbon, 1997). The Nordic countries, as early adopters of normalisation in the 1970s, showed important differences in ID care and policy (Nirje, 1969). Normalisation was the precursor of individualisation and participation, meaning that people with ID have the right to inclusion in the community. The Department of Health in the UK (2001, p.24) described this as follows: 'Inclusion: being part of the mainstream is something most of us take for granted. We go to work, look after our families, visit our GP, use transport and go to the swimming pool or cinema. Inclusion means enabling people with learning disabilities to do those ordinary things, make use of mainstream services and be fully included in the local community'. One of the most important issues in human life is autonomy. Individualisation, living in the community and participating in daily life are expected to make people with ID more autonomous, helping them become full members of the community and receive support to realise this membership role. Such autonomous behaviour also implies active participation of people with ID in relation to health. A good example is the study by Watkins et al. (2006), who developed an epilepsy questionnaire for people with ID, making them participants in their own epilepsy management.

\section{Autonomy of people with ID}

Studies of health care ethics and ID have used four definitions of autonomy. The definition by Wehmeyer et al. (1996) was our point of departure, as this definition focuses on the behaviour and skills of people with ID, and is the most comprehensive of the four. Their autonomy definition reads: 'A behaviour is considered to be autonomous if the person acts (a) according to own preferences, interests, and/or abilities and (b) independently, free from undue external influence or interference' (Wehmeyer et al., 1996, p.632). Wehmeyer's paper mentions three other essential characteristics of self-determined behaviour, viz. self-regulation (using skills in a situation), psychological empowerment (the capacity to perform behaviours to achieve a preferred outcome) and self-realisation (knowing yourself, your strengths and 
limitations and using this in a beneficial way). Our definition of autonomy therefore included not only self-determination and independence but also self-regulation and self-realisation/selfdevelopment. Wolfensberger \& Glen (1975, p.28) proposed defining autonomy as control: 'The term autonomy for clients was defined as: having the same amount of control over his actions, decision-making, wishes and desires as any other person of comparable age'. The third definition we used was that of autonomy as a characteristic of patient history, taken from Proot (2001, p.142): 'Self-determination points at making choices and decisions about one's own life and health, and includes freedom of choice. Independence (physical, psychological and social) concerns planning and organising one's own life, including social contacts and role-taking, and refers to responsibility for one's own life and health care. Self-care includes skills (mobility, communication, cognition) and activities of daily living, necessary for functioning'. Finally, Emanuel \& Emanuel (1992, p.2225) defined autonomy as moral self-development/self-realisation: 'Autonomy requires that individuals critically assess their own values and preferences; determine whether they are desirable; affirm, upon reflection, these values as ones that should justify their actions; and then be free to initiate action to realise values'. This finally resulted in our model of autonomy, which contained four elements: (a) self-determination, (b) independence, (c) selfregulation and (d) self-development/self-realisation.

\section{Scope of the problem}

In the 1990s, the Dutch government accepted the view that people with ID should be included in the community, and changed its policy accordingly. This decision has had major consequences both for the organisation of care and for the everyday life of people with ID. The implementation and funding of the new health care policy and the planning and building of supported accommodations require up-to-date information about the numbers of people with ID who live in the Netherlands, both in residential care facilities and otherwise (with or near relatives, in group homes etc.). The whole chain of health care from residential care to primary care has to be changed. People with ID tend to visit their physicians more frequently (Straetmans et al., 2007) and it takes time, knowledge and skills to identify their primary and secondary health problems (van Schrojenstein Lantman-de Valk \& Noonan Walsh, 2008). GPs have to be prepared for these relatively new aspects of health care. People with ID who live in the community become members of that 
community and try to live autonomously. Jobs, leisure activities and sports facilities need to be made available for people with ID moving into living accommodations at larger distances from residential facilities, and training courses have to be developed to teach these people the skills they need to live in the community.

\section{Aims of the study}

In line with the new paradigm and the problems outlined above, this thesis focuses on three themes:

1. The prevalence of people with ID

The aim was to determine the prevalence of people with ID in the Netherlands, by calculating their number in the province of Limburg and extrapolating these data to the whole country.

2. Transfer of health care

The first aim was to assess what support needed to be provided to GPs to ensure a smooth transfer of the healthcare process of people with ID from residential care facilities to supported accommodations in the community. The second aim was to develop and propagate an individual post-graduate training programme to teach GPs how to care for people with ID.

3. Autonomy of people with ID

The first aim was to find out from the literature how people with ID can exercise autonomy in relation to health, and how GPs, specialists and consultants can give support in everyday practice. The second aim was to study the contributions of GPs, specialists and consultants in supporting the autonomy of people with ID. The third aim was to investigate the preferences of people with ID as regards communication with their physicians.

\section{Methods}

The study reported on in this thesis involved a combination of quantitative and qualitative methods. These included calculations and data extrapolations as well as semi-structured interviews and focus group discussions with health care workers and people with ID. In addition, health care workers were observed during their work with people with ID. 


\section{Structure of this thesis}

Chapter 2 describes the procedure used to identify people with ID and the results of our calculation of the numbers of these people living in the province of Limburg. Chapter 3 explains the methods we used to extrapolate the Limburg data to a national level, reporting high and low estimates of the total numbers of people with ID in the Netherlands.

Chapter 4 reports the results of creating and testing a guideline which we developed for transfer of care. The goal of the guideline is to support health care workers involved in the process of people with ID moving from residential care facilities to supported accommodations in the community. As an implementation study, chapter 5 describes the development of an individual training programme (PIN) for GPs. This PIN was created together with the Dutch College of General Practitioners (NHG) and the Dutch College of ID Physicians (NVAVG). The goal of the training programme was to support GPs in giving appropriate care to all patients with ID registered with their practice.

Chapter 6 presents the results of a literature review about the autonomy of people with ID in relation to health. Chapter 7 describes the results of interviews with and observations of GPs, specialists and consultants at the Centre of Developmental Disability Health Victoria (CDDHV) in Melbourne (Australia), and answers the question: 'Can people with ID exercise autonomy in relation to health during consultations and can health care workers support this?'. Chapter 8 describes the similarities and differences between communication preferences of people with ID during consultations and the communication criteria used by GPs according to the MAAS-Global manual (van Thiel et al., 2000).

The main results of the studies are summarised in chapter 9, which also discusses strengths and limitations and offers recommendations for research, policy and practice. 


\section{References}

Abma TA, Widdershoven GAM, Frederiks BJ, Hooren van RH, Wijmen van F \& Curfs LMG (2008) Dialogical nursing ethics: the quality of freedom restrictions. Nursing Ethics, An International Journal for Health Care Professionals 15, 789-802.

- $\quad$ Braam W, Didden R, Smits MG \& Curfs LMG (2008) Melatonin for chronic insomnia in Angelman syndrome: A randomized placebo-controlled study. Journal of Child Neurology 23, 649-54.

- Department of Health (2001) Valuing people; a new strategy for learning disability for the 21st century. HMSO, London.

- $\quad$ Didden R, Korzilius H, Sturmey P, Lancioni GE \& Curfs LMG (2008) Preference for waterrelated items in Angelman syndrome, Down syndrome and non-specific intellectual disability. Journal of Intellectual \& Developmental Disability 33, 59-64.

- Dutch Association of General Practitioners (Landelijke Huisartsen Vereniging) (2009). Retrieved May 7, 2009, from http://lhv.artsennet.nl.

- $\quad$ Emanuel EJ \& Emanuel LL (1992) Four models of the physician-patient relationship. JAMA 267, 2221-6.

Evers L, Amelsvoort van TAMJ, Boot HMJG \& Curfs LMG (2008) Dopaminergic transmission in the ageing patient with velocardiofacial syndrome and cognitive decline. 13th World Congress International Association for the Scientific Study of Intellectual Disabilities, Cape Town, South Africa, August 25-30. Journal of Intellectual Disability Research 52, 644.

- $\quad$ Kebbon L (1997) Nordic contributions to disability policies. Journal of Intellectual Disability Research 41, 120-5.

- $\quad$ Klerk MMY de (Ed.) (2002) Rapportage gehandicapten. Maatschappelijke positie van mensen met lichamelijke beperkingen of verstandelijke handicaps. Social and Cultural Planning Office of the Netherlands, the Hague, the Netherlands.

- $\quad$ Maas JMAM, Serail S \& Janssen AJM (1988) Frequentieonderzoek geestelijk gehandicapten 1986. IVA, Tilburg, The Netherlands.

- Metsemakers JFM, Höppener P, Knottnerus JA, Kocken RJJ \& Limonard ChBG (1992) Computerized health information in the Netherlands: a registration network of family practices. British Journal of General Practice 42, 102-6.

- $\quad$ Nirje B (1969) The normalization principle and its human management implications. In: Kugl $\mathrm{R}$ \& Wolfensberger $\mathrm{W}$ (Eds.) Changing patterns in residential services for the mentally retarded, pp.181-95. President's Committee on Mental Retardation, Washington, DC.

- $\quad$ POMONA. Retrieved May, 23, 2009 from www.pomonaproject.org.

- $\quad$ Proot I (2001) Changing autonomy. New perspectives on the care for stroke patients in nursing homes. PhD thesis Universitaire Pers Maastricht, The Netherlands.

- Schrojenstein Lantman-de Valk HMJ van, Metsemakers JFM, Soomers-Turlings JMSJG, Haveman MJ \& Crebolder HFJM (1997) People with intellectual disability in general practice: case definition and case-finding. Journal of Intellectual Disability Research 41, 373-9.

- Schrojenstein Lantman-de Valk HMJ van, Metsemakers JFM, Haveman MJ \& Crebolder HFJM (2000) Health problems in people with intellectual disability in general practice: a comparative study. Family Practice 17, 405-7.

- Schrojenstein Lantman-de Valk HMJ van, Wierik MJM te, Akker M van den, Wullink M, Schellevis FG, Dinant GJ, Metsemakers JFM (2004) Morbidity and health care use in people with intellectual disabilities in general practice: First results of a survey in the Netherlands. Journal of Policy and Practice in Intellectual Disabilities 1, 107-9.

- $\quad$ Schrojenstein Lantman-de Valk HMJ van, Wullink M, Akker M van den, Heurn- Nijsten EWA van, Metsemakers JFM \& Dinant GJ (2006). The prevalence of intellectual disability in Limburg, the Netherlands. Journal of Intellectual Disability Research 5o, 61-8.

- $\quad$ Schrojenstein Lantman-de Valk HMJ \& Noonan Walsh P (2008) Managing Health problems in people with intellectual disabilities. $B M J$ 337, 1408-12 [BMJ 2008;337:a2507doi: 10.1136/bmj.a2507]. 
- $\quad$ Statistics Netherlands (Centraal Bureau voor de Statistiek). Retrieved May 8, 2007, from http://www.cbs.nl/Statline/thema's/mensenmaatschappij/bevolking/cijfers/ huishoudens/

- $\quad$ Straetmans Jos MJAA, Schrojenstein Lantman-de Valk Henny MJ van, Schellevis Francois G \& Dinant Geert-Jan (2007) Health problems of people with intellectual disabilities: the impact for general practice. British Journal of General Practice 57, 64-6.

- Thiel J van, Ram P \& Dalen J van (2000) MAAS - Global Manual. Maastricht University, Maastricht, the Netherlands.

- Verstraelen CJF, Maaskant MA, Van Knijff-Raeven AGM, Curfs LMG \& van Schrojenstein Lantman-de Valk HMJ (2009) Weighting the weights: Agreement among anthropometric indicators identifying the weight status of people with intellectual disabilities. Journal of Applied Research in Intellectual Disabilities 22, 307-13.

- Watkins J, Espie CA, Curtice L, Mantala K, Corp A \& Foley J (2006) Development of a measure to assess the impact of epilepsy on people with an intellectual disability: the Glasgow Epilepsy Outcome Scale- Client version (GEOS-C). Journal of Intellectual Disability Research 5o, 161-71.

- Wehmeyer ML, Kelchner K \& Richards S (1996) Essential characteristics of self-determined behavior of individuals with mental retardation. American Journal on Mental Retardation 100, 632-42.

- Wolfensberger W \& Glen L (1975) Program analysis of service systems 3: a method for the quantitative evaluation of human services. NIMR, Toronto.

- $\quad$ Wullink M, Schrojenstein Lantman-de Valk HMJ van, Dinant GJ \& Metsemakers JFM (2007) Prevalence of people with intellectual disability in the Netherlands. Journal of Intellectual Disability Research 51, 511-9. 


\section{Chapter 2}

\section{The prevalence of intellectual disability in Limburg, the Netherlands}

Henny van Schrojenstein Lantman-de Valk Magda Wullink

Marjan van den Akker

Lonneke van Heurn- Nijsten

Job Metsemakers

Geert-Jan Dinant

Published in: Journal of Intellectual Disability Research, 2006, 50, 61-8 


\section{Abstract}

\section{Background}

Current changes in care philosophy and diversity in care arrangements caused a need for a new estimate of the number of people with intellectual disability (ID), based on recent data. Previous estimates were based on client registrations, which was thought unreliable at this time. This manuscript studies the question how many people with ID can be found in (part of) the Netherlands.

\section{Method}

Identification of people with ID though a combination of general practice (GP) data bases and service registrations in the province of Limburg.

\section{Results}

The prevalence of people with ID appeared to be between $0,64 \%$ and $0,70 \%$. About $0,21-0,27 \%$ were living with family or on their own; $55 \%$ of them did not use common ID services.

\section{Conclusion}

Results are based on a combination of identification methods. Thirteen percent of uncertain cases led to minimum and maximum estimates of the population. Limitations of the method and alternative ways of data collection are discussed. 


\section{Introduction}

Care is more expensive than cure. In the Netherlands, care for people with intellectual disability (ID) ranks no.1 in the national budget for health care costs, consuming $7.7 \%$ of the national expenditure on health care. (Meerding et al., 1998, Polder et al., 2002). Prevalence figures are crucial to the allocation of funding and the development for adequate service provision for people with ID (Horwitz et al., 2001). People with ID have more than twice as many health problems as people without ID (van Schrojenstein Lantman-de Valk et al., 2000).

Internationally, most prevalence counts of people with ID are based on client registration, either from service users or people entitled to additional financial supports. In the Netherlands, Maas et al.(1988) found a prevalence of $0.73-0.80 \%$ for people with ID through service registrations. Arvio \& Sillanpää (2003) in Finland found a prevalence of people with severe ID of $0.13 \%$ based on client registers data. The Center for Disease Control in the United States (CDC 1996) reported a prevalence of $0.25-1.57 \%$ (average $0.66 \%$ ) in adults with ID receiving Social Security Disability Insurance (SSDI). People are entitled to receive SSDI when their IQ is 59 and below, or when their IQ is between 60 and 70 and they have additional and substantial (physical or mental) workrelated limitations in functioning. In Sweden, Hagberg et al. (1987) found a prevalence of $0.37 \%$ of people with mild ID and $0.33 \%$ of people with severe ID through census data and IQ values in school children. In South Africa, Christianson et al (2002) found a prevalence of $0.06 \%$ for children with severe ID and a prevalence of $2.9 \%$ for children with mild ID. Their method was based on a house-to-house interview with mothers and further paediatric assessment of children who screened positive.

The Dutch government felt the need for an update of the prevalence figures in this country.

In the past, the amount of people entitled to ID services was obtained by determining and extrapolating the numbers of service users (Maas et al. 1988). Now that people have more options in choosing their own care supply, the government felt that other methods of obtaining an adequate estimate of the number of persons involved had to be explored.

In this paper, we describe a population count of people with ID in Limburg, a province in the Netherlands, which was carried out through primary care files, combined with data from service registrations.

The assumption was, that, since nearly everybody who lives in the Netherlands is registered with a general practitioner (GP), it should be possible to count the number of people with ID through GP data files. 
People with ID who are not registered with a GP are either living in a residential centre for people with ID, in a nursing home or in prison. Throughout the country, 90\% of GPs have their patient data recorded in an electronic data base, a so-called General Practice Health Information System (GPHIS). This GPHIS contains demographic data and information on health problems, diagnostic procedures, interventions and diagnoses. All health information is registered in the International Classification of Primary Care (ICPC), a code system related to the International Classification of Diseases (ICD) (Lamberts \& Wood, 1987). In an earlier study it was found that within this GPHIS, $80 \%$ of the persons with ID enrolled in GPHIS, could be identified by an ICPC code P85 (ID) (van Schrojenstein Lantman-de Valk et al., 1997). The questions for the present study were:

How many people with ID, either living in residential settings or living in the community in the Netherlands, can be found through searching GPHIS and/ or service registrations? What is their age and gender distribution?

\section{Subjects and methods}

Consent for this study was acquired from the Medical Ethical Committee of the Academic Hospital of Maastricht University.

Data collection took place in 2000-2001. The reference date for this study was set on January 1, 2001.

It was decided to count and estimate the number of people with ID in the province of Limburg through GP data bases and residential facilities. Extrapolation of these data to the population of the Netherlands was a next step, which will be described separately.

To determine the number of people with ID, we developed a two-way strategy. First, we asked service providers to provide data about the number of their clients. Thereafter, we identified the people with ID who lived in the community through GP data bases, excluding double counts. All client data were provided anonymously.

\section{Data from service providers}

We started with collecting client data from service providers, which is residential facilities, organsations providing group home living and/or day care facilities and special schools. In the Dutch care system, people using ID services are assessed as having ID before receiving this form of care. Thus, data provided by service providers always referred to people assessed as having ID. 
For each person, the requested data were date of birth in six digits, information on gender and a postal code in four (out of six) digits. We furthermore asked whether the provided data referred to persons who were registered with a GP. If so, the name of the GP was attached to the clients' codes.

\section{Data from General Practice Health Information System}

The search of people with ID in GP data bases was performed within the Registration Network Family Practices (RNH) within the Maastricht University, the Netherlands (Metsemakers et al., 1992). This is a data base containing electronic patient records from academic general practices cooperating with the Department of General Practice of Maastricht University. Data in the RNH practices are made available for primary care research. At the time of this study, the RNH contained data from 100 ooo patients, registered in 21 practices, thus covering about $9 \%$ of the total population of the province Limburg.

Within the GPHIS, people with ID were identified in three phases. We started phase 1, the inclusion phase, with extracting all clients registered under ICPC code P85 in the GP data base. Furthermore, GPs received a list of postal codes of group homes and residential facilities in their area so as to check whether they had patients living on these addresses. The GPs also received the above mentioned client data from special care providers. Finally, GPs were asked to check their memories whether they could come up with clients with ID they knew of and who were not yet included in the steps before.

In phase 2, the exclusion phase, two researchers (MW, EvHN), both $\mathrm{PhD}$ students at that time, interviewed the GPs using an assessment schedule so as to make sure that all patients to whom the diagnosis was not applicable were excluded from the count.

The assessment schedule (Appendix) was developed by consultation of experts who were specialist doctors for people with ID, psychologists, epidemiologists or policy people, working in the field of ID. The schedule contained questions derived from the definition of ID as formulated by the American Association of Mental Retardation (AAMR) (Luckasson et al., 1992) and it also contained practical questions on service use. This definition states that a person with ID has sub-average intellectual functioning, i.e. an IQ below 70-75; this disability has manifested itself before age 18, and the patient has related limitations in two or more out of the following applicable adaptive skill areas: communication, selfcare, home living, social skills, community use, self-direction, health and 
safety, functional academics, leisure or work. The schedule also contained practical questions on service use.

In phase 3, the case finding phase, the GP and one of the researchers checked the patient files for evidence on ID. This evidence could be specialist reports from psychologists, neurologists, paediatricians, psychiatrists and other medical specialists, reports from special schools or special services and other relevant documentation referring to an ID. Patients without evidence materials, for whom no documentation could be found, were labelled as uncertain cases.

\section{Double counts}

Double counts were detected on the basis of birth dates, gender information and postal code. They were subsequently deleted in the GP data base. Twins of the same gender were kept in the registration.

\section{Extrapolation}

Data from $\mathrm{RNH}$ practices were extrapolated to the whole population of the province Limburg. The RNH population is known to have the same gender and age distribution as the whole province (Metsemakers et al., 1992).

\section{Results}

\section{Response}

After two reminders, all 13 organisations providing housing facilities in Limburg (100\%) participated in the study. Seven out of eight special schools (87\%) participated. From the general practices within the RNH, 16 out of 21 practices (87\%) participated with a total of

87060 patients enrolled. Age distribution and degree of urbanization within the five not participating practices did not differ from the other 16 practices.

At the time of data collection, no people with ID could be found in nursing homes or in prison in the research area.

\section{Data from service providers}

This part of the study resulted in data about 6439 persons. 4950 clients appeared to be living in residential facilities or in group homes in the province. The other 1489 either participated in day care facilities $(n=588)$, were students at special schools $(n=874)$ or received home care 
$(\mathrm{n}=27)$. The group who lived in residential facilities consisted out of 2742 $(55,4 \%)$ males and 2196 (44.4\%) females. For 12 persons, data on gender were missing. The mean age of these persons was 41.1 years $( \pm 16,6)$. Their age and gender distribution is given in Table 2.1.

Table 2.1 Age and gender distribution of people with ID living in residential facilities in Limburg.

\begin{tabular}{|c|c|c|c|c|c|c|c|c|}
\hline \multirow{3}{*}{ Age (years) } & \multicolumn{6}{|c|}{ Gender } & \multirow{2}{*}{\multicolumn{2}{|c|}{ Total }} \\
\hline & Males & & Females & & Missing & & & \\
\hline & Abs. N & $\%$ & Abs N. & $\%$ & Abs N. & $\%$ & Abs.N & $\%$ \\
\hline $0-4$ & 26 & 0.9 & 14 & 0.6 & & & 40 & 0.8 \\
\hline 5-19 & 361 & 13.2 & 213 & 9.7 & 8 & 66.7 & 582 & 11.8 \\
\hline $20-34$ & 534 & 19.5 & 438 & 19.9 & 3 & 25.0 & 975 & 19.7 \\
\hline $35-49$ & 1055 & 38.5 & 763 & 34.7 & & & 1818 & 36.7 \\
\hline $50-69$ & 670 & 24.4 & 637 & 29.0 & & & 1307 & 26.4 \\
\hline$\geq 70$ & 96 & 3.3 & 131 & 6.0 & 1 & 8.3 & 228 & 4.6 \\
\hline Total & 2742 & 100 & 2196 & 100 & 12 & 100 & 4950 & 100 \\
\hline
\end{tabular}

\section{Data from General Practice Health Information System}

Inclusion: in the GP data bases, 572 clients were found who were eligible for further data assessment.

Out of these, 402 persons were registered under ICPC code P85; an additional 95 persons were found by checking on postal codes of community-based facilities for people with ID and 24 persons could be added from the information acquired from service providers. Finally, 51 persons were added when asking the GPs to check their memories for persons with ID whom they knew of and who were not yet included in the data selection. The procedure is shown Table 2.2.

Table 2.2 Inclusion and exclusion of patients with ID in general practices.

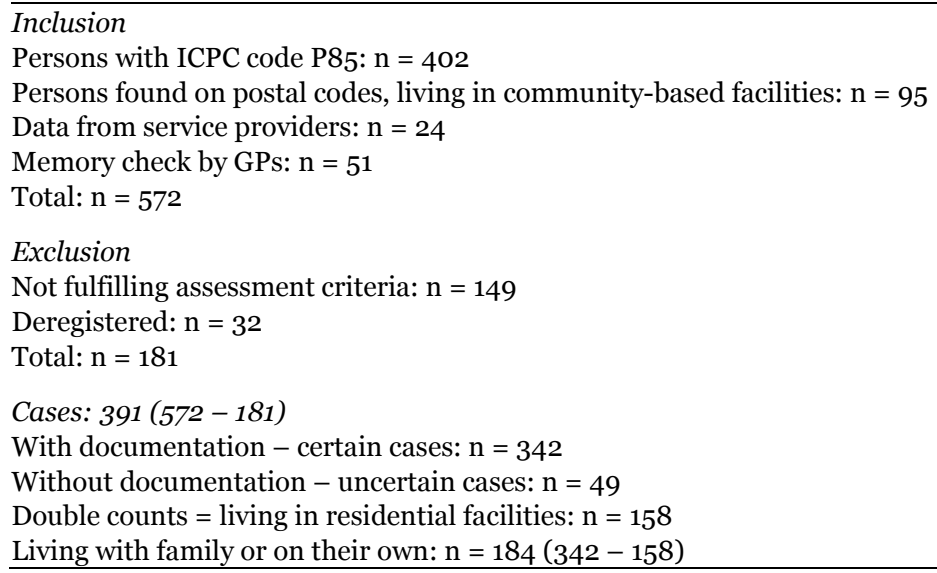


In the exclusion phase (phase 2), the assessment procedure resulted in 391 persons with ID who fulfilled the assessment criteria. A further 149 persons did not fulfil the assessment criteria, did not have an ID and were subsequently excluded. The last 32 persons appeared to be deregistered. Eight of them had moved house, seven had moved to other practices not participating in the $\mathrm{RNH}$, three were deceased, three had moved into a residential facility for people with ID outside the research area, one person had entered a nursing home, she had dementia but not ID. In ten cases the reason of deregistration remained unclear. These 32 persons were excluded as well.

In the case finding phase (phase 3), 49 persons (out of the 391 cases) appeared persons for whom no documentation was available although their GP was fairly sure they had ID. They were labelled as uncertain cases. All these 49 persons lived with their family.

All remaining 342 cases could be labelled as having ID, based on documentation in their patient files. Documentation rarely included an IQ level in digits; most often it was described as level of functioning (e.g. mild, moderate, severe). From these 342 persons, 184 persons lived with their family or on their own; a further 158 persons lived in residential facilities. The latter 158 were considered double counts since they were already included in the first part of the data collection from service registrations and thus excluded from the second part of the study.

The age and gender distribution of the 184 people with ID, registered with GPs participating in the RNH and living outside of residential facilities for people with ID is given in Table 2.3.

Table 2.3 Age and gender distribution of people with ID, registered with GPs participating in the RNH and not living in residential facilities for people with ID.

\begin{tabular}{|c|c|c|c|c|c|c|}
\hline \multirow{3}{*}{ Age (years) } & \multicolumn{4}{|c|}{ Gender } & \multirow{2}{*}{\multicolumn{2}{|c|}{ Total }} \\
\hline & Males & & Females & & & \\
\hline & Abs N. & $\%$ & Abs N. & $\%$ & Abs N. & $\%$ \\
\hline $0-4$ & 4 & 4 & 2 & 2 & 6 & 3.3 \\
\hline 5-19 & 32 & 33 & 31 & 36 & 63 & 34.2 \\
\hline $20-34$ & 21 & 22 & 13 & 15 & 34 & 18.5 \\
\hline $35-49$ & 21 & 22 & 22 & 25 & 43 & 23.4 \\
\hline $50-69$ & 18 & 19 & 14 & 16 & 32 & $17 \cdot 3$ \\
\hline$\geq 70$ & 1 & 1 & 5 & 6 & 6 & 3.3 \\
\hline Total & 97 & 100 & 87 & 100 & 184 & 100 \\
\hline
\end{tabular}

The prevalence of people with ID in RNH practices and living elsewhere than in residential facilities thus can be calculated as 184/ $87060 \mathrm{x}$ $100 \%=0,21 \%$. 
Checking the results from the general practices with those from service providers, it appeared that 99 out of these 184 (55\%) did not use any regular form of ID care supply such as day care, home care or special schools.

\section{From Registration Network Family Practices results to population of Limburg}

The population of the province Limburg at 1 January, 2001 was 1142679 . Extrapolation of the RNH population to that of the province of Limburg (0,21\% persons with ID) means that 2402 persons can be estimated as having an ID and not living in residential facilities. Adding up the 4950 people with ID in residential facilities and the 2402 people with ID not living in residential facilities results in Table 2.4: age and gender distribution of people with ID living in the province of Limburg. The estimated total number of people with ID is then 7352 or $0.64 \%$ of the population of this province. Including the 49 cases for whom no documentation was available as people with ID and extrapolating this to the whole GP population in Limburg would lead to a prevalence of $0.70 \%$ of people with ID in the province of Limburg. It was decided to use both results and to use these as margins between which the real number will be. Table 2.5 gives a schedule of the estimation procedure.

Table 2.4 Age and gender distribution of people with ID living in the province of Limburg (between brackets in percentage of the total population of this province in similar age/gender group).*

\begin{tabular}{lccc}
\hline Age (years) & $\begin{array}{c}\text { Males } \\
\text { Absolute N (\%) }\end{array}$ & $\begin{array}{c}\text { Females } \\
\text { Absolute N (\%) }\end{array}$ & $\begin{array}{c}\text { Total } \\
\text { Absolute N (\%) }\end{array}$ \\
\hline $0-4$ & $76(0.24)$ & $37(0.12)$ & $113(0.18)$ \\
$5-19$ & $779(0.76)$ & $619(0.64)$ & $1398(0.70)$ \\
$20-34$ & $810(0.74)$ & $607(0.57)$ & $1417(0.66)$ \\
$35-49$ & $1331(0.93)$ & $1045(0.76)$ & $2376(0.85)$ \\
$50-69$ & $911(0.65)$ & $818(0.60)$ & $1729(0.63)$ \\
$\geq 70$ & $108(0.24)$ & $199(0.28)$ & $307(0.26)$ \\
Total & $4015(0.90)$ & $3325(0.47)$ & $7352(0.66)$ \\
\hline
\end{tabular}

* in the registration from service providers, documentation on gender was lacking for 12 cases 




\section{Discussion}

Identifying people with ID through GPHIS appeared to be possible, but it was far from easy.

Case identification of people with ID through the GP data bases started with selecting cases registered under ICPC code P85 (ID). In an earlier study it appeared that $80 \%$ of people with ID could be identified by using this code (van Schrojenstein Lantman- de Valk et al., 1997). However, the same study revealed that only half of the cases could be labelled as having ID. Other trawling methods (addresses from known residential facilities, the information from service providers and discussing patients with their GP) resulted in 166 additional people with ID who were subsequently labelled by ICPC code P85.

At the time of the study, the new definition of intellectual disability (Luckasson et al., 2002) still had to be published. The new definition states that ID is characterized by significant limitations in intellectual functioning and in adaptive behaviour as expressed in conceptual, practical and social adaptive skills; the disability originates before age 18. We do not believe that the update would have resulted in different outcome of the assessments as used for this study.

Our result is an estimate. The fact that 5 out of 21 practices did not participate was considered acceptable because population diversity in participating and non-participating practices was similar. Furthermore, we extrapolated the data from $\mathrm{RNH}$ practices to the population of the whole province on a similar ground: the $\mathrm{RNH}$ patients were described as not different from the rest of the population. 
Case-identification was based on studying files, people were not assessed in person. This was not feasible at the time of the study. The result thus found is not better then the quality of the files, but justified by the fact that we only included people for whom documentation of ID was available in the files. All people without documentation were included as uncertain cases in providing minimum and maximum numbers in extrapolating. This regarded 49 out of 391 persons, that is about $13 \%$. Further study is necessary to find out how many in this group are people for whom the diagnosis ID is applicable while documentation is lacking and why.

Introducing a new exclusive ICPC code or a label for ID only, to a great extent, could have facilitated data collection. Acknowledging privacy legislation, this label could improve care provision to a group of people who is in need of more than average health care supply. Although ID is not a disease, it is a risk factor for both handicap-related and life-stylerelated health conditions. In a previous study, we found that people with ID in GPHIS had twice as many health problems than their peers without ID (van Schrojenstein Lantman- de Valk et al., 2000). As it is now, people with ID too often are hidden to their general practitioners. This will hamper adequate service development and adequate allocation of funding.

The equal age and gender distribution of $\mathrm{RNH}$ data base and population of Limburg allowed us to extrapolate our results to the province of Limburg. The unequal distribution of residential facilities over the whole country means that further extrapolation of our results to the whole country needs careful consideration; we will describe this procedure separately. We also checked that at the reference data no people with ID in this province were either in prisons or in nursing homes. The validity of this argument has to be carefully considered when extrapolating data to the national level.

\section{Conclusion}

The prevalence of people with ID in the province of Limburg appeared to be between $0,64 \%$ and $0,70 \%$. (7352-7986 persons). The results are in line with earlier national and international results. Less than half of the group, 0,21-0.27 \% (2402-3036 persons) lived outside of regular residential facilities for people with ID. Within the last group, $55 \%$ did not use any regular ID care supply. These results demonstrate that people with ID can or should be identified not only through service registry data. The ICPC code P85 for ID in itself was insufficient to find a 
Chapter 2

satisfying result and additional identification methods appeared necessary. Assumptions were inevitable to give an estimate with upper and lower margins. 


\section{Appendix}

Assessment schedule for general practices

Patient number

Birth date (dd) (mm) (yr)

Gender: $\mathrm{M} / \mathrm{F}$

\section{Criteria}

1. Patient has sub-average intellectual functioning, i.e. $\mathrm{IQ}<70-75$.

2. The intellectual disability manifested before the age of 18 years.

3. Patient has related limitations in two or more of the following applicable adaptive skill areas: communication, self-care, home living, social skills, community use, self-direction, health and safety, functional academics, leisure or work.

OR:

\section{For children}

Patient fulfils one of the following criteria:

$O$ visits special school, or on a waiting list for special school

$\mathrm{O}$ visits/visited/ is on a waiting list for day centre for children with

ID, or

O lives/used to live/ is on a waiting list for residential living facility for people with ID

O client of respite care facility for people with ID

O client ambulant care for people with ID

$O$ receives special funding for people with ID

$\mathrm{O}$ other criteria to be discussed

\section{For Adults}

Patient fulfils one of the following criteria:

O spent long unsuccessful years at primary school

$\mathrm{O}$ visits/visited/ is on a waiting list for day centre for adults with ID

O lives/used to live/ is on a waiting list for residential living facility

for people with ID

O client of respite care facility for people with ID

O client ambulant care for people with ID

$O$ receives special funding for people with ID

$\mathrm{O}$ other criteria to be discussed 


\section{References}

- $\quad$ Arvio M \& Sillanpää M (2003) Prevalence, aetiology and comorbidity of severe and profound intellectual disability in Finland. Journal of Intellectual Disability Research 47, 108-12.

- $\quad$ Centre for Disease Control (CDC). State Specific Rates of Mental Retardation, United States (1993) MMWR Weekly 45, 61-5. URL: http://www.cdc.gov/mmwr/preview.

- $\quad$ Christianson AL, Zwane ME, Manga P, Rosen E, Venter A, Downs D \& Kromberg JGR (2002) Children with intellectual disability in rural South Africa: prevalence and associated disabilty. Journal of Intellectual Disability Research 46, 179-86.

- Hagberg G, Lewerth A, Olsson E \& Westerberg B (1987) Mild mental retardation in Gothenborg children born between 1966-1970. Changes between two points of time. Uppsala Journal of Medical Sciences Supplement 44, 52-7.

- Horwitz SM, Kerker BD, Owens PL \& Zigler E (2001) The Health Status and Needs of Individuals with Mental Retardation. Special Olympics, Washington D.C.

- $\quad$ Luckasson R, Coulter DL, Polloway EA, Reiss S, Schalock RL, Snell ME, Spitalnick DM \& Stark JA (1992) Mental Retardation. Definition, Classification and Systems of Supports. American Association on Mental Retardation (AAMR) Washington DC.

- $\quad$ Luckasson R, Borthwick-Duffy S, Buntinx WHE, Coulter D, Craig E, Reeve A, Schalock RL \& Snell ME (2002) Mental Retardation. Definitions, Classification and Systems of Support. American Association on Mental Retardation (AAMR), Washington DC.

- $\quad$ Maas JMAM, Serail S \& Janssen AJM (1988) Frequentieonderzoek geestelijk gehandicapten 1986. IVA, Tilburg, the Netherlands.

- Meerding WJ, Bonneux L \& Maas PJ van der (1998) Demographic and epidemiological determinants of health care costs in Netherlands: cost of illness study. British Medical Journal 317, 111-5.

- Metsemakers JFM, Höppener P, Knottnerus JA, Kocken RJ \& Limonard C (1992) Computerized health information in the Netherlands: a registration network of family practices. British Journal of General Practice 42,102-6.

- $\quad$ Polder JJ, Meerding WJ, Bonneux L \& Maas PJ van der (2002) Healthcare costs of intellectual disability in the Netherlands: a cost-of-illness perspective. Journal of Intellectual Disability Research 46, 168-78.

- Schrojenstein Lantman-de Valk HMJ van, Metsemakers JFM, Soomers-Turlings JMSJG, Haveman MJ \& Crebolder HFJM (1997) People with Intellectual disability in general practice: case definition and case-finding. Journal of Intellectual Disability Research 41, 373-9.

- $\quad$ Schrojenstein Lantman-de Valk HMJ van, Metsemakers JFM, Haveman MJ \& Crebolder HFJM (2000) Health problems in people with intellectual disability in general practice: a comparative study. Family Practice 17, 405-7. 


\section{Chapter 3}

\section{Prevalence of people with intellectual disability in the Netherlands}

Magda Wullink

Henny van Schrojenstein Lantman-de Valk

Geert-Jan Dinant

Job Metsemakers

Published in: Journal of Intellectual Disability Research 2007, 51, 511-9 


\section{Abstract}

\section{Background}

Since the 1990s, people with intellectual disability (ID) in the Netherlands have been moving from institutions to supported accommodation in the community. The Government is in need of recent data on the numbers of these people, to ensure adequate care provision and funding. This paper reports on the prevalence of people with ID in the Netherlands. The research question was: what is the lowest and highest estimation of prevalence of people with ID in the Netherlands?

\section{Methods}

Two extrapolation methods were used, each consisting of a number of stages, using general practice data bases and ID care services records.

\section{Results}

The prevalence of people with ID in the Netherlands was $0.7 \%(111,750$ persons). Other assumptions yielded 0.54-0.64\%. Arguments for the two extrapolation methods and the lowest and highest estimation of prevalence are discussed.

\section{Conclusions}

Compared to 1988, there has been a slight decrease in the prevalence of people with ID in the Netherlands, even though we included all age groups and even people with ID of who were not included in ID care services records. By using general practitioner data bases it was possible to identify these not registered people with ID. 


\section{Introduction}

Since the 1990s, the Dutch Government's policy has been to stimulate people with intellectual disability (ID) to move from institutions to supported accommodation in the community (Ministry of Health, Welfare and Sports, 1995). The funding of the care for these people has also been changed. At present, although a large number of people with ID are still living in residential care facilities (23 000 in the year 2004, Statistics Netherlands, 2005), many others have moved to various forms of supported accommodation in the community created over the last ten years (6000 persons moved between 1995 and 2004, Statistics Netherlands, 2005). Hence, the Government needed an update on the overall prevalence of people with ID, to ensure adequate care provision and funding.

The last time the prevalence of ID in the Netherlands was calculated was in 1988. Maas et al. (1988) reported a national prevalence of $0.73-0.8 \%$ of people aged 4-70 years. They counted the numbers of people with ID in ID care services records in four regions and subsequently extrapolated their results to the Netherlands as a whole. These figures no longer seem valid, because they did not include (1) people with ID who were living with relatives and did not have ID care services records; and (2) people younger than 4 and older than 70 years.

People with ID who did not have ID care services records can be derived from general practitioner (GP) data bases, because nearly everybody who lives in the Netherlands is registered with a GP. Exceptions are people with ID who are living in residential centres or supported accommodation in the community, people who live in nursing homes, persons in prison (these three groups receive primary health care from special physicians) and $\mathbf{1 . 2 \%}$ of the inhabitants of the Netherlands who have no health insurance (Social and Economic Council of the Netherlands, 2000). The uninsured group consists of illegal job migrants, foreign visitors, refugees refused a residence permit and homeless people (Kruyswijk et al., 1997).

The aim of the study was to estimate the prevalence of people with ID in the Netherlands. The research question was: what is the lowest and highest estimation of prevalence of people with ID in the Netherlands based on extrapolation of the data collected in the province of Limburg? 


\section{Methods}

\section{Prevalence of people with ID in Limburg province}

Data from our previous study on prevalence were used on this follow-up study (van Schrojenstein Lantman-de Valk et al., 2006). A combination of the general practice data base of the Family Practices Registration Network (RNH) and ID care services records (including data of adults and children visiting day centres and children visiting special schools) in the whole province of Limburg had been accessed to derive the numbers of people with ID (van Schrojenstein Lantman-de Valk et al., 2006). Data for this study were collected in 2000-2001, using January 1, 2001 as the reference date. All client data were provided anonymously and double counts were deleted from the data. The Maastricht University Medical Ethics Committee gave its consent for the study proposal.

The double counts arised, because residential care facilities and supported accommodation are fully responsible for the care of the people with ID. The Government is funding these care on the basis of ID care services records. This funding is supposed to include primary health care by ID physicians. In practice, the primary health care sometimes is performed by GPs.

$\mathrm{RNH}$ consists of academic general practices situated in the southern part of the province of Limburg and is related to the Department of General Practice of the Maastricht University. All the patients of these practices ( $n=100$ 069) were registered in an electronic data base in accordance with the International Classification of Primary Care (ICPC), a code system related to the International Classification of Diseases (ICD) (Lamberts \& Wood, 1987). The anonymous data were available for primary care research. The age and gender distribution of $\mathrm{RNH}$ is the same as in the province of Limburg (Metsemakers et al., 1992).

ID care services records include clients living in residential centres or supported accommodation, and clients visiting day centres or special schools after assessment of ID by psychologists or medical specialists. GPs checked all their patients' records to see whether they met our inclusion criteria for patients with ID described in a checklist (Appendix) and discussed this with two researchers from our team. The inclusion criteria were based on the American Association on Mental Retardation (AAMR) definition of ID (Luckasson et al., 1992) or the use of ID care services. People with ID were identified in RNH by ICPC code P85 (ID), by controlling the addresses of supported accommodations for people with ID and by memory of the GPs. Also, a check was performed for wellknown ID syndromes such as Down syndrome. 
Our study distinguished between definite and unconfirmed cases for $\mathrm{RNH}$ : people with ID were recorded as having a definite diagnosis of ID if they met the inclusion criteria and there was relevant information from a psychologist or a hospital specialist available in the GP's data base. People with unconfirmed ID diagnosis were those who met the inclusion criteria, but whose files did not include specialist information; GPs have the assessment that these persons have ID (based on completing the checklist and on patient and relatives contacts). ID care services records were used to collect the following data: date of birth, gender, postal code (four of the six digits) and name of GP. The RNH data base was used to collect practice and patient numbers, date of birth, gender, postal code (four of the six digits) and information on the ID identification procedure. In the past, people with ID migrated to three provinces (Gelderland, Noord-Brabant and Limburg), because of the history of large residential care facilities. In recent times, people with ID sometimes have moved to supported accommodations in communities were they originally came from. The reference date was used strictly to prevent double counts in data collection.

\section{Extrapolation}

Data from ID care services records were combined with RNH data. Our extrapolation yielded a lowest and a highest estimation of prevalence. The lowest estimation of prevalence in general practices was based on definite diagnoses of ID and the highest estimation of prevalence on the combination of definite and unconfirmed diagnoses. In addition, we used data on the number of people with ID living in care facilities obtained from the Ministry of Health, Welfare and Sports (2000), derived from funding bodies, financing all ID residential care on a perperson basis, data on the numbers of inhabitants of the various provinces and the numbers of people living in nursing homes obtained from Statistics Netherlands (2001) and data on the total number of patients and the number of patients with ID registered in RNH data base from the prevalence study by van Schrojenstein Lantman-de Valk et al. (2006).

Two extrapolation methods were used. Method I was based on the assumption that the prevalence of people with ID is equal in all provinces. Thus, if more places in residential care facilities and supported accommodation in the community are available in a province, this means that fewer people with ID are living with relatives or on their own. Method I consisted of four stages described in Figure 3.1. 


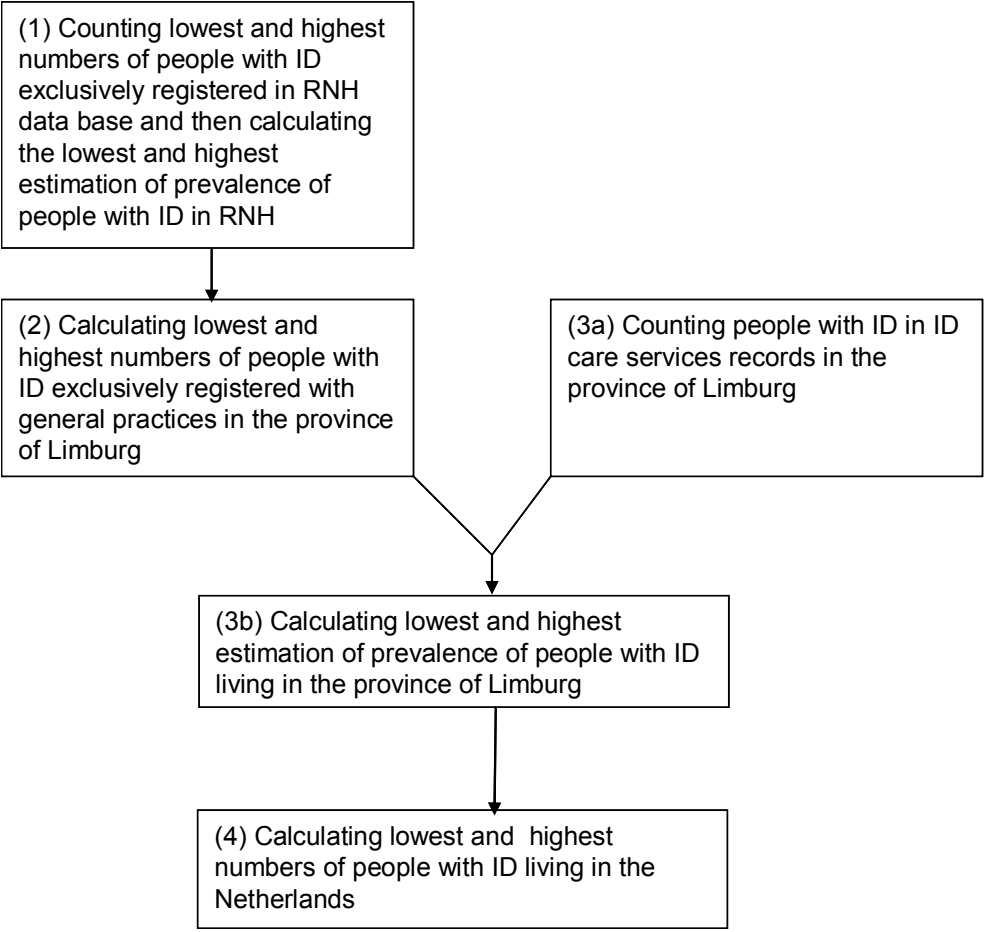

Figure $3.1 \quad$ Extrapolation method I.

Extrapolation method II was based on the assumption that the percentage of people with ID registered with general practices is equal in all the provinces, independent of the number of available places for people with ID in residential care facilities and supported accommodation in the community. Extrapolation method II consisted of 2 stages described in Figure 3.2.

\section{Expert advice}

During this study, six external experts advised us on the extrapolation methods; one senior and one junior official of the Ministry of Health, Welfare and Sports, three epidemiologists, two experts from the National Institute for Public Health and the Environment (RIVM), one expert from the Social and Cultural Planning Office of the Netherlands (SCP) and one professor of ID care (ID physician, Department of General Practice, Erasmus University, Rotterdam). 
In the extrapolation methods, people with ID living in nursing homes and those who were in prison were not removed when calculating the population without ID. In practice, ageing people with ID and those with dementia, rarely move from residential facilities to nursing homes. People with ID with ageing problems, living with relatives also move to residential facilities. Only those with mild ID may move to nursing homes. Until the beginning of the $21^{\text {st }}$ century, it was policy of the judicial authorities to prevent placement of people with ID in prison. The numbers of refugees with ID and homeless people with ID were not added to the total number of people with ID. Our assumption, supported by the external experts, was that the number of people in nursing homes or in prison who were not removed was about equal to the numbers of refugees and homeless people who were not added.

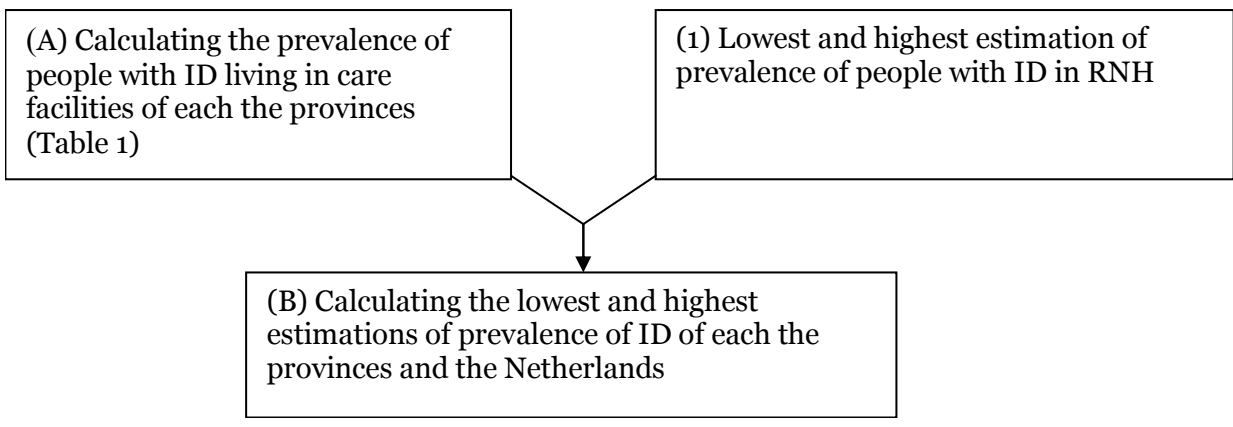

Figure $3.2 \quad$ Extrapolation method II

\section{Results}

Prevalence of people with ID in the Netherlands based on extrapolation method I

The stages of extrapolation method I are showed in Figure 3.1.

Stage 1 - lowest and highest estimation of prevalence of people with ID registered with $\mathrm{RNH}$ practices (counted and calculated)

In total, 87060 patients (87\%) of the $\mathrm{RNH}$ database participated in this follow-up study; of these, 158 people with ID were living in residential care facilities or in supported accommodation in the community; as these persons were already counted in the residential care and supported accommodation group, they were subtracted from the figures from the $\mathrm{RNH}$ database. This left 184 people with a definite diagnosis of ID, and 
233 people with a definite or unconfirmed diagnosis of ID who were living with relatives and were registered with $\mathrm{RNH}$ practices.

The lowest estimation of prevalence of people with ID in the $\mathrm{RNH}$ practices was $184 /(87060-158)=0.212 \%$, and the highest estimation of prevalence of people with ID in RNH practices was 233/ (87 060-158) $=0.268 \%$.

Stage 2 - lowest and highest numbers of people with ID registered with general practices in the province of Limburg (calculated)

The total number of inhabitants of the province of Limburg was 1142 679 (Statistics Netherlands, 2001). The total number of people with ID who were living in residential care facilities and in supported accommodation in the community was 4950 (as counted during this study). The total number of people (without ID) who were living in nursing homes was 4400 (Statistics Netherlands, 2001). The total number of people (without ID) registered with general practices in the province of Limburg was therefore 1142 679-4950-4400 =

1133329.

The lowest number of people with ID registered with general practices in the province of Limburg was thus calculated as $1133329 \times 0.212 \%=$ 2403, while the highest number was

$1133329 \times 0.268 \%=3037$.

Stage 3 - lowest and highest estimation of prevalence of people with ID in the province of Limburg (counted and calculated)

The lowest total number of people with ID in the province of Limburg was $4950+2403=7353$. The highest total number of people with ID in the province of Limburg was $4950+3037=7987$.

The lowest estimation of prevalence of people with ID in the province of Limburg was 7353/ $1142679=0.643 \%$, while the highest estimation of prevalence was 7987/ $1142679=0.699 \%$.

Stage 4 - lowest and highest estimation of prevalence and numbers of people with ID in the Netherlands (calculated)

The total number of inhabitants of the Netherlands on 1 January, 2001 was 15987075 (Statistics Netherlands, 2001). The lowest number of people with ID in the Netherlands was therefore $0.643 \% \times 15987075=$ 102797 , while the highest number was $0.699 \% \mathrm{x}$ $15987075=111750$.

Prevalence of people with ID in the Netherlands based on extrapolation method II

The stages of extrapolation method II are described in Figure 3.2. 
Stage A - calculating the prevalence of people with ID living in care facilities of each the provinces

The prevalence was calculated by dividing the numbers of people with ID living in care facilities (Table 3.1) by the total numbers of inhabitants of each province (Table 3.1). The results are reported in Table 3.2.

Table 3.1 Calculated numbers of inhabitants registered with general practices in each Dutch province \#

\begin{tabular}{lrccc}
\hline Province & Inhabitants * & $\begin{array}{c}\text { Number of people } \\
\text { with ID living in } \\
\text { care facilities ** }\end{array}$ & $\begin{array}{c}\text { Number of people } \\
\text { living in nursing } \\
\text { homes * }\end{array}$ & $\begin{array}{c}\text { Inhabitants } \\
\text { registered with } \\
\text { general practices }\end{array}$ \\
\hline Groningen & 566489 & 1882 & 2012 & 562595 \\
Friesland & 630539 & 2130 & 2307 & 626102 \\
Drenthe & 474506 & 1971 & 1663 & 470872 \\
Overijssel & 1086280 & 3098 & 4053 & 1079129 \\
Flevoland & 328936 & 417 & 640 & 327879 \\
Gelderland & 1934314 & 8195 & 6958 & 1919161 \\
Utrecht & 117997 & 4370 & 3526 & 1110101 \\
Noord-Holland & 2534599 & 6887 & 9473 & 2518239 \\
Zuid-Holland & 3420700 & 10126 & 12889 & 3397685 \\
Zeeland & 374920 & 1152 & 1610 & 372158 \\
Noord-Brabant & 2375116 & 7974 & 7188 & 2359954 \\
Limburg & 1142679 & $4950 * *$ & 4400 & 1133329 \\
The Netherlands & 15987075 & 53152 & 56719 & 15877204 \\
\hline
\end{tabular}

* Calculation method: inhabitants - numbers of people with ID living in care facilities - numbers of people living in nursing homes $=$ number of inhabitants registered with general practices ${ }^{*}$ Statistics Netherlands (2001) ${ }^{* *}$ Ministry of Health, Welfare and Sports (2000) ${ }^{* * *}$ Results of present study

Table 3.2 Total lowest and highest estimation of prevalence of people with ID living in the various provinces**

\begin{tabular}{lccc}
\hline Provinces & $\begin{array}{c}\text { \% Living in care facilities } \\
\#\end{array}$ & $\begin{array}{c}\text { Lowest estimation of } \\
\text { prevalence }\end{array}$ & $\begin{array}{c}\text { Highest estimation of } \\
\text { prevalence \$ }\end{array}$ \\
\hline Groningen & 0.33 & 0.54 & 0.60 \\
Friesland & 0.34 & 0.55 & 0.60 \\
Drenthe & 0.42 & 0.63 & 0.69 \\
Overijssel & 0.29 & 0.50 & 0.56 \\
Flevoland & 0.13 & 0.34 & 0.40 \\
Gelderland & 0.42 & 0.63 & 0.69 \\
Utrecht & 0.39 & 0.60 & 0.66 \\
Noord-Holland & 0.27 & 0.48 & 0.54 \\
Zuid-Holland & 0.30 & 0.51 & 0.57 \\
Zeeland & 0.31 & 0.52 & 0.58 \\
Noord-Brabant & 0.34 & 0.55 & 0.61 \\
Limburg* & 0.43 & 0.64 & 0.70 \\
The Netherlands* & 0.332 & 0.543 & 0.599 \\
\hline
\end{tabular}

\#Calculation method: numbers of people with ID living in care facilities divided by inhabitants (Table 3.1) \$Calculation method: numbers of column 2 plus lowest or highest \% people with ID in general practice ( $0.21 \%$ or $0.27 \%$, respectively) 
Stage B - calculating the lowest and highest estimation of prevalence of ID of each the provinces and The Netherlands

The results of stage A were added to the lowest and highest estimation of prevalence of ID of stage 1. Table 3.2 presents the results.

Table 3.3 summarises the lowest and highest estimation of prevalence and numbers of people with ID in the Netherlands, based on the two extrapolation methods.

Table 3.3 Lowest and highest estimation of prevalence and numbers of people with ID in the Netherlands

\begin{tabular}{lcccc}
\hline & \multicolumn{2}{c}{ Extrapolation method I } & \multicolumn{2}{c}{ Extrapolation method II } \\
\hline $\begin{array}{l}\text { Lowest estimation of prevalence and } \\
\text { numbers }\end{array}$ & $0.643 \%$ & 102797 & $0.543 \%$ & 86812 \\
$\begin{array}{l}\text { Highest estimation of prevalence and } \\
\text { numbers }\end{array}$ & $0.699 \%$ & 111750 & $0.599 \%$ & 95703 \\
\hline
\end{tabular}

\section{Expert advice}

A validity check was performed during the extrapolation process. The numbers of people with ID living in care facilities $(n=4950$, as counted in this study) were compared with data from ID care services records provided by the Ministry of Health, Welfare and Sports $(n=4997)$ (Ministry of Health, Welfare and Sports, 2000). The difference was 1\%.

\section{Discussion}

The aim of this study was to determine the prevalence of people with ID in the Netherlands, indicating lowest and highest estimation values based on extrapolation. We conclude that the most plausible prevalence of people with ID in the Netherlands is $0.7 \%$ (the highest estimation of method I).

The reason for choosing this highest estimation of prevalence is that we used rather strict criteria to identify people with ID in the GP files. The restriction that 'there had to be relevant information from a psychologist or hospital specialist' for a definite ID diagnosis may have been too strict. GPs' judgements can be regarded as reliable because they know all their listed patients personally, and have mostly known them for years. GPs often take care of more than two generations of patients. They are able to evaluate the skills of their patients and to judge the nature and 
seriousness of ID. In the Netherlands, GPs are working in the vicinity where his listed patients live too.

The basic assumptions underlying the two extrapolation methods were chosen after consulting experts and seemed the best possible options. The argument for the first basic assumption (the prevalence of people with ID is equal in all the provinces) is the principle that greater availability of housing facilities for people with ID must mean that fewer of them are living with their relatives. The SCP (de Klerk, 2002) described in its report that all ID care facilities are fully occupied, that the number of facilities available is growing and that there are waiting lists. All these arguments support our assumption.

The second extrapolation method was tried, because there is a concentration of residential care institutions in three provinces of the Netherlands. Both the experts and the researchers were unable to find arguments in favour of this second extrapolation method (which assumed that the percentage of people with ID registered with general practices is equal in all provinces). The argument against the assumption underlying method II is the diversity of patients in general practices. GPs in urban areas have more relatively young patients, whereas those in rural areas have more older patients. Older people with ID are more likely to live in ID care facilities than younger patients (de Klerk, 2002). The policy is to register people with ID who live in supported accommodations, with general practices. They may also remain registered with the ID physicians of ID care facilities. All these arguments speak against the assumption underlying method II.

Some prevalence rates of people with ID in other countries have been reported in the literature. Christianson et al. (2002) reported a prevalence of $2.9 \%$ people with mild ID and $0.06 \%$ people with severe ID in children aged 2-9 years in rural South Africa. Larson et al. (2001) described a prevalence of $0.78 \%$ of ID in the non-institutionalised population of the United States. Patja (2001) reported prevalence rates for people with ID in Finland of $0.35-1.83 \%$ for those with mild ID aged 5-20 years and $0.27-0.63 \%$ for those with moderate, severe and profound ID aged $0-20$ years. Wen (1997) described a prevalence of $0.3-0.4 \%$ for people with ID in Australia. Comparing these data with ours is difficult, because of differences in health care systems between countries and methods of data collection (e.g. interview surveys and follow-up of national cohorts). Nevertheless, the differences in prevalence are remarkable.

The face validity of the identification method in general practices seems good, because the identification process of people with ID in RNH was performed by two researchers with the use of the checklist and the use of 
ID care services records. The unconfirmed cases of RNH consisted of patients for whom the specialist reports were lacking, while the GP assessed that it concerned patients with ID.

The highest prevalence of ID in the province of Limburg is not surprising. In the past (in three provinces), a lot of residential care facilities were built, because of the healthy scenery with forests.

A representative part of RHN participated in this study. There is no difference in age distribution and degree of urbanisation between the participating $87 \%$ and the other $13 \%$.

The data of Ministry of Health Welfare and Sports (2000) on the number of people with ID living in care facilities was $1 \%$ more than the data of the present study (2001). The external experts and the authors both concluded that it was acceptable to use the Ministry's data for the other provinces (as listed in Table 3.1).

Our results show that the estimation of prevalence of people with ID in the Netherlands decreased from $0.73-0.8 \%$ to $0.7 \%$ between 1988 and 2001, even though we included all age groups of people with ID and even those people with ID who made no use of ID care services. Those not using ID care could only be identified, because GPs knew the patients registered with them and because we could use the $\mathrm{RNH}$ general practice database. The prevalence of people with ID that we calculated can be used for service planning and budget calculations. It must be noted, however, that the organisation on health care is changing rapidly, with a fundamental change in the funding system in the year 2006. We are aware that the continuing process of closing down residential care facilities and the changes in care provision and funding may mean that the numbers of people with ID and their use of the whole range of care will have to be updated again in the near future. 


\section{Appendix}

Assessment schedule for general practices

Patient number

Birth date (dd) (mm) (yr)

Gender: $\mathrm{M} / \mathrm{F}$

\section{Criteria}

1. Patient has sub-average intellectual functioning, i.e. $\mathrm{IQ}<70-75$.

2. The intellectual disability manifested before the age of 18 years.

3. Patient has related limitations in two or more of the following applicable adaptive skill areas: communication, self-care, home living, social skills, community use, self-direction, health and safety, functional academics, leisure or work.

OR:

\section{For children}

Patient fulfils one of the following criteria:

$O$ visits special school, or on a waiting list for special school

$\mathrm{O}$ visits/visited/ is on a waiting list for day centre for children with

ID, or

O lives/used to live/ is on a waiting list for residential living facility for people with ID

O client of respite care facility for people with ID

O client ambulant care for people with ID

$O$ receives special funding for people with ID

$\mathrm{O}$ other criteria to be discussed

\section{For Adults}

Patient fulfils one of the following criteria:

O spent long unsuccessful years at primary school

$\mathrm{O}$ visits/visited/ is on a waiting list for day centre for adults with ID

O lives/used to live/ is on a waiting list for residential living facility

for people with ID

O client of respite care facility for people with ID

O client ambulant care for people with ID

$O$ receives special funding for people with ID

$\mathrm{O}$ other criteria to be discussed 


\section{References}

- $\quad$ Christianson AL, Zwane ME, Manga P, Rosen E, Venter A, Downs D \& Kromberg JGR (2002) Children with intellectual disability in rural South Africa: prevalence and associated disability. Journal of Intellectual Disability Research 46, 179-86.

- $\quad$ Klerk MMY de (Ed.) (2002) Rapportage gehandicapten. Maatschappelijke positie van mensen met lichamelijke beperkingen of verstandelijke handicaps. Social and Cultural Planning Office of the Netherlands, The Hague, the Netherlands.

- $\quad$ Kruyswijk M, Weert H van \& Hoekstra J (1997) Populatie en morbiditeit binnen een centrum voor onverzekerden [Population and morbidity in a centre for people without health insurance]. Huisarts en Wetenschap 4o, 14-7.

- $\quad$ Lamberts H \& Wood M (Eds.) (1987) ICPC. International Classification of Primary Care. Oxford University Press, Oxford.

- $\quad$ Larson SA, Lakin KC, Anderson L, Kwak N, Hak Lee J \& Anderson D (2001) Prevalence of Mental Retardation and Developmental Disabilities: Estimates from the 1994/1995 National Health Interview Survey Disability Supplements. American Journal on Mental Retardation 106, 231-52.

- $\quad$ Luckasson R, Coulter DL, Polloway EA, Reiss S, Schalock RL, Snell ME, Spitalnik DM \& Stark JA (1992) Mental Retardation. Definition, Classification, and Systems of Supports. American Association on Mental Retardation (AAMR), Washington DC.

- $\quad$ Maas JMAM, Serail S \& Janssen AJM (1988) Frequentieonderzoek geestelijk gehandicapten 1986. IVA, Tilburg, the Netherlands.

- Metsemakers JFM, Höppener P, Knottnerus JA, Kocken RJJ \& Limonard ChBG (1992) Computerized health information in the Netherlands: a registration network of family practices. British Journal of General Practice 42, 102-6.

- $\quad$ Ministry of Health, Welfare and Sports (1995) Ministerie van Volksgezondheid, Welzijn en Sport. De perken te buiten: meerjarenprogramma intersectoraal gehandicaptenbeleid 19951998. Ministerie van VWS, Rijswijk, the Netherlands.

- $\quad$ Ministry of Health, Welfare and Sports (2000). Numbers of people with ID living in care facilities. Internal memo.

- $\quad$ Patja K (2001) Life expectancy and mortality in intellectual disability [dissertation]. Finnish Association on Mental Retardation Research publication No.81, Helsinki.

- $\quad$ Schrojenstein Lantman-de Valk HMJ van, Wullink M, Akker M van den, Heurn- Nijsten EWA van, Metsemakers JFM \& Dinant GJ (2006) The prevalence of intellectual disability in Limburg, the Netherlands. Journal of Intellectual Disability Research 5o, 61-8.

- $\quad$ Social and Economic Council of the Netherlands (SER) (2000) Naar een gezond stelsel van ziektekostenverzekeringen. Advies uitgebracht aan de Minister van Volksgezondheid, Welzijn en Sport. SER publication number 12, the Hague, the Netherlands.

- $\quad$ Statistics Netherlands (Centraal Bureau voor de Statistiek). Retrieved October, 26 and 31, 2001, from http://www.cbs.nl/Statline/mensenmaatschappij/gezondheidenwelzijn/historiegezondheid/

- $\quad$ Statistics Netherlands (Centraal Bureau voor de Statistiek). Retrieved December, 20, 2005, from http://www.cbs.nl/Statline/thema's/mensenmaatschappij/bevolking/cijfers/huishoudens Wen X (1997) The definition and prevalence of intellectual disability in Australia. Australian Institute of Health and Welfare, Canberra. 


\section{Chapter 4}

Improving the transfer of care to general practice for people with intellectual disability:

development of a guideline

Magda Wullink

Henny van Schrojenstein Lantman-de Valk

Marjan van den Akker

Job Metsemakers

Geert-Jan Dinant

Published in: Journal of Policy and Practice in Intellectual Disability, 2007, 4, $241-7$. 


\section{Abstract}

\section{Background}

In the Netherlands, a public policy shift has led to a movement of people with intellectual disability (ID) from residential congregate care facilities to normative housing in their communities. Along with these physical transfers, medical care has also been transferred from specialty intellectual disability physicians (IDPs) associated with the residential facilities to general practitioners (GPs) native to the community. To facilitate these changes, the authors created a set of guidelines for the transfer of ID medical care. In developing these guidelines, the authors queried: (1) What elements have to be included in the draft guidelines? (2) What are the barriers to using the draft guidelines in practice and how can these barriers be overcome? and (3) What elements have to be included in the final form of the guidelines?

\section{Methods}

Data for the draft guidelines were drawn from information gathered during interviews and discussions with physicians and allied workers.

\section{Results}

The guidelines call for a feasible working agreement between IDPs and GPs regarding handing over patient files containing problem lists and histories and arrangements of out-of-hours house calls, practice visits, medication delivery, and paramedical treatments.

\section{Discussion}

Inherent barriers to the implementation of the guidelines might be communication difficulties among persons involved in the transfer of care and governmental rules that fail to overcome organizational barriers. 


\section{Introduction}

Since the 1990s, thousands of people with intellectual disability (ID) in the Netherlands have moved from residential congregate care facilities to alternative housing in their home communities (Ministry of Health, Welfare and Sports, 1995). In conformity with the support paradigm, people with ID can choose where and with whom they want to live and they have the right to receive the support they need (van Gennep, 1997 \& 2002).

Some people have moved to housing facilities near a residential care facility, but most have moved over larger distances, sometimes back to the region where they grew up. For practical reasons, the residential managers are obligated to transfer the medical care from the intellectual disability specialist physicians (IDPs) associated with the residential care facilities to the general practitioners (GP) working in the vicinity of the new housing facilities.

In the Netherlands, general practice physicians form the backbone of community medical care. Almost every person in the country is on the list of one GP in their community and GPs perform the gatekeeper's role with respect to specialist care (excluded are people living in residential care facilities and nursing homes - they have their own medical specialist). As a result, GPs deliver optimal continuity of care, both in person and in time (including out-of-hours), and for patients with any disease. However, GPs do refer to specialists for select problems or conditions, and after a referral, the specialist sends a report to the GP (including recommendations for changes in the use of medications).

Most GPs have some experience with patients who have mild to moderate ID in their practices as many may treat a child with ID living with family or an adult living in the community near relatives. However, GPs do not have experience with patients with more complex ID who become enlisted in their practice after moving to supported accommodations in the vicinity. Furthermore, as there are no strict criteria for moving to the community, GPs will face patients at different ages and with a variety of levels of ID. Some of these individuals will end up living alone; others may live in groups of between two and ten persons. As every person with ID has been given the opportunity to move to housing options in the community, it is expected that the complexity of care by local GPs for these patients will increase. It is also expected that the GPs will keep in close contact with medical specialists to organize the care for these patients with ID.

Information from the experiences of other countries that could aid in the transfer of medical care is rare. In the State of Victoria in Australia, 
residential care facilities started to close in the 1980 s and the medical care for people with ID was transferred from physicians at the residential care facilities to GPs in the community. Yet, more than ten years later, Lennox et al. (1997) still described many barriers to these transfers and suggested some solutions. Both Lennox \& Kerr (1997) and Iacono \& Johnson (2004) identified communication problems between GPs and patients with ID as a major obstacle to these effective transfers.

In practice, every residential care facility tries to find the best way to transfer medical information about the newly moved residents. However, a systematic transfer model that guarantees good quality and continuity of medical care and saves time for all involved has not been developed to help facilitate these transfers. While many countries, for example, Australia, Scandinavia (European Intellectual Disability Research Network, 2003) and England (Department of Health, 2001) have closed (almost all) their residential care facilities, the Netherlands and several other European countries have been slow in this process. Yet, in the Netherlands, public policy has mandated that people with ID continue to move from residential care facilities to a range of housing facilities in the community. These moves also include better accommodating aging people, who may move from one to another supported accommodation. Thus, a formalized, systematic model that guides transfers could significantly contribute to continuity of care and could be useful for all the coming transfers of care.

\section{Specific aims}

The aim of this initiative was to create a viable Guideline for the Transfer of Medical Care of People with ID ('the Guideline') to facilitate the transfer of medical care from residential-based IDPs to communitybased GPs or from one GP to another GP. The questions raised were: (1) What elements have to be included in such a Guideline? (2) What are the expected barriers to using the Guideline in practice and how can these barriers be overcome? and (3) What elements have to be included in the final Guideline?

\section{Methods}

\section{Design}

The project was carried out in three stages: (1) developing the draft Transfer Guideline; (2) testing the draft; and (3) drawing up a final 
version. In each stage, a variety of concerned parties were invited to participate.

\section{Participants}

The following groups participated in developing and testing the draft Transfer Guideline: (1) IDPs; (2) GPs and practice assistants; (3) people with ID and their relatives or legal representatives; (4) support staff of people with ID; and (5) general managers of residential care facilities for people with ID. All the participants had previous experience in the transfer of care to GPs or were involved in transfer during the research period. Figure 4.1 describes the process of development and testing of the Guideline.

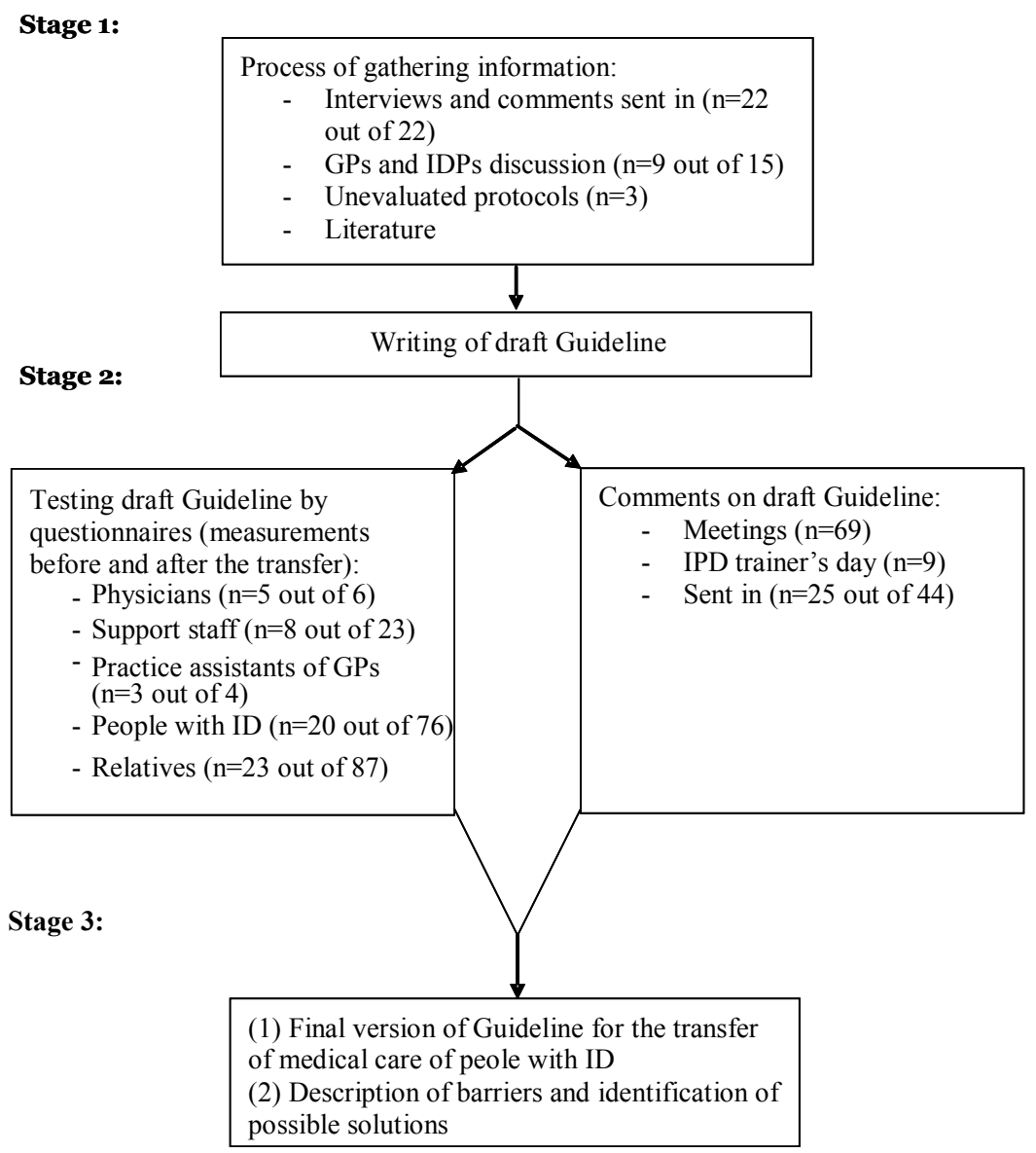

Figure 4.1 Development and testing of Transfer of ID Care Guideline 


\section{Elements included in the draft Guideline}

The draft Guideline incorporated information obtained from: (1) interviews with people who had experience with the transfer of ID care; (2) three existing, though unevaluated, protocols provided by the participating residential care facilities; (3) a group discussion of GPs and IDPs; and (4) written comments by general managers of residential care facilities. In addition, incorporated were issues found in the literature (Lennox et al., 1997; Lennox \& Kerr, 1997; Iacono \& Johnson, 2004).

\section{Testing the draft Guideline and identifying barriers to its use}

The draft Guideline was applied in several instances of the transfer of ID care and than feedback was obtained by questionnaires given out to the people involved. IDPs were asked if there were short-term plans to transfer medical care for people with ID to local GPs. IDPs, GPs, practice assistants, and support staff within the geographic area where the study was performed (i.e. the southern part of the Netherlands) completed a questionnaire at the start of transfer, as well as 6 months after the transfer. The questionnaires gathered information about a number of agreements that were organized between IDPs and GPs, between GPs and pharmacists and between practice assistants and support staff. There were also questions about referrals and barriers to working with the draft Guideline. (Problems encountered during this phase were related to postponement of the expected transfers of ID care which made it difficult to find participating IDPs.)

People with ID were interviewed twice during the study period and their relatives or legal representatives twice filled in a questionnaire about their satisfaction with physician-patient relations provided by IDPs and GPs, first before and again after the transfer of ID care.

To augment the information collected, input from interested parties not involved in the transfer of care at the time of data collection was obtained. The draft Guideline and its ingredients were discussed in three meetings and at one IDP trainer's day. Personal and general invitations for these meetings were sent to a range of potential participants. Information about the meetings was also provided by means of articles, websites, and interviews in six Dutch journals and newspapers (Appendix 1). During the research period, the draft Guideline was posted on the website of the Department of General Practice at the Maastricht University (Wullink et al., 2003). The site also included a page with information - wording adapted to be readily understood by to people with ID. To support the transfer of care process, the website is still available. 


\section{Elements included in the final version of the Guideline}

All information gathered during the testing period, including reactions received at the meetings and a variety of personal comments, was used to identify the barriers to implementing the draft Guideline. This information was also used to suggest some possible ways to overcome obstacles to implementation and to construct the final version of the Guideline.

\section{Medical Ethics Committee}

The Medical Ethics Committee at the Maastricht University gave its consent to the study proposal. People with ID and their relatives or legal representatives were recruited by support staff and agreed to participate in the project. They were ten asked to fill in and sign an informed consent form before participating in interviews or filling in questionnaires.

\section{Results}

\section{Participants}

Figure 4.1 shows the numbers and variety of people participating in developing and testing the draft Guideline. Overall, a total of 193 persons participated and 44 interested persons asked for a printed copy of the draft Guideline. Twenty-five of them (57\%) responded with written comments, after being invited to do so.

\section{Elements included in the draft Guideline}

The following elements were included in the draft Transfer Guideline: (1) agreements between IDPs and GPs about handing over patient files and other information from IDP to GP; storage of patient files with the IDP and the GP; out-of-hours house calls and practice visits and referrals to paramedical services; (2) agreements between IDP, GP and pharmacists; (3) appropriate communication between support staff and practice assistants; and (4) appropriate communication between GP, practice assistant and the person with ID.

\section{Testing the draft Guideline and identifying barriers to its use}

There were some difficulties experienced in attempting to test the draft version in practice for a variety of reasons: (1) because of a number of 
postponements of expected transfers of ID care (mostly because of the delay of the construction of new buildings or purchase delays because of excessive prices of the desired houses); (2) fear of investing too much time to go through the process by support staff; (3) failure on the part of support staff to distribute the invitational letters to people with ID and their relatives to participate in the trials; and (4) a lack of familiarity with research protocols by people with ID and their relatives. In the end, only 16 out of 33 (48\%) potential care workers tested the draft Guideline and only 43 out of 163 (26\%) people with ID and relatives gave information about their degree of satisfaction with physician-patient relations provided by IDPs and GPs before and after the transfer of ID care (see the questionnaire section of Figure 4.1).

During the testing period, a variety of barriers came to light and they fell into two categories.

1. Barriers in daily practice (all related to communication):

- First contact with a GP: general managers of the residential settings asked the GPs to register people with ID after they had moved into housing facilities in the vicinity. GPs did not like being confronted with a fait accompli and not being consulted beforehand.

- GPs did not get any information about the residential organization.

- Lack of good and clear communication between all participants involved in the transfer of ID care (for example, GPs do not know IDPs; support workers did not know the rules of general practices).

2. Organisational barriers (related to financial issues):

- Health insurers did not reimburse referrals by GPs to IDPs.

- Reimbursement of out-of-hours service by primary care GPs was impossible for those persons with ID who were registered under the Exceptional Medical Expenses Act (AWBZ).

- IDPs (whose salary is based on the AWBZ) were not allowed to prescribe medication to patients who were registered within the primary health care system.

- Discounts on medication costs, which are quite common in residential chronic health care settings, proved not to be applicable to primary care pharmacies. Supplying medications from the original residential facilities was cheaper, but took longer and was problematic in urgent cases.

- The primary responsibility for updating medication lists was unclear if two pharmacies were involved in medication delivery to an individual patient with ID. 


\section{Elements included in the final version of the Guideline}

The final version of the Guideline was adjusted to the findings of stage 2 (Figure 4.1). The text of the final Guideline is provided in Appendix 2. It is posted on the website of the Department of General Practice at the Maastricht University (Wullink et al., 2003).

The main differences between the draft and final version of the Guideline are: (1) the IDP now makes the initial contacts with the local GP; (2) the IDP now makes the arrangements with the regional GPs about out-ofhours services and with the involved local and residential pharmacists involved about medication delivery and updating medication lists; (3) the patient files now have to include information about dentition and dental care; (4) the GP now has to keep the patient files and is fully responsible for the patients with ID; (5) referral to the IDP for specific health problems is facilitated (GPs only fill in the referral letter and IDPs fill in all the forms); and (6) arrangements now should be made about training in health problems of people with ID for GPs and practice assistants by IDPs.

\section{Discussion}

From the feedback we received, there is a strong indication that the Guideline for the transfer of medical care of people with ID that we developed fills a need. Many GPs and IDPs participated in this study, they asked for and downloaded the Guideline; further, they attended the meetings and provided valuable feedback. From an operational standpoint, we found a number of barriers to the effective implementation of the Guideline. These barriers were associated with either practical issues or organisational problems. The Guideline includes a Checklist for Transfer of Patient Information and sample agreements about cooperation.

The process of developing consensus on the Guideline was not free of problems. For one, as Lennox et al. (2005) have described, there are problems that have to be overcome when recruiting people with ID for research purposes. This was also our experience as well, as we were able to include less than half of the numbers of the intended participating groups in this project. In addition, we might have obtained a more balanced overview if more managers, administrators, policymakers, and support staff had participated in the discussions or had filled in the questionnaires. Physicians were well represented, although more so in the meetings than among those completing the questionnaires. 
Removing the barriers to transfer of ID care in daily practice can be easy if every care worker involved tries to communicate more effectively with other workers. While the communication barrier can be dealt with by training, overcoming the organisational barriers appears to be more complicated, because these barriers are inherent in the Dutch financing system (AWBZ), and government rules have to be changed to make this process work more smoothly.

Comments from persons who contributed to the study lead us to believe that the Guideline can facilitate the entire transfer process, and should therefore be more widely distributed. Large residential care facilities still exist in Europe (for example, in Belgium, Germany, Greece and Spain) (European Intellectual Disability Research Network, 2003) and they could benefit from adopting the Guideline before undergoing a shift to community care. Continuity of care could certainly be strengthened by further studying implementation strategies, which could contribute to measurable quality improvements in the care for people with ID. 


\section{Appendix 1}

\section{Meeting information in Dutch about the draft Guideline for the transfer of medical care of people with ID}

- Derksen G. (2003). Drukke dokters. Huisarts niet voorbereid op nieuwe patiëntengroep. Markant, 8, 22-24.

- Gunst S. van. (2003). Medische zorg mensen met een verstandelijke beperking naar huisartsenpraktijken. NVDAnieuws, 31, 24-25.

- Melchior M. (2003). Zorgoverdracht verstandelijk gehandicapten geregeld. Medisch Contact, 58. Retrieved April 16-18, 2003, from http://medischcontact.artsennet.nl/ezine.asp?a=25567\&s= $987 \& \mathrm{I}=264$

- Mulder J. (April 29, 2003). Taakverdeling voor huisarts en AVG-er. MedischVandaag, 8, 19.

- Mulder J. (May 14, 2003). Huisarts en AVG moeten wennen aan elkaar. MedischVandaag, 9, 31.

- Wullink M. (2003). Samenwerking huisarts en AVG bij community living. Mediator, 14, $n r$ 2, 16. 


\section{Appendix 2}

Guideline for the transfer of medical care of people with ID

\section{Basic assumptions}

All people with ID have the right to be heard and to participate in decisions about their own lives and health.

Care is to be based on the support paradigm, which means that all people with ID work, live, study, recreate etc. in the community and receive the support they need.

\section{Goals of the Guideline for the transfer of medical care of people with ID}

The goals of the Transfer Guideline are:

- Unequivocal transfer of care from IDP to GP.

- Informing all persons involved about the transfer of care well in advance.

- Good transfer and continuity of care.

- Close cooperation between all persons involved in the care of people with ID.

- Efficient time management.

\section{$1 \quad$ Finding a general practitioner}

The person who is responsible for making arrangements with the GP has to start looking for a GP as soon as possible, but at least six month before the person with ID is to move to housing in the community. The GP can obtain further information from the IDP and from the residential care facility. The residential care facility can enter into consultation with GPs. Three months before the move, the residential care facility informs the GP of the planned date for this move.

One month before the move, the residential care facility sends the GP the patient files.

\section{Agreements between GP, IDP and pharmacists}

\subsection{Handing over patient files}

The IDP passes on to the GP the information mentioned in the Checklist for Transfer of Patient Information. 
Checklist for Transfer of Patient Information:

- The problem list

- A summary of the person's history, including:

- Aetiology of the disability and current co-morbidity;

- Current medication and medical history;

- Current other treatments.

- The person's level of intellectual, social and physical capacities.

- Information about the state of the person's sensory organs.

- Information about the state of dentition and dental care provided to the person.

\subsection{Agreements between GP, IDP and pharmacists}

The agreements between GP, IDP and pharmacists are included in a Checklist on Agreements between GPs, IDPs and pharmacists. Content of the Checklist on Agreements between GPs, IDPs and pharmacists:

- Patient file storage

The GP keeps all patient files. Care plans are kept at the housing facilities in the community. These plans also record relevant medical information, which can be used by GPs providing out-of-hours house calls and practice visits.

- Out-of-hours house calls and practice visits

The person responsible for finding a GP has to make arrangements with the GP about out-of-hours house calls and practice visits. If frequent out-of-hours house calls and practice visits are expected, the GP will provide further medical information in the care plan for the person with ID.

- Arrangements about medication delivery and updating medication lists with the pharmacists involved (local and residential).

- Paramedical treatments (e.g. physiotherapist, speech therapist etc.) The GP refers the person with ID only to those paramedical therapists who are properly trained to treat people with ID.

- Responsibility

The Guideline for the transfer of medicalcare of people with ID recommends that GPs should be made fully responsible for their patients with ID and that it should be made very easy for them to refer these patients to IDPs. 


\section{Checklist for Support Staff and Practice Assistants}

After a person with ID has moved to a housing facility in the community, a support worker contacts the GP's practice assistant. The support worker informs the practice assistants about the Checklist for Support Staff and Practice Assistants.

Content of the Checklist for Support Staff and Practice Assistants:

- The support worker introduces her/himself to the practice assistants.

- The support worker asks for a brochure with details about the general practice and inquires about the way the practice is organized.

- The support worker makes arrangements with the practice assistants about the minimum amount of information that the GP needs for a practice visit.

- The support worker gives the practice assistants a list of those persons with ID who are able to make appointments for practice visits with the GP by themselves.

- The support worker gives the practice assistants a list of those persons with ID who can come in for practice visits with the GP without the help of a support worker.

\section{Background of the Guideline for the transfer of medical care of people with ID}

Over the last twenty years, there has been a tendency for people with ID to move from residential care facilities to housing facilities in the community, where they are to be provided with care by the local GPs. The greater co-morbidity rate among these patients, and the different way in which they communicate is likely to increase the GPs' workload. This Guideline intends to facilitate the work of GPs and their practice assistants.

\section{Definitions}

Support worker: the professional who spends the most time with the person with ID (e.g., direct care staff, team leader, house supervisor, client services manager, etc.)

Problem list: a list of relevant health problems not resolved within 6 months (e.g., diabetes, obesity, etc.). 


\section{References}

- Department of Health (2001) Valuing people: a new strategy for learning disability for the $21^{\text {st }}$ Century. HMSO, London.

- $\quad$ European Intellectual Disability Research Network (2003) Intellectual Disability in Europe: Working papers. Tizard Centre, University of Kent at Canterbury, Canterbury.

- $\quad$ Gennep ATG van (1997) Paradigma-verschuiving in de visie op zorg voor mensen met een verstandelijke handicap. Universiteit Maastricht, Maastricht.

- $\quad$ Gennep ATG van (2002) De tweedeling. Universiteit Maastricht, Maastricht.

- $\quad$ Iacono T \& Johnson H (2004) Patients with disabilities and complex ommunication needs. Australian Family Physician 33, 585-9.

- $\quad$ Lennox NG \& Kerr MP (1997) Primary health care and people with an intellectual disability: the evidence base. Journal of Intellectual Disability Research, 41, 365-72.

- Lennox NG, Diggens JN \& Ugoni AM (1997) The general practice care of people with intellectual disability: barriers and solutions. Journal of Intellectual Disability Research, 41, 380-90.

- $\quad$ Lennox N, Taylor M, Rey-Conde T, Bain C, Purdie DM \& Boyle F (2005) Beating the barriers: recruitment of people with intellectual disability to participate in research. Journal of Intellectual Disability Research, 49, 296-305.

- Ministry of Health, Welfare and Sports (1995) Ministerie van Volksgezondheid, Welzijn en Sport. De perken te buiten: meerjarenprogramma intersectoraal gehandicaptenbeleid 19951998. Ministerie van VWS, Rijswijk, the Netherlands.

- Wullink M, Schrojenstein Lantman - de Valk HMJ van, Metsemakers JFM \& Dinant GJ (2003) Overdracht van zorg naar de huisarts voor mensen met een verstandelijke beperking die in de wijk (gaan) wonen. www.hag.unimaas.nl/richtlijn-zorgoverdracht 



\section{Chapter 5}

\section{Changing care for people with intellectual}

disability: an individual educational programme for daily general practice

Magda Wullink

Henny van Schrojenstein Lantman-de Valk

Vroon Pigmans

Geert-Jan Dinant

Job Metsemakers

Zorg voor mensen met een verstandelijke beperking

Magda Wullink, Henny van Schrojenstein Lantman - de Valk en Geert-Jan Dinant Programma voor Individuele Nascholing

Utrecht: Nederlands Huisartsen Genootschap

ISBN 90-5793-201-6 


\section{Abstract}

\section{Background}

General practitioners (GPs) have to take care of a larger number of people with intellectual disability (ID) and more complex problems of some of them after the move of thousands of people with ID to supported accommodations in the vicinity. Education is needed to prepare GPs on this extensive task. This study aimed to develop and edit an individual (electronical) education (PIN) on health care in people with ID adapted to the needs expressed by GPs and in line with the demands of clients and carers.

\section{Methods}

A literature search was performed in Medline to develop a practicebased postgraduate course (the preliminary form of the PIN). No courses were found, but recommendations for education were. Our course was evaluated in four groups of GPs. In collaboration with the Dutch College of General Practitioners (NHG) the PIN was made and published. Cases and propositions are the central point in the education. The NHG disseminated the booklet, including its Internet version.

\section{Results}

The main themes of the PIN were described in six cases: presentation of complaints, physician-patient communication, co-morbidity of people with ID and cooperation between GPs and medical specialists, including the ID-physician.

\section{Discussion}

Strategies to improve health care for people with ID are needed, so education has to be developed. The validity of the PIN seems good. All the parties involved in the care of people with ID gave comments on draft texts; subjects and cases with the highest prevalence of complaints and syndromes in daily practical care of people with ID were used. Further dissemination and other implementation strategies of the PIN are needed to reach all the GPs. 


\section{Introduction}

In the Netherlands, general practitioners (GPs) have been taking care of people with intellectual disability (ID) who live with their relatives, for decades. On average, 10 adults and 1-2 children with ID are registered with every general practice (Evenhuis, 2001). Because people with ID have been moving from residential care facilities to supported accommodations in the community a greater number of people with ID are enlisted at the general practices, whose physicians have to take care of those people, including their more complex medical and social problems. However, in medical school, very little attention is given to medical care for people with ID (Lindsay \& Burgess, 2006). In the Netherlands, but also in other countries, education of ID care in GP vocational training and in continuous medical education is rare. This lack of education is contradicting to the GPs' extensive tasks that require specific expertise and skills in this area of medicine.

Howells (1986), a GP in the United Kingdom, made an inventory of ID care and stated that GPs experience difficulties in communication with people with ID, and because of that had a lack of awareness of their special needs. Lennox et al. (2001) described that current health care for people with ID gave evidence of significant shortcomings: 'The GPs found that the synopsis of the literature was the best intervention for increasing knowledge and was also the most practical to use in general practice' (Lennox et al., 2001). Baxter et al. (2006) described the risk of unrecognised illness in people with ID. Aspray (2006) stated that training of physicians urgently needs priority and Phillips (2004) published an inventory of the wished contents of these trainings.

The Netherlands Organisation for Health Research and Development (ZonMw) invited our research group 'Health care in general practice for people with ID' to develop an individual postgraduate education (PIN) in cooperation with the Dutch College of General Practitioners (NHG). Our research group consists of GPs, one ID physician (IDP) and one health scientist. The precise aim of the assignment was: to develop and edit an individual (electronical) education (PIN) on health care in people with ID adapted to the needs expressed by GPs and in line with the demands of clients and carers.

\section{Methods}

The PIN was based on a practice-based postgraduate course (the preliminary form of the PIN) given by two members of our research 
group. A search in Medline with the MeSH terms '(under/post)graduate, (medical) education, health, general practitioner, family physician, mental retardation and intellectual disability/disabilities' was performed. No education or courses were found, except one Australian study with a few recommendations (Phillips, 2004). More than $70 \%$ of the interviewed GPs of Victoria (Australia) wanted to receive further education on behavioural or psychiatric problems and syndrome-specific medical problems of people with ID. Other subjects mentioned for education were: preventative and primary health care, neurological problems or diseases (e.g., epilepsy), orthopaedic problems, gastrointestinal problems, complex medical problems, human relations/sexuality issues and collaboration with other services (Phillips, 2004).

Our research group was experienced in training GPs on health issues of people with ID. Together with GPs, they had made a postgraduate course to educate groups of GPs. Cases and propositions were collected for this course. Three cases and four propositions from GPs and two cases from the ID-physician of our research group were used. The subjects of the cases were: coughing, constipation, epilepsy, troubles with food intake and use of oral contraceptives (the pill). The subject of the propositions was: tasks of GPs for people with ID who live in supported facilities in the vicinity. During one year, this course was given four times to a total of 50 GPs. Active participation of the GPs was required. All groups evaluated the course positively. Later on the material of the course was used to create the PIN.

After the first draft text of the PIN was written, comments were asked and received from two non-involved GPs, one GP of the NHG, two noninvolved IDPs, five relatives of people with ID and one senior employee of the Federation of Societies of Persons with Intellectual Disabilities and their Families (FvO). The comments of the professionals concerned the text issues. Relatives commented on legal issues and treatment. Comments were also asked from two persons with ID. A draft text in adapted language was sent by e-mail to them. Furthermore, the two people with ID were interviewed about their ideas of the perfect practice visit.

Comments and interviews were used for the second draft of the PIN. Textual comments of three GPs of the NHG resulted in the general practice-based final version. 


\section{Results}

The main themes of the PIN were: (1) presentation of complaints and physician-patient communication, (2) co-morbidity of people with ID and (3) cooperation between GPs and medical specialists, including IDPs (Wullink et al., 2005). The education consisted of cases with questions and answers, propositions, additional information and an assessment with open questions.

The subjects of three extended cases were: coughing, constipation and difficulty with food intake; the subjects of three small cases were epilepsy. All cases have an emphasis on de-concentration of care and complex care. The cases represented persons with ID living in supported accommodations in the vicinity. Their background features were: Down syndrome, Autistic Spectrum Disorder, Sanfilippo B syndrome, and severe or unknown level of ID. The propositions deal with: (1) the tasks of GPs for people with ID who live in supported accommodations in the vicinity and (2) the cooperation between GPs and IDPs.

The case of Léon will be mentioned as an example. Léon, a man of 61 years of age has Down syndrome. His complaint is constipation and he is going with a support worker to the GP for a practice visit. In the PIN, the co-morbidity of Down syndrome and possible causes and solutions of constipation are described. It seems that Léon suffers from the first symptoms of dementia. The help of an IDP (or specialised GP) is essential in case of further assessment, because people with ID cannot perform regular memory tests.

The ideas of people with ID for practice visits all regarded respectful treatment and were: (1) putting questions about complaints to the person with ID, (2) listening to the person with ID, (3) ask permission to the person with ID before starting to talk with the support worker or relative about the person with ID, (4) speak serious to the person with ID, (5) take the opinion of the person with ID into consideration, (6) take time for the practice visit, (7) explain and demonstrate before starting the physical examination and (8) explain therapy. People with ID will be content with treatment if physicians perform practice visits in accordance with their wishes. This information on communication and practice organisation was used in the definitive text of the PIN.

The PIN was disseminated to 2537 GPs since December 2005. The acquired knowledge of the GPs can be tested by a written assessment of the PIN. If GPs pass the assessment accreditation points are acquired. Until July 2006, 327 GPs returned their assessment to NHG. In the past, 800 assessments were returned in the year following the dissemination of a PIN. 


\section{Discussion}

Strategies to improve GP care for people with ID are needed, because the frequency and presentation of complaints of these people are different compared to people without ID. The contents of the PIN were adapted to these differences.

The subjects of the PIN cover six out of the nine expressed wishes for an education programme of the GPs in Victoria (Phillips et al., 2004). It is impossible to consider all the desired issues in one PIN booklet. Much attention was given to: (1) communication of GPs with people with ID, their relatives and support workers, and to (2) gaps in GP's knowledge concerning daily medical care of people with ID. A continuing medical education strategy, such as practice-based interventions are maybe more effective (Davis et al., 1995) to improve the dearth of educational materials for GPs (Lindsay \& Burgess, 2006).

Until now, the PIN is not systematically evaluated, but a considerable number of physicians, both GPs and IDPs, gave comments on the draft text. In the near future, an evaluation study could be performed to know what implementation strategies are needed to stimulate every GP to study the PIN and to check what further education GPs need. Training of GPs is necessary, because there exist few specialists in medical ID care (IDPs or specialised GPs) and the number of people with ID listed in general practices increases.

The external validity of the PIN seems good: (1) the subjects were daily practical care of people with ID, (2) the cases with the highest prevalence of complaints and syndromes in people with ID were used, (3) every physician can use the individual (electronical) education, and (4) every physician can evaluate the improvement of knowledge by using the assessment.

Further research is necessary to clarify if the PIN really meets GPs needs and if it improves the health care for people with ID. Further dissemination and other implementation strategies have to be performed to educate the Dutch GPs (7,500 persons) in daily practical care of people with ID. Most likely, the PIN can be used in other countries after translation in another language. 


\section{References}

Aspray TJ, Francis RM, Tyrer SP \& Quilliam SJ (2006) Patients with learning disability in the community. BMJ 318, 476-7.

- $\quad$ Baxter H, Lowe K, Houston H, Jones G, Felce D \& Kerr M (2006) Previously unidentified morbidity in patients with intellectual disability. British Journal of General Practice 56, 93-8.

- Davis DA, Thomson MA, Oxman AD \& Haynes B (1995) Changing physician performance A systematic review of the effect of continuing medical education strategies. JAMA 274, 700-5.

- $\quad$ Evenhuis HM (2001) Want ik wil nog lang leven. Moderne gezondheidszorg voor mensen met verstandelijke beperkingen. Een achtergrondstudie voor de Raad voor de Volksgezondheid en Zorg ten behoeve van haar advies inzake 'Comminity care'. Erasmus Universiteit, Rotterdam.

- $\quad$ Howells G (1986) Are the medical needs of mentally handicapped adults being met? Journal of the Royal College of General Practitioners 36, 449-53.

- Lennox NG, Green M, Diggens J \& Ugoni A (2001) Audit and comprehensive health assessment programme in the primary healthcare of adults with intellectual disability: a pilot study. Journal of Intellectual Disability Research 45, 226-32.

- $\quad$ Lindsay P \& Burgess D (2006) Care of patients with intellectual or learning disability in primary care: no more funding so will there be any change? British Journal of General Practice 56, 84-6.

- Phillips A, Morrison J \& Davis RW (2004) General practitioners' educational needs in intellectual disability health. Journal of Intellectual Disability Research 48, 142-9.

- $\quad$ Wullink M, Schrojenstein Lantman - de Valk HMJ van, Dinant GJ (2005) Zorg voor mensen met een verstandelijke beperking. Programma Individuele Nascholing. Dutch College of General Practitioners (NHG), Utrecht, the Netherlands. 



\section{Chapter 6}

\section{Autonomy in relation to health among people with intellectual disability: a literature review}

Magda Wullink

Guy Widdershoven

Henny van Schrojenstein Lantman-de Valk

Job Metsemakers

Geert-Jan Dinant

Published in: Journal of Intellectual Disability Research, 2009, 53, 816-26 


\section{Abstract}

\section{Background}

Since the 1990s, individualisation, participation, normalisation and inclusion have been the main principles of care for people with intellectual disability (ID). Autonomy has become an important issue for these people. This review of the literature tried to answer the question: how do people with ID exercise autonomy in relation to health?

\section{Methods}

Searches in Cochrane, Medline and PsycINFO were based on the following aspects of autonomy: self-determination, independence, selfregulation and self-realisation.

\section{Results}

Thirty-nine of 791 articles met our criteria, including 14 on selfdetermination, seven on independence, 15 on self-regulation, and three on self-realisation.

\section{Conclusions}

In spite of decades of promoting autonomy, the exercise of autonomy in relation to health has so far rarely been an issue in the literature. 


\section{Introduction}

Since the 1990s, individualisation and participation of people with intellectual disability (ID) have been guiding principles in care provision. This has led to new approaches in care, for example by using individual and flexible planning of care and support in consultation with clients (Kebbon, 1997). The Nordic countries, as early adopters of normalisation in the 1970s, showed considerable differences in ID care and policy (Nirje, 1969). Normalisation was the precursor of individualisation and participation.

People with ID have a right to inclusion in the community. The UK Department of Health (2001, p.24) described this as: 'Inclusion: being part of the mainstream is something most of us take for granted. We go to work, look after our families, visit our GP, use transport and go to the swimming pool or cinema. Inclusion means enabling people with learning disabilities to do those ordinary things, make use of mainstream services and be fully included in the local community'. One of the most important issues in human life is autonomy, and individualisation and living in the community are expected to make people with ID more autonomous.

In this review, we explored published studies to find information on the way in which people with ID exercise autonomy in relation to health. We focused on everyday activities, such as making an appointment with a physician, discussing visits to the doctor with a support worker, being interviewed during research studies or taking part in a programme to give up smoking.

We first searched for definitions of autonomy in studies of health care ethics and ID, and found four definitions.

The first definition referred to autonomy as self-determination and independence: 'A behaviour is considered to be autonomous if the person acts (a) according to own preferences, interests, and/or abilities and (b) independently, free from undue external influence or interference' (Wehmeyer et al., 1996, p.632). Wehmeyer's article mentioned three other essential characteristics of self-determined behaviour, viz. self-regulation (using skills in a situation), psychological empowerment (the capacity to perform behaviours to achieve a preferred outcome) and self-realisation (knowing yourself, your strengths and limitations and using this in a beneficial way).

The second definition referred to autonomy as control: 'The term autonomy for clients was defined as: having the same amount of control over his actions, decision-making, wishes and desires as any other person of comparable age' (Wolfensberger \& Glen, 1975, p.28). 
The third definition referred to autonomy as a characteristic of patient history, consisting of three dimensions: self-determination, independence and self-care. 'Self-determination points at making choices and decisions about one's own life and health, and includes freedom of choice. Independence (physical, psychological and social) concerns planning and organising one's own life, including social contacts and role-taking, and refers to responsibility for one's own life and health care. Self-care includes skills (mobility, communication, cognition) and activities of daily living, necessary for functioning' (Proot, 2001, p. 142).

The fourth definition referred to autonomy as moral self-development or self-realisation: 'Autonomy requires that individuals critically assess their own values and preferences; determine whether they are desirable; affirm, upon reflection, these values as ones that should justify their actions; and then be free to initiate action to realise values' (Emanuel \& Emanuel, 1992, p.2225).

We chose the definition of autonomy by Wehmeyer et al. (1996) as our point of departure, as this definition was formulated with people with ID in mind, focuses on their behaviour and their skills, and is the most comprehensive of the four definitions. In addition to the two elements explicitly distinguished by Wehmeyer, namely self-determination and independence, we included self-regulation (including psychological empowerment) and self-realisation. Together, these elements cover most of aspects mentioned in the other definitions. This resulted in a model of autonomy containing four elements: (a) self-determination, (b) independence, (c) self-regulation and (d) self-realisation. This model was used to analyse articles found in the literature on exercising autonomy in relation to health among people with ID. We assessed determinants of personal autonomy, actual situation in everyday health care practice and positive experiences in relation to health.

\section{Methods}

A literature search was performed in Cochrane, Medline and PsycINFO, using four groups of search terms: (1) mental retardation, intellectual disability, intellectual disabilities, (2) health, (3) personal autonomy, self-determination/self-direction, independence, self-realisation/selfrealization, self-regulation, psychological empowerment, (4) referral and consultation, office visits, ambulatory care, house calls. All articles in Dutch, English, French and German were included. The search period was set from January 1990 to February 2007. 
As the combination of search terms (1), (2), (3) and (4) yielded hardly any articles, the search was repeated with the combination of search terms (1), (2) and (3). The risk of this procedure was that it might yield a number of irrelevant articles, for example about studies testing the use of medication or studies using support staff as research participants. We also expected to find some suitable articles with the search terms 'menstrual management' and 'smoking cessation', as these subjects offer good opportunities for people with ID to exercise autonomy. Hence, an additional search was performed with these terms in combination with search term (1). Exclusion criteria were: (a) no abstract and (b) unclear methods (methods and results not matching).

\section{Results}

The searches in Cochrane, Medline and PsycINFO resulted in 791 articles; 331 articles were duplicates and ten were in an excluded language, leaving 450 for the analysis. Figure 6.1 outlines the search results. A total of 413 articles (of the 450) did not focus on the autonomy of people with ID in relation to health, but on topics like pharmacological interventions, health services and attitude of health care staff. Thirty-seven articles (of the 450) were examined further, and two articles were excluded because their description of the methods was unclear. The additional searches on smoking cessation and menstrual management resulted in four articles, yielding a total of 39 articles that were examined.

In tables $6.1-6.4$, these 39 articles have been classified according to the four elements of our autonomy model, (a) self-determination, (b) independence, (c) self-regulation, and (d) self-realisation. For each element, we focused on three aspects: determinants, situation in practice and positive experiences. We thus clustered the articles into 12 categories (three aspects for each of the four elements of autonomy). Of course, this classification of the articles is somewhat arbitrary, since many of them address more than one aspect or even more than one element. 


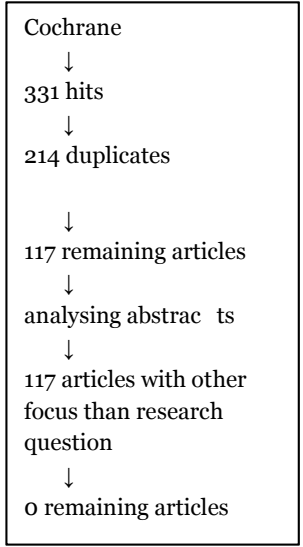

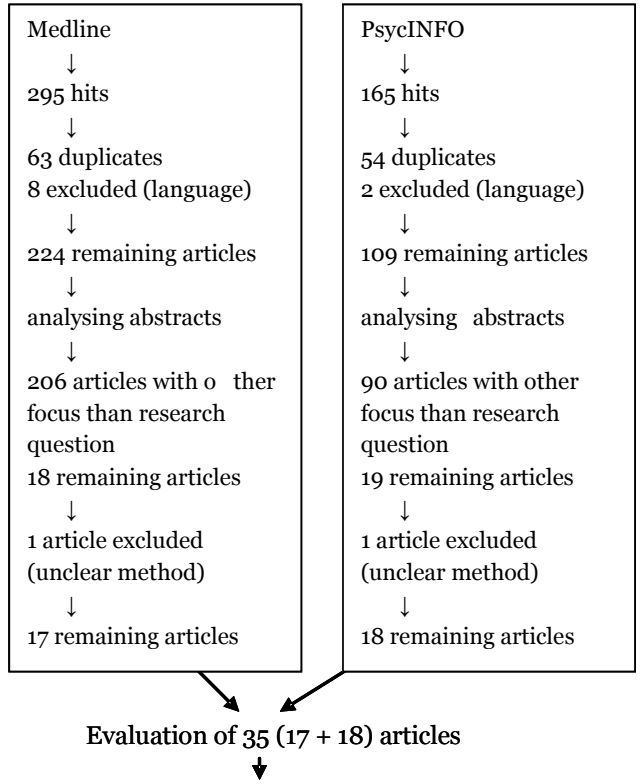

A total of 39 articles were evaluated

Figure 6.1 Search results.

\section{(a) Self-determination}

Fourteen articles were classified under this element. Their contents are summarised in Table 6.1.

\section{Determinants}

Wehmeyer et al. (1996) used a series of self-report measures to interview people with ID, recruited from self-advocacy groups, to examine the characteristics of self-determination. These characteristics [selfdetermination / acting according to one's own preferences, independence, self-regulation (including skills), psychological empowerment (including skills) and self-development/self-realisation] were also used in our review. Algozzine et al. (2001) mentioned selfadvocacy and choice-making as the major intervention themes of selfdetermination. They also reported that self-determination can be taught by a variety of educational methods. Stancliffe (2001) confirmed the view that self-determined competencies can be learned. Haelewyck et al. (2005) described that $89 \%$ of adolescent people with ID were satisfied 
with an exercise book to facilitate self-determination. Smith (2003) recommended the use of support brokers to improve the process of making choices, because support workers have a double role, working both for the people with ID and for the organisation that employs them.

\section{Situation in practice}

The majority of the interviewed people with ID did not exercise selfdetermination as regards major and minor life decisions, such as with whom and where to live or to eat, and recruitment and retention of care staff (Robertson et al., 2001). Five years later, Forbat (2006) confirmed the findings of this study, reporting that it is difficult to implement the four key principles of Valuing People (choice, independence, rights and inclusion) in daily practice. In a National Consumer Survey in the USA, Wehmeyer \& Metzler (1995) concluded that people with ID still had fewer choices and less control than those without ID. This survey covered 46 states and five territories, assessing self-determination. One of its 27 questions concerned health: do you give consent for medical care?

Self-determination is not easy to achieve. Hoyle (1992) advocated autonomy of women with ID, giving them the right to refuse a pelvic exam or decide whether the exam will be performed without sedation. Beckwith (2004) recommended using the real contents of selfdetermination, that is, giving people with ID choices concerning their lives and destinies. Ashbaugh (2002) recommended that selfdetermination should be used correctly and that money should be invested in it. People with ID need support to exercise self-determination and support workers need time and thus money to provide this support.

\section{Positive experiences in relation to health}

Living in the community was reported to have favourable effects on the health of people with ID. Improved quality of life was found after people with ID had moved into community housing; 26 (out of 76) persons with ID went to see their doctor during a 7-day diary reporting period (Ager et al., 2001). In a study by Taylor et al. (2004), 6\% of the interviewed people were smokers; both smokers and non-smokers were able to mention examples of risks (lung cancer, heart attack). Compared to the general Swedish population, people with ID were found to have satisfactory oral health, in spite of an increased prevalence of caries in the less restrictive living arrangements (Gabre, 2000). 
Table 6.1 Examination of 14 studies on self-determination.

\begin{tabular}{|c|c|c|}
\hline Authors & Subject of study & $\begin{array}{l}\text { Role and number of people with } \\
\text { ID }\end{array}$ \\
\hline Ager et al. (2001) & $\begin{array}{l}\text { Improvement of quality of life after moving } \\
\text { to community living arrangements }\end{array}$ & $\mathrm{n}=76$ as respondents \\
\hline $\begin{array}{l}\text { Algozzine et al. } \\
\text { (2001) }\end{array}$ & $\begin{array}{l}\text { Self-advocacy and choice-making are the } \\
\text { main themes of interventions to promote } \\
\text { self-determination }\end{array}$ & As subject of research \\
\hline Ashbaugh (2002) & $\begin{array}{l}\text { Advocating self-determination and } \\
\text { investing money in this }\end{array}$ & As subject of research \\
\hline Beckwith (2004) & $\begin{array}{l}\text { Stop using self-determination 'as a cover } \\
\text { for cutbacks in funding' }\end{array}$ & As subject of research \\
\hline Forbat (2006) & $\begin{array}{l}\text { People with ID and dementia have hardly } \\
\text { any choice in forms and locations of day } \\
\text { services }\end{array}$ & $\begin{array}{l}\text { Key people }(n=8) \text { were } \\
\text { interviewed }\end{array}$ \\
\hline Gabre (2000) & $\begin{array}{l}\text { Less restrictive living arrangements and } \\
\text { mild mental retardation are correlated } \\
\text { with high caries prevalence }\end{array}$ & As subject of observation \\
\hline $\begin{array}{l}\text { Haelewyck et al. } \\
(2005)\end{array}$ & $\begin{array}{l}\text { Satisfaction with a training manual to } \\
\text { teach self-determination }\end{array}$ & $\mathrm{n}=10$ as respondents \\
\hline Hoyle (1992) & $\begin{array}{l}\text { Medical best interest versus the autonomy } \\
\text { of women with ID concerning pelvic } \\
\text { examination with/without sedation }\end{array}$ & $\begin{array}{l}\text { Professionals talked about } \\
\text { women with ID }\end{array}$ \\
\hline $\begin{array}{l}\text { Robertson et al. } \\
\text { (2001) }\end{array}$ & $\begin{array}{l}\text { Little progress achieved in } 30 \text { years of } \\
\text { self-determination }\end{array}$ & $\begin{array}{l}10 \text { groups (total } \mathrm{n}=281 \text { ) as } \\
\text { respondents }+ \text { key informants }\end{array}$ \\
\hline Smith (2003) & $\begin{array}{l}\text { Qualified support brokers are needed to } \\
\text { assist people with ID for real choice and } \\
\text { control over supports }\end{array}$ & As subject of research \\
\hline Stancliffe (2001) & $\begin{array}{l}\text { Every person with ID can learn to make } \\
\text { choices }\end{array}$ & As subject of research \\
\hline Taylor et al. (2004) & $\begin{array}{l}\text { Knowledge of risks of smoking assessed } \\
\text { in social services day centres }\end{array}$ & $\begin{array}{l}\mathrm{n}=435 \text { as respondents }+ \text { key } \\
\text { workers if necessary }\end{array}$ \\
\hline $\begin{array}{l}\text { Wehmeyer \& } \\
\text { Metzler (1995) }\end{array}$ & Survey on self-determination & $\begin{array}{l}\mathrm{n}=4544 \text { as respondents and/or } \\
\text { a family member or surrogate if } \\
\text { necessary }\end{array}$ \\
\hline $\begin{array}{l}\text { Wehmeyer et al. } \\
\text { (1996) }\end{array}$ & $\begin{array}{l}\text { Characteristics of self-determined } \\
\text { behaviour are analysed }\end{array}$ & $\begin{array}{l}20 \text { groups (total } \mathrm{n}=407 \text { ) as } \\
\text { respondents }\end{array}$ \\
\hline
\end{tabular}

\section{(b) Independence}

\section{The contents of seven examined articles are summarised in Table 6.2.}




\section{Determinants}

In one study, aspects preconditional to independence were trained in three health-related workshops: coping with worry and stress, responsibilities and different ways of communicating. Sharing ideas and working together can be used in many situations (McNally, 1996).

Several researchers concluded that more attention was needed for the subject of independence. Reiss (2000) recommended a mindful approach to people with ID. Test scores are not enough, as an open mind is required to consider the needs of people with ID. The Consumer Satisfaction Survey described health services as one of nine services received, and did not include health-related skills in the list of independent choice-making (Sands et al., 1991).

\section{Situation in practice}

Both too much and too little independence of people with ID have been reported in the literature. One article described the dilemma of leaving the choice about food intake to a person with ID vs. offering professional care by support workers. In this study, although losing weight was not healthy for a particular patient, no intervention was initiated until he had lost $15 \mathrm{~kg}$, which was far too late, as recovery in the hospital took several months (Crichton, 1998). Another article described the struggle of 'Barry', who wanted independence, but was refused it by support staff; sometimes Barry tended to hurt himself to the point where hospitalisation was necessary, because 'nobody wants me around at Thanksgiving'. Barry and his mates were unable to convince their support workers to let them make medical appointments by themselves. They had to fight for active participation in the community (Peter, 1999, p.811).

\section{Positive experiences in relation to health}

One article reported how a period of $4.7 \mathrm{yrs}$ of integrated living led to an increased level of participation in a group of persons with ID in terms of grocery shopping and cooking, while the incidence of caries did not change, although $40 \%$ of the respondents $(n=55)$ gained weight (Gabre et al., 2002).

In another study, a smoking cessation programme was offered to a selected group of people with mild ID $(n=11)$; 'they have relatively independent decision making with respect to their smoking habits'. During the 7-week programme, the number of people who wanted to give up smoking increased from five to nine persons; three persons 
actually stopped and three significantly decreased their smoking habits (Tracy \& Hosken, 1997, p.417).

Table 6.2 Examination of 7 studies on independence.

\begin{tabular}{lll}
\hline Authors & Subject of study & $\begin{array}{l}\text { Role and number of people with } \\
\text { ID }\end{array}$ \\
\hline Crichton (1998) & $\begin{array}{l}\text { Case of weight loss in a man who chose } \\
\text { his own food intake }\end{array}$ & $\mathrm{n}=1$ as respondent \\
$\begin{array}{l}\text { Gabre et al. } \\
\text { (2002) }\end{array}$ & $\begin{array}{l}\text { Increased independence by integrated } \\
\text { living does not result in differences in } \\
\text { incidence of caries 4.7 yrs after the move }\end{array}$ & $\mathrm{n}=55$ were observed \\
McNally (1996) & $\begin{array}{l}\text { People with ID and staff are training } \\
\text { other people with ID in self-advocacy } \\
\text { skills workshops }\end{array}$ & $\begin{array}{l}\mathrm{n}=2 \text { as trainer; } \mathrm{n}=12 \text { as } \\
\text { respondent }\end{array}$ \\
$\begin{array}{l}\text { Case report of a blind man with ID } \\
\text { Reiss (2000) }\end{array}$ & $\begin{array}{l}\text { Most people with ID do not meet their } \\
\text { goals on 16 basic desires, for example } \\
\text { independence }\end{array}$ & $\mathrm{n}=1$ as respondent \\
As subject of research \\
$\begin{array}{l}\text { Sands et al. } \\
\begin{array}{l}\text { (1991) } \\
\text { Tracy \& Hosken satisfaction with health services among } \\
\text { (1997)* }\end{array}\end{array}$ & $\begin{array}{l}\text { people with ID } \\
\text { Development of smoking education course }\end{array}$ & $\mathrm{n}=36$ as respondents \\
\hline
\end{tabular}

* from additional search on smoking cessation and menstrual management

\section{(c) Self-regulation}

Fifteen articles were examined; the contents are summarised in Table 6.3 .

\section{Determinants}

Good communication is a prerequisite of autonomy and health workers have opportunities to improve their own skills and to stimulate the skills of people with ID. Technology (Hammel, 2003) and skills training (Beadle-Brown et al., 2000) can be used to improve the communication skills of persons with ID. Group home managers have to stimulate people's interest in communication. In a study by DeSimone \& Cascella (2005), group home managers expressed favourable opinions on the use of communication quality indicators in their group homes, but the article reported no communication goals and no use of picture boards.

Even after decades of community living, it is difficult to find the balance between protection and self-determination. Although legislation protects people with ID, they have to learn skills to exercise self-determination, 
with individual influence and participation as important themes (Kebbon, 1997).

\section{Situation in practice}

The skills of both the staff and the people with ID have to be improved, as was reported by some of the articles found in our review. One article reported that staff training is needed to improve service delivery in relation to menstrual management (Carlson \& Wilson, 1996). Another study concluded that support workers need to actively stimulate the inclusion of people with ID who have epilepsy or use large amounts of medication (McConkey et al., 2005). A third study recommended that people with ID should learn skills in their natural context, for example learning to brush their teeth before going to bed, which has consequences for the organisation of support (Saunders \& Spradlin, 1991). Another article reported on a tool kit for medical consultation, with forms to help people prepare for a visit to the doctor and to record pain, menstruation, etc., which was developed and tested in a pilot study (Lennox et al., 2004). Researchers can also help to facilitate the empowerment process of people with ID, by working together with them and listening to them (Ramcharan, 2005).

\section{Positive experiences in relation to health}

Support workers can help people with ID to achieve positive results by using the right model. An intervention model to assist menstrual management was found to yield good results (Griffin et al., 1994). A study of hospital experiences found that people with ID were given more fluid to drink and more assistance in getting out of bed if a support person was with them. In addition, 50\% percent of the people with ID asked the staff of the hospital for help (Iacono \& Davis, 2003).

McGillicuddy (2006) concluded that people with ID used slightly smaller amounts of cigarettes, alcohol and illicit drugs than peers. Better results can be achieved by tailoring the regular programmes for the prevention and treatment of abuse to this group of people. A decade earlier, Minihan (1999) reported less smoking among people with ID and more among support staff, compared to the general population. The State of Massachusetts prohibits staff smoking in supported houses while people with ID are permitted to smoke in designated areas. Rustin (1998) reported success over the 5-year period of a programme to give up smoking. This led to favourable results in terms of non-smoking, without an increase in aggressive behaviour among the programme's participants. 


\section{In another study, physicians and caregivers helped people with ID to familiarise them with office visits (Prater \& Zylstra, 2006).}

Table 6.3 Examination of 15 studies concerning self-regulation.

\begin{tabular}{|c|c|c|}
\hline Authors & Subject of study & $\begin{array}{l}\text { Role and number of people } \\
\text { with ID }\end{array}$ \\
\hline $\begin{array}{l}\text { Beadle-Brown et al. } \\
\text { (2000) }\end{array}$ & $\begin{array}{l}\text { Increase in communication skills of } \\
\text { people with ID over a decade }\end{array}$ & $\mathrm{n}=146$ as respondents \\
\hline $\begin{array}{l}\text { Carlson \& Wilson } \\
\text { (1996) }\end{array}$ & $\begin{array}{l}\text { Suggestions for staff training concerning } \\
\text { menstrual management }\end{array}$ & $\begin{array}{l}\text { Service providers }(\mathrm{n}=63) \text { were } \\
\text { interviewed }\end{array}$ \\
\hline DeSimone (2005) & $\begin{array}{l}\text { Implementation of communication } \\
\text { quality indicators }\end{array}$ & $\begin{array}{l}\text { Group home managers }(\mathrm{n}=31) \\
\text { were interviewed }\end{array}$ \\
\hline Griffin et al. (1994)* & $\begin{array}{l}\text { A model to support menstrual } \\
\text { management }\end{array}$ & $\begin{array}{l}\text { Case of a woman with ID as an } \\
\text { example }\end{array}$ \\
\hline Hammel (2003) & $\begin{array}{l}\text { Use of technology to improve } \\
\text { communication }\end{array}$ & As subject of research \\
\hline $\begin{array}{l}\text { Iacono \& Davis } \\
\text { (2003) }\end{array}$ & $\begin{array}{l}50 \% \text { of people with ID tell hospital staff } \\
\text { what they need }\end{array}$ & $\begin{array}{l}\mathrm{n}=119 \text { as respondents }+ \\
\text { support persons if necessary }\end{array}$ \\
\hline Lennox et al. (2004) & $\begin{array}{l}\text { Development and pilot of 5-yr health } \\
\text { diary and educational session }\end{array}$ & $\begin{array}{l}\mathrm{n}=7 \text { as respondents and } \mathrm{n}=19 \\
\text { parents as respondents }\end{array}$ \\
\hline Kebbon (1997) & $\begin{array}{l}\text { Normalisation is a success, but integration } \\
\text { in the community not yet achieved }\end{array}$ & As subject of research \\
\hline $\begin{array}{l}\text { McConkey et al. } \\
(2005)\end{array}$ & $\begin{array}{l}\text { Persons with ID who are more dependent } \\
\text { in self-care are less likely to engage in } \\
\text { family or community activities }\end{array}$ & $\begin{array}{l}\text { Key workers }(\mathrm{n}=110) \text { gave } \\
\text { answers }\end{array}$ \\
\hline $\begin{array}{l}\text { McGillicuddy } \\
(2006)^{*}\end{array}$ & $\begin{array}{l}\text { Prevention and treatment programmes on } \\
\text { the use of cigarettes, alcohol and drugs }\end{array}$ & As subject of research \\
\hline Minihan (1999) & $\begin{array}{l}\text { Transition from smoking habits to smoke- } \\
\text { free behaviour }\end{array}$ & As subject of research \\
\hline $\begin{array}{l}\text { Prater \& Zylstra } \\
(2006)\end{array}$ & $\begin{array}{l}\text { Requirements of good practice for visits } \\
\text { and recommendations for caregivers to } \\
\text { familiarise people with ID with office and } \\
\text { staff. }\end{array}$ & $\begin{array}{l}\text { Information was given to } \\
\text { health professionals }\end{array}$ \\
\hline Ramcharan (2005) & $\begin{array}{l}\text { Recommendations for people with ID to } \\
\text { improve their skills }\end{array}$ & As subject of research \\
\hline Rustin (1998)* & $\begin{array}{l}\text { Describes an addiction treatment } \\
\text { programme for nicotine dependence. }\end{array}$ & As subject of research \\
\hline $\begin{array}{l}\text { Saunders \& Spradlin } \\
\text { (1991) }\end{array}$ & $\begin{array}{l}\text { Stimulating the training of 'Supported } \\
\text { Routines Approach' }\end{array}$ & As subject of research \\
\hline
\end{tabular}

* from additional search on smoking cessation and menstrual management 


\section{(d) Self-realisation}

Three articles were examined; their contents are summarised in Table 6.4 .

\section{Determinants}

People with ID have to be supported to develop capacities for living in the community. In self-advocacy groups, people with ID learn to deal with crucial events, for example travelling independently or insisting on the use of the word 'learning difficulties' (Goodley, 2005). Romer et al. (2003) argued that good support is flexible support, matching the strengths and limitations of the people with ID.

\section{Situation in practice}

Self-realisation is not easily fostered; one article describes a case of care for a person with Prader-Willi syndrome, focusing on self-realisation (Hooren et al., 2002).

Positive experiences in relation to health

No articles were found in this category.

Table 6.4 Examination of studies concerning self-realisation.

\begin{tabular}{|c|c|c|}
\hline Authors & Subject of study & $\begin{array}{l}\text { Role and number of people with } \\
\text { ID }\end{array}$ \\
\hline Goodley (2005) & Results of a self-advocacy movement & As subject of research \\
\hline $\begin{array}{l}\text { Hooren et al. } \\
(2002)\end{array}$ & $\begin{array}{l}\text { Elaboration of autonomy with the } 4 \\
\text { models proposed by Emanuel \& Emanuel } \\
\text { (1992) concerning prevention of obesity } \\
\text { in patients with Prader-Willi syndrome }\end{array}$ & $\begin{array}{l}\text { Parents }(n=23) \text { and caregivers } \\
(n=14) \text { of people with ID }(n=18) \\
\text { were interviewed }\end{array}$ \\
\hline $\begin{array}{l}\text { Romer et al. } \\
(2003, \text { p.293) }\end{array}$ & $\begin{array}{l}\text { Statement: 'People with disabilities } \\
\text { should be in charge of their own life' }\end{array}$ & As subject of research \\
\hline
\end{tabular}

Based on our examination of the literature, the answer to our research question is that people with ID have so far been exercising autonomy in relation to health to a limited degree only. Although positive and promising situations have been described, the need for improvement has also been stressed. Studies in which people with ID were the subject of research have shown that these people have clear opinions on their own autonomy and wish to improve it. 


\section{Discussion}

This review of the literature examined studies about exercising autonomy in relation to health among people with ID. Out of a total of 791 articles retrieved by our search, only 39 explicitly dealt with this subject. The people with ID in these articles were actively participating in research studies as respondents. More than 30 years after the start of normalisation, the autonomy of people with ID in relation to health is still hardly an issue in the literature.

One editorial (Horton, 2007) expressed the clear opinion that people with ID were still being ignored in the health services. Responsibility for 'your own health' has rarely been an issue in the autonomy discussion, nor in research or training. It seems that after a decade, the findings by Wehmeyer \& Metzler (1995) are still valid, that is, that people with ID still have fewer choices and less control than people without ID, in spite of 20 years of promoting self-determination. This conclusion is compatible with the conclusions of some authors on non-health-related subjects. Robertson et al. (2001) reported that although inclusion and self-determination have been the standard in ID care for 30 years, little progress has been made, in that people with ID do not have opportunities for self-determination as regards decisions like where to live and with whom. And Wehmeyer (2000) reported about the struggle of one person with ID to achieve a satisfactory existence in the community.

Although positive suggestions have been published in recent decades, the effects in daily practice seemed to be minimal. Monfils (1985, p.183) proposed: 'It is of critical importance to group members that the social worker develops sensitivity to the unique needs of each individual'. According to Hoogland (2005), autonomy training for people with ID is a must, not a choice. Wiltz (2007) recommended efforts to increase selfdetermination, for example as regards roommate selection, with the help of a guidebook.

Abma et al. (2006) consulted people with ID when developing an agenda for research on topics relevant to them and they expressed clear views on this; they wanted treatment on the basis of equality; they wanted to make their own decisions and wanted to have free choices, but their parents and support staff obstructed their wishes. They also commented on the way physicians treat them, and stated that improvements are needed in terms of communication, equality and authority in relation to health.

Researchers found that less restrictive living arrangements for people with ID living in the community led to an increased prevalence of caries 
(Gabre, 2000) and weight gains (Gabre et al., 2002). In terms of autonomy, these are positive results, because it means that people with ID come to look more like ordinary people. In terms of health care, however, it means that new health promotion skills have to be trained. Improving autonomy in relation to health is not easy to achieve. It would be interesting to know the relationship between having the ability to consent and exercising autonomy. Both require certain skills, which can be trained, but there are some complicating factors. Dye et al. (2007) reported that people with mild to moderate ID who communicated verbally found it difficult to understand the seven questions of the Ability to Consent Questionnaire, as the criteria for 'able' were described in terms of cognitive standards. A report on an ethical discussion on the autonomy of people with ID in health issues concluded that other criteria would be more suitable. One should listen to stories of people with ID and observe their activities to assess their level of ability (Widdershoven \& Berghmans, 2004).

Based on our review, we conclude that self-determination can be taught (Tracy \& Hosken,1997; Algozzine et al.,2001; Stancliffe, 2001 \& Haelewyck et al., 2005), although it is difficult to find a balance between independence and professional care (Crichton, 1998). Health care workers can help people with ID to familiarise with office visits (Prater \& Zylstra, 2006) and self-realisation is not easily fostered (Hooren et al., 2002). Recent literature on other aspects than health confirms the selfdetermination aspects of our conclusion (Antaki et al., 2008; Arvidsson et al., 2008; Martorell et al., 2008 \& Miller \& Chan, 2008).

A great deal of work remains to be done to improve the autonomy of people with ID. Although some authors have made recommendations during the last decades (Saunders \& Spradlin, 1991; Schwartz, 1995; Faw et al., 1996; Bigby, 1997; Peter, 1999), putting these recommendations into practice seems to be difficult (Horton, 2007). Further research should focus on: (1) implementation of self-determination (Robertson et al., 2001; Forbat, 2006) and (2) experimentations with new methods to improve autonomy, for example listening to stories of people with ID (Widdershoven \& Berghmans, 2004). Policy and practice could work on: (1) the introduction of tailored prevention programmes for example against abuse of cigarettes, alcohol and illicit drugs (McGillicuddy, 2006) and (2) teaching health workers, parents and people with ID the skills to ensure that people with ID can exercise autonomy (e.g. as regards menstrual management) (Saunders \& Spradlin, 1991; Carlson \& Wilson, 1996; Kebbon, 1997; Lennox et al., 2004; McConkey et al., 2005; Wong \& Wong, 2008). 
The choice to include people with ID in the community must be taken seriously. People with ID have the basic human right to autonomy. They can tell their stories, and we can empower them, so that they can participate actively in the community, as well as in research. 


\section{References}

Abma T, Nierse C, Caron-Flinterman F, Broerse J, Heuvelman C, Dijk J van, Smit J \& Zeeuw M (2006) Onderzoek met en voor mensen met een verstandelijke beperkingen. Maastricht University, Maastricht, the Netherlands.

- $\quad$ Ager A, Myers F, Kerr P, Myles S \& Green A (2001) Moving home: social integration for adults with intellectual disabilities resettling into community provision. Journal of Applied Research in Intellectual Disabilities 14, 392-400.

- $\quad$ Algozzine B, Browder D, Karvonen M, Test DW \& Wood WM (2001) Effects of interventions to promote self-determination for individuals with disabilities. Review of Educational Research 71, 219-77.

- $\quad$ Antaki C, Finlay W, Walton C \& Pate L (2008) Offering choices to people with intellectual disabilities: an interactional study. Journal of Intellectual Disability Research 52, 1165-75.

- $\quad$ Arvidsson P, Granlund M \& Thyberg M (2008) Factors related to self-rated participation in adolescents and adults with mild intellectual disability - a systematic literature review. Journal of Applied Research in Intellectual Disabilities 21, 277-91.

- Ashbaugh JW (2002) Down the garden path of self-determination. Mental Retardation 4o, 416-7.

- $\quad$ Beadle-Brown J, Murphy G, Wing L, Gould J, Shah A \& Holmes N (2000) Changes in skills for people with intellectual disability: a follow-up of the Camberwell cohort. Journal of Intellectual Disability Research 44, 12-24.

- $\quad$ Beckwith RM (2004) Will the real elephant please stand up? Mental Retardation 42, 67-9.

- $\quad$ Bigby C (1997) Later life for adults with intellectual disability: A time of opportunity and vulnerability. Journal of Intellectual \& Developmental Disability 22, 97-107.

- Carlson G \& Wilson J (1996) Menstrual management and women who have intellectual disabilities: Service providers and decisionmaking. Journal of Intellectual and Developmental Disability 21, 39-57.

- $\quad$ Crichton J (1998) Case Report: Balancing restriction and freedom in the care of people with intellectual disability. Journal of Intellectual Disability Research 42, 189-95.

- $\quad$ Department of Health (2001) Valuing people; a new strategy for learning disability for the $21^{\text {st }}$ century. HMSO, London.

- DeSimone EA \& Cascella PW (2005) Communication quality indicators: a survey of Connecticut group home managers. Journal of Developmental and Physical Disabilities 17, 117.

- $\quad$ Dye L, Hare DJ \& Hendy S (2007) Capacity of people with intellectual disabilities to consent to take part in a research study. Journal of Applied Research in Intellectual Disabilities 2o, 16874 .

- $\quad$ Emanuel EJ \& Emanuel LL (1992) Four models of the physician-patient relationship. JAMA 267, 2221-6.

- $\quad$ Faw GD, Davis PK \& Peck C (1996) Increasing self-determination: teaching people with mental retardation to evaluate residential options. Journal of Applied Behavior Analyses 29, 173-88.

- $\quad$ Forbat L (2006) An analysis of key principles in Valuing People. Implications for supporting people with dementia. Journal of Intellectual Disabilities 1o, 249-60.

- $\quad$ Gabre P (2000) Studies in oral health in mentally retarded adults. Swedish Dental Journal Supplement 142, 1-48.

- $\quad$ Gabre P, Martinsson T \& Gahnberg L (2002) Move of adults with ID from institutions to community-based living: changes of food arrangements and oral health. Swedish Dental Journal 26, 81-8.

- Goodley D (2005) Empowerment, self-advocacy and resilience. Journal of Intellectual Disabilities 9, 333-43.

- Griffin J, Carlson G, Taylor M \& Wilson J (1994) Menstrual management and intellectual disability: New Perspectives. Occupational Therapy International 1, 141-57.

- $\quad$ Haelewyck M, Bara M \& Lachapelle Y (2005) Facilitating self-determination in adolescents with intellectual disabilities. Evaluation Review 29, 490-502. 
- $\quad$ Hammel J (2003) Technology and the environment: supportive resource or barrier for people with developmental disabilities? Nursing Clinics of North America 38, 331-49.

- $\quad$ Hoogland J (2005) Tussen wens en drang. Hoe verhoudt zich de autonomie van de cliënt tot de professionele autonomie van de hulpverlener. Nederlands Tijdschrift voor de Zorg aan mensen met verstandelijke beperkingen 31, 184-202.

- Hooren RH van, Widdershoven GAM, Borne HW van den \& Curfs LMG (2002) Autonomy and intellectual disability: the case of prevention of obesity in Prader-Willi syndrome. Journal of Intellectual Disability Research 46, 560-8.

- $\quad$ Horton R (Ed.)(2007) Learning disability: a neglected concern. The Lancet 369, 966.

- Hoyle D (1992) The autonomy of adult women should be paramount, not the exam. The Journal of Clinical Ethics 3, 76-7.

- Iacono T \& Davis R (2003) The experiences of people with developmental disability in Emergency Departments and hospital wards. Research in Developmental Disabilities 24, 24764 .

- $\quad$ Kebbon L (1997) Nordic contributions to disability policies. Journal of Intellectual Disability Research 41, 120-5.

- Lennox N, Taylor M, Rey-Conde T, Bain C, Boyle FM \& Purdie DM (2004) Ask for it: development of a health advocacy intervention for adults with intellectual disability and their general practitioners. Health Promotion International 19, 167-75.

- Martorell A, Gutierrez-Recacha P, Pereda A \& Ayuso-Mateos JL (2008) Identification of personal factors that determine work outcome for adults with intellectual disability. Journal of Intellectual Disability Research 52, 1091-1101.

- McConkey R, Walsh-Gallagher D \& Sinclair M (2005) Social inclusion of people with intellectual disabilities; the impact of place of residence. Irish Journal of Psychological Medicine 22, 10-4.

- McGillicuddy NB (2006) A review of substance use research among those with mental retardation. Mental Retardation and Developmental Disabilities Research Reviews 12, 41-7.

- $\quad$ McNally S (1996) Self-advocacy skills workshop: a report. British Journal of Nursing 5, 99103.

- Miller SM \& Chan F (2008) Predictors of life satisfaction in individuals with intellectual disability. Journal of Intellectual Disability Research 52, 1039-47.

- Minihan PM (1999) Smoking policies and practices in a state-supported residential system for people with mental retardation. American Journal on Mental Retardation 104, 131-42.

- $\quad$ Monfils MJ (1985) Theme-centered group work with the mentally retarded. Social Casework Journal of Contemporary Social Work 66, 177-84.

- $\quad$ Nirje B (1969) The normalization principle and its human management implications. In: Kugl $\mathrm{R} \&$ Wolfensberger $\mathrm{W}$ (Eds.) Changing patterns in residential services for the mentally retarded, pp.181-95. President's Committee on Mental Retardation, Washington DC.

- $\quad$ Peter D (1999) The client role: a help or a hindrance? Disability \& Society 14, 805-18.

- $\quad$ Prater CD \& Zylstra RG (2006) Medical care of adults with mental retardation. American Family Physician 73, 2175-83.

- $\quad$ Proot I (2001) Changing autonomy. New perspectives on the care for stroke patients in nursing homes. PhD thesis Universitaire Pers Maastricht, the Netherlands.

- Ramcharan P (2005) Special issue on empowerment and advocacy. Journal of Intellectual Disabilities 9, 283-7.

- $\quad$ Reiss S (2000) A mindful approach to mental retardation. Journal of Social Issues 56, 65-80.

- $\quad$ Robertson J, Emerson E, Hatton C, Gregory N, Kessissoglou S, Hallam A \& Noonan Walsh P (2001) Environmental opportunities and supports for exercising self-determination in community-based residential settings. Research in Developmental Disabilities 22, 487-502.

- $\quad$ Romer LT, Richardson M, Aigbe E \& Porter A (2003) Down the garden path of selfdetermination: a response to Ashbaugh. Mental Retardation 41, 290-8.

- $\quad$ Rustin TA (1998) Incorporating nicotine dependence into addiction treatment. Journal of Addictive Diseases 17, 83-108. 
- Sands DJ, Kozleski EB \& Goodwin LD (1991) Whose needs are we meeting? Results of a consumer satisfaction survey of persons with developmental disabilities in Colorado. Research in Developmental Disabilities 12, 297-314.

- $\quad$ Saunders RR \& Spradlin JE (1991) A supported routines approach to active treatment for enhancing independence, competence and self-worth. Behavioral Residential Treatment 6, 11-37.

- Schwartz C (1995) Assessing levels of personal autonomy among Israeli adults with intellectual disabilities living in group homes and apartment settings. Australia \& New Zealand Journal of Developmental Disabilities 2o, 41-50.

- $\quad$ Smith P (2003) Self-determination and independent support brokerage: creating innovative second-level supports. Mental Retardation 41, 290-8.

- Stancliffe RJ (2001) Living with support in the community: predictors of choice and selfdetermination. Mental Retardation and Developmental Disabilities Research Reviews 7, 918.

- Taylor NS, Standen PJ, Cutajar P, Fox D \& Wilson DN (2004) Smoking prevalence and knowledge of associated risks in adult attenders at day centres for people with learning disabilities. Journal of Intellectual Disability Research 48,239-44.

- $\quad$ Tracy J \& Hosken R (1997) The importance of smoking education and preventative health strategies for people with intellectual disability. Journal of Intellectual Disability Research 41, 416-21.

- Wehmeyer ML \& Metzler CA (1995) How self-determined are people with mental retardation? The National Consumer Survey. Mental Retardation 33, 111-9.

- Wehmeyer ML, Kelchner K \& Richards S (1996) Essential characteristics of self-determined behavior of individuals with mental retardation. American Journal on Mental Retardation 100, 632-42.

- Wehmeyer M, Bersani H \& Gagne R (2000) Riding the third wave: self-determination and self-advocacy in the $21^{\text {st }}$ century. Focus on Autism and other Developmental Disabilities 15, 106-15.

- $\quad$ Widdershoven GAM \& Berghmans RLP (2004) Wilsbekwaamheid in de zorg voor mensen met een verstandelijke beperking. Een alternatief kader. Nederlands Tijdschrift voor de Zorg aan mensen met verstandelijke beperkingen 3o, 166-80.

- Wiltz J (2007) Self-determined roommate selection for individuals with intellectual disabilities: barriers and new directions. Journal of Policy and Practice in Intellectual Disabilities 4, 60-5.

- Wolfensberger W \& Glen L (1975) Program analysis of service systems 3: a method for the quantitative evaluation of human services. NIMR, Toronto.

- $\quad$ Wong PKS \& Wong DFK (2008) Enhancing staff attitudes, knowledge and skills in supporting the self-determination of adults with intellectual disability in residential settings in Hong Kong: a pre-test - post-test comparison group design. Journal of Intellectual Disability Research 52, 230-43. 



\section{Chapter 7}

Supporting health-related autonomy among people with intellectual disability: contributions of physicians and consultants in Victoria (Australia)

Magda Wullink

Henny van Schrojenstein Lantman-de Valk Bob Davis Guy Widdershoven Job Metsemakers Geert-Jan Dinant

Submitted 


\section{Abstract}

\section{Background}

One of the consequences of the inclusion of people with intellectual disability (ID) in the community and their normalisation is autonomy. The study question was: During consultations, do physicians and consultants support people with intellectual disability in exercising autonomy in relation to health?

\section{Methods}

Semi-structured interviews with physicians and consultants of a specialist health centre in Victoria, after which physicians were observed during their consultations.

\section{Results}

All 11 interviewed health care workers were able to describe examples of autonomy. Three reported more specific information: one physician described how persons with ID can be supported in exercising autonomy by using a specific training tool, and the two Human Relations consultants reported that after having learned skills, people with ID were able to exercise autonomy in relation to health.

\section{Conclusions}

Physicians and consultants supported people with mild to moderate ID in acting autonomously with regard to choices and decisions about their health. 


\section{Introduction}

Some decades ago, policies on intellectual disability (ID) care changed from medically centred to community-centred care. Inclusion and normalisation became the underlying themes in service planning and development. People with ID started living in the community instead of in residential care facilities, the aim being that they would become active members of the community. With this move came rights and duties, one of the rights being autonomy (European Intellectual Disability Research Network, 2003; Department of Health, 2001).

Some countries, for example Sweden, started to close down their residential care facilities from the 1950s, and the United Kingdom and Australia did so from the 1980 os (European Intellectual Disability Research Network, 2003; Davis et al., 2002). Small-scale communitybased services were developed, and specialist health centres were organised to support doctors responsible for the medical care of people with ID living in the community, and to guarantee effective health care for these people (Davis et al., 2002). Since the Netherlands has lagged somewhat behind in the process of closing down residential care facilities, the necessary information for good ID care must be acquired from other countries. Australia is an interesting example in this respect, because housing and day care are funded by the State Government and the process of closing down residential care facilities started two decades ago and in a similar way as in the Netherlands. Unlike the Netherlands, Australia became one of the leading countries in this development.

The Centre for Developmental Disability Health Victoria (CDDHV) is the only specialist health centre for people with ID in the State of Victoria (Australia). It is a joint venture of the University of Melbourne and Monash University. The CDDHV was formed by the amalgamation of two units within the departments of general practice at both universities in 1998, with the aim of supporting general practitioners in managing the health of what was now a community-based population. As a result of the policy change, people with ID living in Victoria started to live in houses with five or fewer residents within the community. General practitioners (GPs) in the community took over the medical care of these people from the GPs attached to residential care facilities.

The CDDHV provides a clinical advisory and referral service to GPs and psychiatrists of the State of Victoria treating patients with ID. These referrals require completion of a comprehensive questionnaire, to collect relevant information so that the staff at CDDHV can decide which of their clinicians is the most appropriate for the review. The consultations with CDDHV staff take place at the CDDHV building, in an outpatient 
clinic of a local hospital or at home, if the person with ID lives in or near Melbourne. For those living in rural areas, help is offered to GPs and psychiatrists in writing or by telephone (4 million people live in the State of Victoria, 3 million of whom in Melbourne). GPs and psychiaters have consultations with people with ID, usually, together with support workers and/or relatives. The Human Relations Consultants and a communication specialist assist people with ID during consultations or various training sessions.

Since the requirements of living in and being a member of the community differ from those of living in residential care facilities, support workers nowadays have to teach people with ID new community skills. In a literature review, Wullink et al. (2009) found few articles about the autonomy of people with ID in relation to health. Although the skills needed to exercise autonomy were rarely an issue in the examined literature, Algozzine et al. (2001) reported that self-determination/selfdirection can be learned by a variety of educational methods and Stancliffe (2001) reported that self-determination competencies can be learned.

CDDHV has developed Personal Health Records (PHRs) to empower people with ID to take responsibility for their own health and to relieve the task of support workers. PHRs can be actively used by all persons involved in health care (people with ID, support workers and physicians) who can use them to record their information. A PHR may include special optional pages for menstruation, weight chart, epilepsy seizure chart, patient health care record, contact persons, health care providers, cumulative medical record, significant family history, communication skills and strategies, immunisation record, allergy record, annual health review record and running health contact record. People with ID can use these PHRs to make appointments by themselves and discuss their health and preventive care with their GPs and support workers. Examples of subjects for discussion include general health problems, smoking habits and physical exercise. Both support workers and GPs try to stimulate healthy behaviour among people with ID (personal information from Mary Burbidge). Until now, we have not found any international references on PHR.

Four definitions of autonomy were found in studies of health care ethics and ID (Wullink et al., 2009). The first definition referred to autonomy as self-determination and independency, and mentioned three other essential characteristics of self-determined behaviour, viz. selfregulation, psychological empowerment and self-realisation (Wehmeyer et al., 1996). The second definition referred to autonomy as control (Wolfensberger \& Glen, 1975). The third definition referred to autonomy 
as a characteristic of patient history, consisting of three dimensions: selfdetermination, independence and self-care (Proot, 2001). The fourth definition referred to autonomy as moral self-development/selfrealisation (Emanuel \& Emanuel, 1992).

We chose the definition of autonomy by Wehmeyer et al. (1996) as our point of departure, as this definition was formulated with people with ID in mind, focuses on their behaviour and their skills, and is the most comprehensive of the four. In addition to the two elements explicitly distinguished by Wehmeyer, namely (1) self-determination/selfdirection and (2) independence, we added (3) self-development/selfrealisation and (4) the skills to exercise autonomy from the other definitions.

To explore the practical situation of people with ID who had been living in the community for over ten years, the State of Victoria offered us an opportunity to study the autonomy of people with ID in relation to health. Living in the community gives people with ID an opportunity to exercise autonomy, and we wanted to know the opinions and attitudes of the staff at CDDHV in Melbourne. The research question was: During consultations, do physicians and consultants support people with intellectual disability in exercising autonomy in relation to health?

\section{Materials and methods}

\section{Participants}

Physicians and consultants of CDDHV who have contacts with patients/clients with ID during consultations or training sessions regarding sexuality or communication (theoretical sampling), were interviewed and observed by one of the authors (MW). These included four GPs, one GP-registrar (in her final year of traineeship), one psychiatrist, two psychiatry registrars (PRs, one in her final year and one in her first year of traineeship) and two Human Relations Consultants (HRCs, both specialised in Sexuality and Disability) and one communication specialist; 11 persons in total.

\section{Interviews}

The 11 semi-structured interviews took place in a room at CDDHV over a period of two months. On average, each interview lasted half an hour and each staff member was interviewed once. Based on the autonomy definitions, the interviews focused on the following question (after the 
interviewees had been shown these definitions): 'During consultations, do you support people with intellectual disability in exercising autonomy (self-determination/self-direction and independence) in relation to health?' The interview topics covered experiences of physicians and consultants related to self-development/self-realisation and skills of people with ID, as well as factors that hamper support by health workers.

\section{Observations}

The interviewer (MW) attended three consultations of the PR who was in her final year of traineeship and one home visit by a GP. The goal was to observe aspects of autonomy in relation to health. MW was introduced to the patients and parents/staff as a researcher from the Netherlands, and permission for her presence was asked and given.

\section{Analyses}

The audio-taped interviews were transcribed and the whole text was shown to the interviewees, after which the text was adjusted on the basis of their corrections. Afterwards, the text was analysed by means of coding, by the interviewer (MW), using qualitative content analysis (Lucassen \& Hartman, 2007). These analyses were done by hand and focused on experiences with supporting autonomy in relation to health. Data saturation in terms of themes relating to autonomy support was achieved after seven of the 11 interviews. The themes were shown to the interviewees and were adjusted on the basis of their comments. The final four interviews were used to improve the reliability of the findings by finding further examples of similar experiences and to obtain more quotations. The information on autonomy gathered during the observations was linked to the information gathered during the interviews and was discussed with the PR and the GP.

\section{Reliability and validity}

Member check and theoretical sampling were used to ensure reliable and valid results; we used the comments of interviewees on transcribed texts and on themes that emerged from these texts and combined the results of the observations with those of the interviews. 


\section{Results}

Based on the autonomy definitions, four characteristics were focused on, i.e. (1) self-determination/self-direction, (2) independence, (3) selfdevelopment/self-realisation and (4) skills. After seven interviews, the following themes regarding autonomy support had emerged: the use of training tools for people with ID, personal experiences with specific clients with ID and long-term personal experiences with clients with ID. These three themes were described for each of the characteristics. One factor that was reported to be important was the difference between people with mild/moderate ID and those with severe ID, as health workers can communicate with people with mild/moderate ID, and these people can be trained to exercise autonomy. Interviews 8 to 11 covered not only the pre-prepared questions, but also the themes which had emerged from the analyses of the first seven interviews. By way of member check, all the interviewees were invited to comment on the themes.

Autonomy support by health workers proved to be limited by the fact that some people with moderate/severe ID had poor verbal skills, hampering communication about autonomy and attempts to offer support.

\section{(1) Self-determination/self-direction}

The physicians were able to describe examples of autonomy that had occurred during their consultations with patients with ID, without referring to a specific training tool. An example was:

'When patients have a mild ID it is possible to include the patient in the consultation, to discuss the management of the problems and to make decisions. Good skills are very important. But most patients have a more severe level of ID, so doing things together is not possible. Then self-determination/self-direction is not an issue' (GP4).

CDDHV consultants also described situations during consultations and training sessions, or in general, without referring to a particular client. According to them, self-determination/self-direction can be improved by learning, e.g.

'Who can touch you where on your body, learn to say what you want and do not want' (HRC1). 


\section{(2) Independence}

An experienced GP who used PHRs was able to describe situations of autonomy more specifically:

'I saw an example of independence when I used PHR, in the case of a woman who felt sick of all the things she had to do at work. She wanted to stay at home by herself. We concluded that she could do that and staff permitted her to do so' (GP1).

An example of independence mentioned by one of the PRs was:

'A person with ID wants to go on with his life, so I manage his symptoms as best I can, I encourage his independence, look at the whole person (including work, living, friends etc). The more skilled people with ID are, the more independent they can be'(PR1).

\section{(3) Self-development/self-realisation}

People with mild and moderate levels of ID had changed their smoking habits and their physical exercise behaviour with the help of PHR, active staff and a motivated GP. This is a good example of selfdevelopment/self-realisation.

Examples of self-development were seldom given by the physicians, but were mentioned by the consultants. HRC1 told the story of a man with ID who did not take care of himself; he strangulated his peripheral circulation and put sticks into his penis. The consultant negotiated with him about his own values and what values he wanted to be realised. When the man told the consultant that he would like to be well dressed and spend his days in a useful manner, they came to the following agreement:

'When I visited him he had to be shaved, well dressed and his wounds had to be taken care of (HRC1).

She complimented him on his behaviour.

'Look for the needs of the individual. The choices and decisions of a person with ID can be incorporated during the making of a care plan' (PR1). 


\section{(4) Skills}

Several physicians reported that training people with ID to improve their communication skills was not their responsibility, but that communication could be improved if these people had better skills. The importance of skills training to improve autonomy was already clear to the government of the State of Victoria, which has initiated a specialist health management programme, developed by universities in cooperation with the State Department of Human Services. Staff can teach people with ID to prepare questions before visiting the doctor, or to self-manage epilepsy.

Other examples of positive results of skills were mentioned:

'Focus groups are active for example for epilepsy training'(GP2).

'Planning menus and food choice is a good opportunity for people with ID to participate; unfortunately some houses in the community order the food from Internet shops to decrease expenses' (GP3).

Communication skills and understanding the other person during communication were mentioned as important prerequisites of exercising autonomy. The interviewees reported examples of both increasing and decreasing communication skills:

'A good thing is that parents expect of their child with ID that it will have friends, sex etc. This is a positive change and makes it possible to teach the child skills. Learning good social skills is very important if you want to be a member of the community. A problem is that it is hard to learn these skills, because they change very often over time and to persons (everybody is behaving different to his grandmother compared to a child)' (HRC1).

'Personnel in the day centres have very stereotyped ideas of what elderly people with ID can do or want to do. They think sitting is the main activity, not learning new skills, exploring a new area of knowledge, etc' (GP3).

At the start of consultations, all physicians and consultants talked to the person with ID, trying to make contact, and if the patient had poor verbal skills they tried very carefully to find gestures and other alternatives for communication, for example the use of communication boards or signs, or to learn the communication method used by support 
workers and relatives. The need for respectful relations was always emphasised in the education of GPs, GPRs and medical students.

\section{Discussion}

We can conclude that CDDHV staff has recognised the problems associated with the autonomy of persons with ID and that they have tried to solve these problems. The interviewees described promising experiences and tools, and the interviews showed that consultants and physicians can support people with ID in exercising autonomy in relation to health. All the health workers we interviewed were able to report experiences with supporting the exercise of autonomy in specific cases, based on long-term work with patients/clients with ID. They all emphasised that teaching patients certain skills was an important condition of autonomy. One physician reported that she was able to support people with ID in exercising health-related autonomy by using the PHR tool. Training for these skills was not considered to be the responsibility of physicians, but better skills can improve communication. Communication with people with moderate/severe ID may be even more difficult when communication with the help of pictures or symbols is impossible; exercising autonomy then becomes very difficult.

The results of our observations corroborated what was said in the interviews. The results also confirmed earlier publications reporting examples of people with ID who exercise autonomy in relation to health (Bigby, 1997; Crichton, 1998; Peter, 1999; Stancliffe, 2001; Ramcharan, 2005).

Our study used various models of autonomous behaviour, some of which were developed for people with ID (Wehmeyer et al., 1996; Wolfensberger \& Glenn, 1975) while others were developed for patients without ID (Emanuel \& Emanuel, 1992 \& Proot, 2001). However, similarities in physician-patient relations and health care between patients with and without ID justify the use of the last two models.

A limitation of this study was that all the interviewees worked at the same centre. However, since most of them have also a job outside this centre, for example as a GP in the community, as a psychiatrist for people with dementia, or as an HRC in prison, this did not imply a narrow perspective on health care during the interviews. Saturation of themes occurred after 7 (out of 11) interviews, so the risk of having missed important themes was low. 
Another limitation was that clients of CDDHV were all referred patients/clients, and staff were thus asked to assist in solving complex problems of people with mostly moderate to severe levels of ID. This meant there was a certain bias towards considering the perspective of this group in the discussion on health care and autonomy. Exercising autonomy is not easy for persons with moderate to severe levels of ID, and supporting their autonomy is difficult.

If more time is available for consultations, people with ID will have a good opportunity to exercise autonomy in relation to health. The new Medicare system in Australia, which offers better remuneration, is therefore a positive development for the autonomy of people with ID.

Inclusion of people with ID in the community gives them opportunities to become full members of society, and taking responsibility for their own health is important for the well-being of people with ID. Autonomy in relation to health needs to be promoted, even though implementation is difficult, as was also reported by Wilkinson \& Cerreto (2008).

All health workers need to support people with ID in exercising autonomy in relation to health. Developing this support will require further, large-scale research to support people with ID in exercising autonomy. The government and health care funding bodies should make funding available to teach people with ID new skills, so they can exercise autonomy in relation to health. 


\section{References}

Algozzine B, Browder D, Karvonen M, Test DW \& Wood WM (2001) Effects of interventions to promote self-determination/self-direction for individuals with disabilities. Review of Educational Research 71, 219-77.

- $\quad$ Bigby C (1997) Later life for adults with intellectual disability: A time of opportunity and vulnerability. Journal of Intellectual \& Developmental Disability 22, 97-107.

- Crichton J (1998) Case Report: Balancing restriction and freedom in the care of people with intellectual disability. Journal of Intellectual Disability Research 42, 189-95.

- Davis R, Phillips A \& Nankervis K (2002) Service delivery to people with an intellectual disability in Victoria and Australia. A report to the Scottish National Review of the Contribution of Nurses to the Care and Support of People with a Learning Disability. Centre for Developmental Disability Health Victoria, Monash University, Melbourne.

- Department of Health (2001) Valuing people: a new strategy for learning disability for the $21^{\text {st }}$ century. HMSO, London. Retrieved Sept 14, 2001 from www.doh.gov.uk/ learningdisabilities

- $\quad$ Emanuel EJ \& Emanuel LL (1992) Four models of the physician-patient relationship. JAMA 267, 2221-6.

- $\quad$ European Intellectual Disability Research Network (2003) Intellectual disability in Europe: Working papers. Tizard Centre, University of Kent at Canterbury, Canterbury.

- $\quad$ Lucassen PLBJ \& Hartman TC olde (Eds.)(2007) Kwalitatief onderzoek. Praktische methoden voor de medische praktijk. Bohn Stafleu van Loghum, Houten.

- $\quad$ Peter PD (1999) The client role: a help or a hindrance? Disability \& Society 14, 805-18.

- Proot I (2001) Changing autonomy. New perspectives on the care for stroke patients in nursing homes. PhD thesis, Universitaire Pers Maastricht, Maastricht, the Netherlands.

- Ramcharan P (2005) Special issue on empowerment and advocacy. Journal of Intellectual Disabilities 9, 283-7.

- Stancliffe RJ (2001) Living with support in the community: predictors of choice and selfdetermination. Mental Retardation and Developmental Disabilities Research Reviews 7, 918.

- Wehmeyer ML, Kelchner K \& Richards S (1996) Essential characteristics of self-determined behavior of individuals with mental retardation. American Journal on Mental Retardation 100, 632-42.

- Wilkinson JE \& Cerreto MC (2008) Primary care for women with intellectual disabilities. Journal of the American Board of Family Medicine 21, 215-22.

- Wolfensberger W \& Glen L (1975) Program analysis of service systems 3: a method for the quantitative evaluation of human services. NIMR, Toronto.

- Wullink M, Widdershoven GAM, Schrojenstein Lantman - de Valk HMJ van, Dinant GJ \& Metsemakers JFM (2009) Autonomy in relation to health among people with intellectual disability: a literature review. Journal of Intellectual Disability Research, 53, 816-26. 


\section{Chapter 8}

\section{Doctor-patient communication with people with intellectual disability}

Magda Wullink

Wemke Veldhuijzen

Henny MJ van Schrojenstein Lantman-de Valk Job FM Metsemakers

Geert-Jan Dinant

Published in: BMC Family Practice 2009,10:82 


\section{Abstract}

\section{Background}

People with intellectual disability (ID) expressed dissatisfaction with doctor-patient communication and mentioned certain preferences for this communication (our research). Since many people with ID in the Netherlands have recently moved from residential care facilities to supported accommodations in the community, medical care for them was transferred from ID physicians (IDPs) to general practitioners (GPs) in the vicinity of the new accommodation. We addressed the following research question: 'What are the similarities and differences between the communication preferences of people with ID and the professional criteria for doctor-patient communication by GPs?'

\section{Methods}

A focus group meeting and interviews were used to identify the preferences of 12 persons with ID for good communication with their GP; these were compared with communication criteria used to assess trainee GPs, as described in the MAAS-Global manual.

\section{Results}

Eight preferences for doctor-patient communication were formulated by the people with ID. Six of them matched the criteria used for GPs. Improvements are required as regards the time available for consultation, demonstrating physical examinations before applying them and triadic communication.

\section{Conclusions}

People with ID hold strong views on communication with their doctors during consultations. GPs, people with ID and their support workers can further fine-tune their communication skills. 


\section{Introduction}

In the last decade, thousands of people with intellectual disability (ID) in the Netherlands have moved from residential care facilities to supported accommodations in the community (Statistics Netherlands, 2007). These are mainly persons with mild to moderate levels of ID, but people with profound to severe ID are now also living in the community (Klerk, 2002). Consequently, the medical care for these people has been transferred from the general practitioner (GP) or ID physician (IDP) connected to the residential care facility to local GPs in the neighbourhood of the new accommodations. Before, most GPs had 10-12 registered patients with ID in their practice (van Schrojenstein Lantman - de Valk, 1997), but this number is now rising. GPs are the gate keeper in the Dutch health care system. By including individualisation and participation in the community as the guiding principles in care provision, GPs are expected to take on more responsibility for the health of people with ID, but are unprepared for this increasing task.

People with ID frequently complain about the communication with doctors during consultations (Lennox et al, 1997; Iacono \& Johnson, 2004). Persons with ID who participated in our studies told us that they often felt that GPs did not understand them. This was also emphasised by people with ID who were on the client panel of the 'Innovation of health care for people with ID' research programme of the Netherlands Organisation for Health Research and Development (ZonMw; personal information).

In one study, $78 \%$ of people with ID had visited their physician during the previous year (Emerson et al., 2006), while Straetmans et al. (2007) found an average of 5.4 contacts of people with ID with their GP in one year, compared to 3.2 contacts for people without ID. Because of the higher frequency of visits and because of their dissatisfaction, it is understandable that people with ID have preferences concerning doctorpatient communication. Doctor-patient communication may also be hampered by the GPs' lack of awareness of visual impairment and hearing loss among people with ID, which are frequently underdiagnosed (Splunder et al., 2006; Meuwese - Jongejeugd et al., 2006 and 2008).

During their traineeship, GPs are trained to communicate on the basis of professional criteria. During our work with GPs to establish a Transfer of Care Guideline (Wullink et al, 2006), and during the development of an individual post-graduate education programme for ID care (Wullink et al., 2005), we found that GPs did not want a paragraph about communication criteria for patients with ID to be included in these 
documents. Their opinion was that they had been very thoroughly trained in communication and that their professional communication criteria sufficed for the communication with people with ID.

There was thus an obvious gap between the people with ID, who felt that doctor-patient communication should be improved, and GPs who believed that their professional communication criteria skills were sufficient to meet the needs of people with ID. The present study tried to bridge this gap. The study design included a focus group session and semi-structured interviews. The study aimed to explore to what extent professional communication criteria for GPs correspond with the needs of people with ID and what additional requirements might be necessary. The research question was: "What are the similarities and differences between communication preferences of people with ID and the professional criteria used to assess doctor-patient communication by GPs?'

The definition of intellectual disability of Luckasson (2002) was used; this definition states that ID is characterized by significant limitations in intellectual functioning and in adaptive behaviour as expressed in conceptual, practical and social adaptive skills; the disability originates before age 18 .

\section{Methods}

\section{Data collection}

As part of the Transfer of Care Guideline study, intended to facilitate the transfer of medical care from IDPs to GPs (Wullink et al., 2006), we organised a focus group discussion and interviewed people with ID. During the focus group meeting and two interviews, the participants worked together with the researcher (MW) to formulate their communication preferences.

As participants for our focus group we recruited people with ID from the client council of a residential care facility in the south-east of the Netherlands. This ensured that our participants were both interested in and able to discuss issues related to the quality of their health care. All ten council members participated, some of them living in the residential care facility, others in houses in the community. The participants had been members of the client council for over a year, and had learned to discuss all kinds of subjects with each other. The council's support worker helped ensure that all members took part in the discussion and listened to each other, thus creating a safe environment for group 
discussion. The regular chair of the council, a woman with ID, chaired the meeting, and the support worker was present during the focus group discussion. Before the meeting, all participants were sent written information in easy-to-understand language about the purpose and topic of the meeting. The focus group session was moderated by HvSLdV; as an IDP, she has several decades of experience in communication with people with ID. The first author was present as an observer. The goal of the meeting was to identify the communication preferences of the participants. During the focus group meeting, the observer kept notes about the content and course of the discussion. Audiotaping of this meeting was not allowed because of the vulnerability of the participants. The chair, the support worker and the moderator assisted in the process of discussion, to ensure that all members of the client council could participate.

For the purpose of this study, we adjusted focus group procedures to suit the specific characteristics of our participants. The main aim was to support our participants in accurately formulating their preferences for the communication with GPs. At the start of the discussion, we used a critical incident technique by asking the participants to describe positive and negative experiences in their communications with GPs. The participants were stimulated to reflect on the kind of communicative behaviour they had liked or, in the case of a negative incident, to suggest more preferable behaviour. After an incident or topic had been discussed in detail, the moderator summarised the main points of the discussion and the preferences for GP-patient communication that had been formulated. The participants were then asked whether they agreed or disagreed with the way the preference had been worded, or whether they would prefer to alter it. At the end of the focus group meeting, the researcher read out all formulated preferences and again asked for confirmation (participant check). This 'on the spot' participant check was chosen because, in our experience, people with ID appreciate discussions and make suggestions during group meetings or individual interviews, but checking the accuracy of interpretations with them on a later occasion is difficult.

To triangulate the data from the focus group and to widen the sample of participants, two semi-structured interviews were held in another part of the country. Two client council members from the ZonMw research consultation group were recruited: one member from the north-west of the country and one from the south-west of the country. The first interview was carried out by telephone; the second was a face-to-face interview in the presence of the participant's support worker. Before the interviews, written information in easy-to-understand language was sent 
to the interviewees. The interviewer took notes during the interviews. The methodology was similar to that used in the focus group interviews. Participants were first asked to reflect on their experiences and stimulated to formulate preferences for GP behaviour. These preferences and those formulated in the focus group were then submitted to the interviewees and they were asked to confirm or reject these preferences or to suggest alterations. The resulting list of preferences, which had been confirmed by the focus group participants and further validated and expanded in the individual interviews, was considered the final list and used for further analysis.

The Maastricht University Hospital/Maastricht University Medical Ethics Committee gave its consent to this qualitative study proposal.

\section{Analysis}

The preferences of people with ID concerning communication with their GPs, as formulated during the focus group sessions and interviews, were then compared with the communication criteria for GPs included in the MAAS-Global manual (van Thiel et al., 2000). The MAAS-Global is an assessment instrument for communication skills which can be compared to the Calgary-Cambridge Guides (Silverman et al., 2005). The MAASGlobal is also the most widely used guideline for GP-patient communication in general practice training in the Netherlands (Veldhuijzen et al., 2007). The instrument is accompanied by a manual listing the criteria for 'excellent' communication skills (Addendum: introduction, follow-up consultation, request for help, physical examination, diagnosis, management, evaluation of consultation, exploration, emotions, information provision, summarising, structuring and empathy). The wording of the preferences formulated by people with ID and the criteria in the manual were analysed (content analysis) (Lucassen \& Hartman, 2007). For each of the items in the MAAS-Global manual, the assessors scored whether it matched one or more of the preferences expressed by the people with ID. Similarities and differences with these preferences were coded. The content analysis was conducted by the first author (MW) and an independent researcher, who discussed any differences of interpretation until consensus was reached. The researchers underlined the similarities in the MAAS-Global manual, and the number of the corresponding preference was written against it in the margin (initial agreement). The overall degree of agreement was calculated by counting the difference and similarity scores for each preference, calculating the percentage of similarity for each preference and calculating the mean percentage of similarity with the preferences. 


\section{Results}

\section{Participants}

All members of the client council (seven women and three men) participated in the focus group discussion. They were all middle-aged, had mild/moderate levels of ID and could speak for themselves (i.e. were verbally competent). All members would normally visit the doctor together with their support worker.

Both interviewees (one woman and one man) were verbally competent, had a mild level of ID and were middle-aged. Interviewee 1 explained that she usually visited her GP on her own, while the second interviewee visited his doctor together with his support worker.

Focus group meeting and interviews

At the client council's initiative, they discussed the information they had received with the council's support worker before the focus group meeting. During the meeting, participants often interrupted each other, but the chair, the support worker and the moderator assisted the process of discussion and ensured that all participants could finish their stories and tell what they wanted to tell. Although the council members and the interviewees visited different doctors and had different experiences of doctor-patient communication, this did not prevent them from reaching agreement about preferences. The preferences they formulated were based on both positive and negative experiences with doctor-patient communication.

\section{Preferences}

The people with ID held strong views on doctor-patient communication. During the focus group discussion and the interviews, clients made statements like:

'My doctor did not talk to me, but to my support worker' (focus group member).

'My doctor did not ask permission to talk to my support worker about me' (interviewee 2).

'I go to the doctor without my support worker. I can talk very well with him' (interviewee 1). 
The participants formulated the following preferences for communication with their doctors:

1. The doctor should allow me to tell him/her about my symptoms.

2. The doctor should ask me questions about my symptoms.

3. The doctor should listen carefully to me.

4. The doctor should take me seriously.

5. The doctor should take sufficient time for the practice visit.

6. The doctor should show consideration for what I want.

7. The doctor should explain and demonstrate before starting a physical examination.

8. The doctor should ask me for permission before talking to my support worker about me.

Preferences 1-7 were formulated during the focus group meeting. Interviewee 1 suggested eight preferences for communication with her GP, adding one new preference (no. 8) to the seven formulated by the focus group. Preference 8 was also the first one to be expressed by interviewee 2 and considered by him to be the most important one. In addition, he spontaneously mentioned the seven other preferences that had been formulated by the focus group. During our study, all participants told the researcher that they appreciated being asked to participate.

\section{Comparison of preferences and criteria}

Comparing the preferences expressed by people with ID with the criteria listed in the MAAS-Global manual was complicated by that fact that the preferences were a combination of behaviours and attitudes, whereas the manual only describes behaviour. In addition, the people with ID and the GPs differ in their presuppositions and the language they used. This initially resulted in a low level of agreement between the two researchers who did the content analysis (55\%). After some discussion, however, consensus was usually easily reached. Preferences 3 (listening), 5 (time) and 6 (showing consideration) led to the most discussion. Although listening was not explicitly described in the manual, doctors behaved in accordance with other relevant criteria, e.g. checking if requests for help have been addressed, giving patients room to respond and summarising. Preference 5 was discussed extensively. The people with ID wanted to have more time to talk to the doctor. They felt there was too little time for communication during a regular consultation; the normal scheduled time is 10 minutes, and occasionally GPs had planned double consultation times for patients with ID. The discussion considered the 
feeling of insufficient time that was expressed by the patients with ID and the criterion for sufficient consultation time contained in the MaasGlobal manual. During the discussion, one of the authors of the MaasGlobal manual was consulted by e-mail. He stated that the manual did make recommendations for consultation time, but that in practice, consultation time is set at 10 minutes, based on remuneration agreements between health care funding bodies and GPs. We therefore decided to omit this item from Table 8.1, which presents the agreement between preferences and criteria. The discussion on preference 6 related to showing consideration. The manual did mention certain aspects of consideration, e.g. checking patient's questions, anticipating patient's reactions to the examination, asking patient's reaction and discussing the management strategy with the patient with ID and with the support worker.

\section{Similarities and differences between criteria and preferences}

Similarities with the criteria in the manual were found for preferences 1 (tell symptoms), 2 (ask questions), 3 (listening), 4 (taking seriously), 6 (showing consideration) and (partly) 7 (physical examination). Preferences 5 and 8 did not fully correspond with the criteria. In the case of preference 5 (consultation time), this was because the people with ID felt there was too little time for the consultation, and this aspect was only implicitly included in the criteria for good communication. As regards number 8 (talking to the support worker) there was a complicating factor, namely triadic communication. During consultations with a person with ID, the support worker was usually in the consultation room as well, and actively took part in the communication. The preference expressed by the people with ID was that they themselves should be the person addressed primarily by the doctor, but this appeared not to be regular practice. The communication criteria gave no suggestions about handling triadic communication. 
Chapter 8

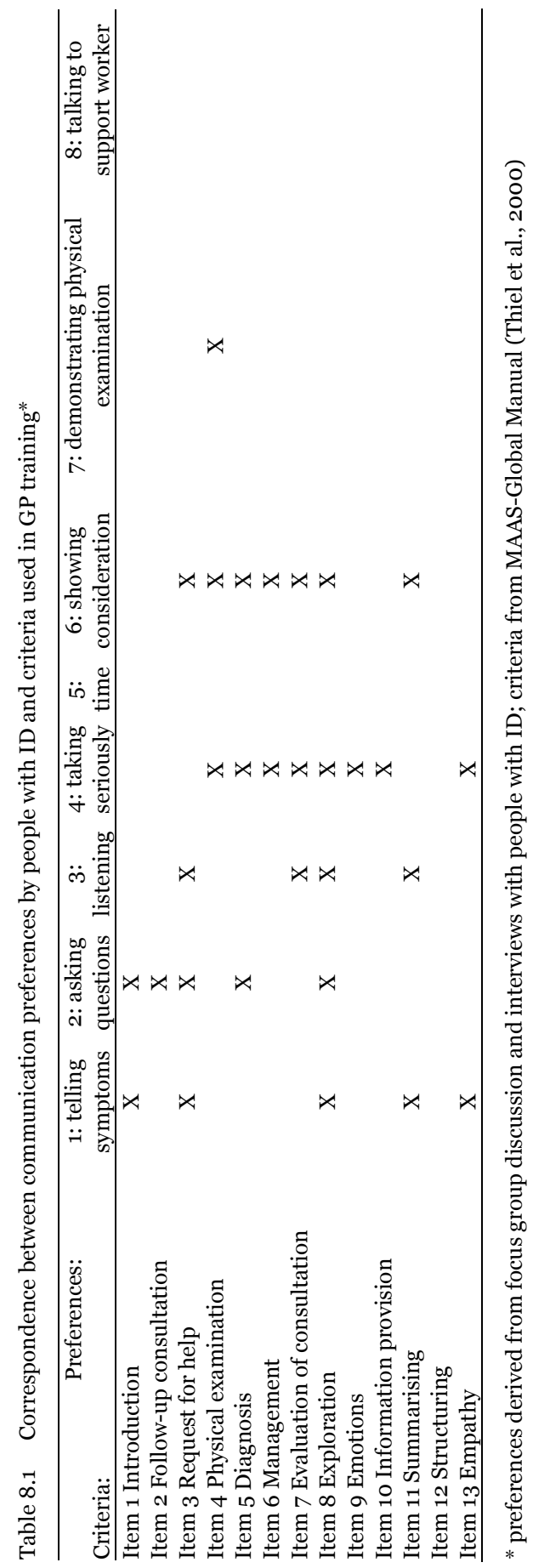




\section{Discussion}

In this qualitative study, we interviewed people with ID in a focus group meeting and during semi-structured individual interviews. Our aim was to explore the extent to which professional communication criteria used to assess trainee GPs correspond with the needs of people with ID, and what additional requirements could be identified.

\section{Strengths and weaknesses}

To our knowledge, this was the first study in which persons with ID themselves were asked to state their communication preferences, as policies with regard to health care for people with ID are usually paternalistic, in the sense that they are based on assumptions of benevolent others about what people with ID need. Lennox et al. (2005a) recommended not abandoning this group of people, who often experience social exclusion (Emerson et al., 2006). The participants appreciated being asked to participate in the study, and social exclusion may be an important aspect of the discussion about doctor-patient communication. GPs and support workers can improve their own communication skills and also support people with ID in improving theirs. The potential advantage of improving communication skills, both for health care workers and the people with ID themselves, is that it may help people with ID exercise autonomy and that it may lead to improved health care.

It is unclear if data saturation was achieved, as only one focus group meeting and two interviews were performed. But interviewee 1 added only one new point to the list of seven preferences established the focus group, and interviewee 2 confirmed these eight preferences, which suggests that we were at least close to saturation. In conducting this study, we were hampered by regulations intended to protect this vulnerable group of people in research, in that privacy rules prevented audiotaping or videotaping. This meant that no verbatim transcription was possible, precluding a thorough analysis of the spoken texts. As an alternative, a participant check was performed during the meeting and interviews, and the participants were asked if they could agree with the proposed wording of the preferences. We consider these limitations acceptable, as the aim of this study was to draw up a list, and not to build and test a theory. 
The other requirements for qualitative focus group research were met: a homogeneous group of people with ID, a clear research question, preparation of the participants by written information in easy-tounderstand language and unequivocal interpretation of the focus group and interview results, promoted by the assistance of an independent researcher.

As regards the generalisability of our results, it must be remembered that older or younger (rather than middle-aged) persons, persons with visual or hearing disabilities, persons with more severe ID or verbally incompetent persons could have other communication preferences.

\section{Previous research}

The following recommendations on doctor-patient communication are included in the Australian Management Guidelines Developmental Disability: '... people with developmental disability appreciate doctors who: talk to them respectfully, do not shout, explain what is happening, treat them as if they are worthwhile, listen to what they are trying to say, say when they do not understand them, allow enough time for the consultation' (Lennox, 2005b, p.17). These issues fit in with the preferences of people with ID we found in our study, although the latter were more specific. Although there is not a great deal of literature on doctor-patient communication with regard to people with ID, there is extensive literature on doctor-patient communication in other situations (Bensing, 2000). For instance, triadic communication and its specific problems have been described for doctor-parent-child communication (Silverman, 2005; Tates et al., 2002a and 2002b). Since we found no studies on health-related triadic communication with people with ID, we refer to the studies by Tates et al. (2002a and 2002b) about doctorparent-child communication. They state that both GP and parent have a role in educating the child in illness and health care management, so the child's participation is important. Although GPs do try to involve children into the communication during consultations, GPs and parents often do not behave in a way that is supportive to the child. When dealing with less competent patients, GPs sometimes specifically fail to ask permission to talk with someone else about the patient. The preferences of people with ID are in agreement with the recommendations formulated by Tates et al. (2002a and 2002b) for triadic communication in doctor-parent-child communication.

Another aspect of communication problems with people with ID is the underdiagnosis of visual and hearing impairments among people with ID (Splunder et al., 2006; Meuwese - Jongejeugd et al., 2006 and 2008). 
These problems greatly increase the risk that people with ID may miss gestures, looks, etc. We therefore recommend direct communication by health professionals with people with ID, which was also one of the preferences expressed by the people with ID in our study.

In a study on GPs' workload and the awareness of psychological problems in patients, Zantinge et al. (2007) reported less patient-centred behaviour on the part of GPs who have 'a subjective experience of a lack of time'. Patients with ID may sense this behaviour, and this may relate to preference 5 (time) as expressed in our study.

Although in other areas of professional practice good examples can be found, more emphasis should be given to the inclusion of people with ID as a reseach participant or research partner. People with ID expressed clear views in interviews; they wanted treatment on the basis of equality; they wanted to make their own decisions and wanted to have free choices (Abma et al., 2006). People with ID in England report that for example their housing, work and payment should be improved (Emerson et al., 2006). People with ID improved their decision-making capacity with regard to sexuality issues after following a sex education intervention (Dukes \& McGuire, 2009).

\section{Recommendations for daily practice}

The people with ID in our study would appreciate improvements to the communication skills of GPs and support workers. The results of our study therefore allow the following recommendations to be formulated to improve communication. (i) Doctors should plan double consultation time to give people with ID the opportunity to formulate questions, as well as to give themselves more room so they will not feel hurried during busy practice hours. People with ID should prepare the consultation together with their support worker. (ii) Doctors should demonstrate any physical examination before starting it, becomes possible if the recommended double consultation times are used. (iii) Doctors should observe the rules of triadic communication (just as in communication with a child and a parent). Taking a training course or studying a book on communication instructions will be helpful for all parties involved in consultations. This is in agreement with an editorial about illness in people with ID by Ali \& Hassiotis (2008), who recommended communication skills training for health professionals. This is already established practice in Australia, where health care workers use an instruction book, the Australian Management Guidelines Developmental Disability, which was developed to support them in their contacts with people with ID (Lennox, 2005b). 
The differences between the preferences expressed by our respondents and the criteria in the MAAS-Global manual and the Australian recommendations support the hypothesis that additional requirements for communication may help doctors as well as people with ID and their support workers to improve their communication skills.

\section{Recommendations for research, policy and practice}

Research is needed to develop methods for involving people with ID in participatory research. Although our method worked well for our qualitative study to identify preferences, it would probably be insufficient for more extensive theory building.

Research is also needed into the consequences of the increased numbers of patients with ID currently being registered in general practices. The health care funding system for GPs is based on a standard practice with 2350 registered patients (Dutch Association of General Practitioners, 2009). The influx of people with ID who have higher morbidity rates and need more consultation time because of communicative differences adds to the GPs' workload. Our study showed that people with ID need a slightly different communicative approach than that described in communication criteria for GPs. Adjustments to other aspects of GPs' usual practice may also be necessary to meet the needs of people with ID. Another area which should be investigated is that of triadic communication between the doctor, the patient with ID and the support worker. Research should examine if the recommendations for triadic communication with children can be applied to adult people with ID; should this not be the case, then new recommendations should be formulated. In addition, the influence of visual and hearing impairment on communication during consultations should be investigated.

Recommendations for communication should be implemented by all ID health care workers as well as to people with ID. We recommend the development of training courses and an instruction book for people with ID and health care workers to improve communication.

Verbally competent people with ID can be included as research partners in communication studies. The use of videotaping to record facial expressions and gestures should be allowed for studies among verbally incompetent people with ID.

The current general communication criteria in GP training manuals should be supplemented with a section on triadic communication. 


\section{Conclusions}

Despite the differences between people with ID and GPs in terms of in presuppositions and the language they use, there are many similarities between the communication preferences of people with ID and the criteria for good doctor-patient communication specified in the MAASGlobal training manual for GPs. The most important elements that were added by our respondents with ID to the communication criteria were that doctors should demonstrate any physical examinations before carrying them out, and that doctors should address the person with ID as their principal communication partner in triadic communication. We found that it was very well possible to draw up a list of preferences of people with ID on this subject, as they held strong views on the communication with their doctors, were able to express these views and were able to confirm or modify the wording of preferences based on their views during focus group meetings. 


\section{Addendum}

Criteria for 'excellent' communication skills of GPs, as described by van Thiel et al. (2000)

\section{Communication criteria for each separate phase}

\section{Item 1 Introduction}

In the initial phase of the consultation the doctor orientates himself with regard to the reason for the visit by giving the patient room to talk about his complaints, problems or questions to encourage the patient. General questions include questions about how long the patient has the problem or complaint, how serious it is and what it means to the patient. The opening question is not rated.

The doctor explores whether there are any other reasons for the patient's visit. In rating this aspect the timing of this question is crucial: before starting detailed history-taking.

\section{Item 2 Follow-up consultation}

In a follow-up consultation the doctor makes the connection with the previous consultation by naming the previous complaints, requests for help and arrangements made.

The doctor also finds out whether the patient has complied with the agreed management plan.

The doctor also asks about the course of the complaint and the effect of the treatment or management strategy.

\section{Item 3 Request for help}

The doctor names the patient's requests for help, preferences or expectations.

In addition the doctor names the reason the patient states why he came for the visit.

The doctor completes the request for help by checking whether all patient's questions, preferences or expectations have been addressed.

\section{Item 4 Physical examination}

The doctor tells the patient before he performs the physical examination where it will take place, which parts of the body should be uncovered and what the patient should do (lie, sit, etc). 
The doctor explains what the examination entails and explains his further actions during the examination if necessary.

The doctor treats the patient with care and respect. He anticipates the patient's reactions to the examination, e.g. pain, and addresses them. When no physical examination is performed, either indicated or not, 'n.a.' should be circled.

When, for any reason, no physical examination is performed, n.a. should be circled.

\section{Item 5 Diagnosis}

The doctor names the main findings from the history and physical examination, followed by a diagnosis or working hypothesis.

In addition the doctor tells about the causes of the complaint or disorder, or the connection between findings and diagnosis.

The doctor gives a concrete indication to the seriousness, the expected duration of the complaint and the course, with or without treatment.

Finally, the doctor asks the patient to give his reaction to the findings, diagnosis, prognosis etc.

\section{Item 6 Management}

The doctor discusses the management strategy by letting the patient have his say by asking the patient's opinion or by making an inviting pause. The risks and benefits of the proposed management strategy are also discussed. Depending on the nature of the complaint the doctor may need to discuss alternatives or indicate that there are no alternatives. The risks and benefits of the proposed management strategy and any alternative strategies are also discussed.

The doctor talks about the feasibility of the proposed strategy taking into account the patient's possibilities and the doctor verifies if and to what extent the patient will adhere to the proposed management strategy.

The doctor makes concrete arrangements about further medical actions (who, what, when).

Finally, the doctor asks about the patient's reactions to the proposed course of action and arrangements.

\section{Item 7 Evaluation of consultation}

At the end of the consultation the doctor asks a general question about what the patient thinks or feels at this moment. The question need not concern any specific aspect of the consultation.

At the end of the consultation the doctor checks whether the patient's requests for help have been adequately addressed. 
The doctor checks whether the patient has been offered perspective for the time being.

\section{General communication criteria}

\section{Item 8 Exploration}

The doctor explores the patient's request for help, wishes or expectations by asking questions. This should be done in an inviting manner.

The doctor explores the patient's reaction to the information given. This applies in particular to the phases 'diagnosis' and 'management'

Exploration takes place within the patient's frame of reference.

While exploring the doctor responds to nonverbal behaviour and cues.

\section{Item 9 Emotions}

The doctor asks about the patient's feelings or he asks questions when the patient shows emotions.

The doctor reflects the feelings that the patient shows and expresses appropriately, with respect to both their nature and intensity.

The doctor pays attention to the feelings throughout the consultation by asking questions and reflecting feelings sufficiently and with an appropriate balance of time, i.e. not too much and not too little.

\section{Item 10 Information giving}

The doctor announces to the patient that he is going to give information about a subject and explains which categories will be dealt with.

The information is given in small quantities and the doctor explains details concretely.

The doctor uses language that is easy to understand for this particular patient.

The doctor checks whether the patient has understood the information by asking questions.

\section{Item 11 Summarizations}

The doctor demonstrates throughout the consultation that he has heard what the patient has to say through sufficient and well balanced summarizations, phrases concisely, in his own words, content wise correct, and he offers the patient room to respond (pause, questioning, intonation, asking questions). 


\section{Item 12 Structuring}

The doctor gives guidance to the consultation by ordering phases in a logical way, consecutively: introduction, follow-up, consultation, request for help, history, physical examination, diagnosis, management and evaluation.

The doctor also divides his time between phases used in a well balanced way and, if necessary, intervenes to cut the story of a very talkative patient short. The doctor brings structure to the consultation by announcing the phases used.

\section{Item 13 Empathy}

The doctor's attitude is inviting and shows his concern for the patient. Also he is sincere in showing empathy. This attitude is reflected in gestures, eye contact and tone of voice.

The doctor expresses empathy in brief verbal responses. 


\section{References}

Abma T, Nierse C, Caron-Flinterman F, Broerse J, Heuvelman C, Dijk J van, Smit J \& Zeeuw M (2009) Onderzoek met en voor mensen met een verstandelijke beperkingen. Maastricht University, Maastricht, the Netherlands.

- $\quad$ Ali A \& Hassiotis A (2008) Illness in people with intellectual disabilities. BMJ 336, 570-1.

- Bensing J (2000) Bridging the gap. The separate worlds of evidence-based medicine and patient-centred medicine. Patient Education and Counseling 39, 17-25.

- $\quad$ Dukes E \& McGuire BE (2009) Enhancing capacity to make sexuality-related decisions in people with an intellectual disability. Journal of Intellectual Disability Research 53, 727-34.

- Dutch Association of General Practitioners (Landelijke Huisartsen Vereniging) Retrieved May 7, 2009, from http://lhv.artsennet.nl

- Emerson E, Malam S, Davies I \& Spencer K (2006) Adults with Learning Difficulties in England 2003/4. Retrieved April 5, 2006 from www.dh.gov.uk/en/Publicationsandstatistics/ Publications/PublicationsStatistics/DH_4120033

- $\quad$ Iacono T \& Johnson H (2004) Patients with disabilities and complex communication needs. Australian Family Physician 33, 585-9.

- $\quad$ Klerk MMY de (Ed.) (2002) Rapportage gehandicapten. Maatschappelijke positie van mensen met lichamelijke beperkingen of verstandelijke handicaps. Social and Cultural Planning Office of the Netherlands, the Hague.

- Lennox NG, Diggens JN \& Ugoni AM (1997) The general practice care of people with intellectual disability: barriers and solutions. Journal of Intellectual Disability Research 41, $380-90$.

- $\quad$ Lennox N, Taylor M, Rey-Conde T, Bain C, Purdie DM \& Boyle F (2005a) Beating the barriers: recruitment of people with intellectual disability to participate in research. Journal of Intellectual Disability Research 49, 296-305.

- $\quad$ Lennox N (Ed.) (2005b) Management Guidelines Developmental Disability. Therapeutic Guidelines Limited, North Melbourne. (sales@tg.com.au; www.tg.com.au).

- $\quad$ Lucassen PLBJ \& Hartman TC olde (Eds) (2007) Kwalitatief onderzoek. Bohn Stafleu van Loghum, Houten, the Netherlands.

- $\quad$ Luckasson R, Borthwick-Duffy S, Buntinx WHE, Coulter D, Craig E, Reeve A, Schalock RL \& Snell ME (2002) Mental Retardation. Definitions, Classification and Systems of Support. American Association on Mental Retardation (AAMR), Washington DC.

- Meuwese-Jongejeugd A, Vink M, van Zanten B, Verschuure H, Eichhorn E, Koopman D, Bernsen R \& Evenhuis H (2006) Prevalence of hearing loss in 1598 adults with an intellectual disability: cross-sectional population based study. International Journal of Audiology 45, 660-9.

- $\quad$ Meuwese-Jongejeugd A, van Splunder J, Vink M, Stilma JS, van Zanten B, Verschuure H, Bernsen R \& Evenhuis H (2008) Combined sensory impairment (deaf-blindness) in five percent of adults with intellectual disabilities. American Journal on Mental Retardation 113, 254-62.

- Schrojenstein Lantman-de Valk HMJ van, Metsemakers JFM, Soomers-Turlings JMSJG, Haveman MJ \& Crebolder HFJM (1997) People with intellectual disability in general practice: case definition and case-finding. Journal of Intellectual Disability Research 41, 373-9.

- $\quad$ Silverman J, Kurtz S \& Draper J (2005) Skills for communicating with patients. Oxford: Radcliffe Publishing.

- $\quad$ Statistics Netherlands (Centraal Bureau voor de Statistiek). Retrieved May 8, 2007, from http://www.cbs.nl/Statline/thema's/mensenmaatschappij/bevolking/cijfers/ huishoudens/ Splunder J van, Stilma JS, Bernsen RM \& Evenhuis HM (2006) Prevalence of visual impairment in adults with intellectual disabilities in the Netherlands: cross-sectional study. Eye 2o, 1004-10.

- $\quad$ Straetmans Jos MJAA, Schrojenstein Lantman - de Valk Henny MJ van, Schellevis Francois G \& Dinant Geert-Jan (2007) Health problems of people with intellectual disabilities: the impact for general practice. British Journal of General Practice 57, 64-6. 
- $\quad$ Tates K, Elbers E, Meeuwesen L \& Bensing J (2002a) Doctor-parent-child relationships: a 'pas de trois'. Patient Education and Counseling 48, 5-14.

- Tates K, Meeuwesen L, Elbers E \& Bensing J (2002b) 'I've come for his throat': roles and identities in doctor-parent-child communication. Child: care, health and development 28, 109-16.

- Thiel J van, Ram P \& Dalen J van (2000) MAAS - Global Manual. Maastricht University, Maastricht, the Netherlands.

- $\quad$ Veldhuijzen W, Ram PM, Weijden T van der, Wassink MR \& Vleuten CPM van der (2007) Much variety and little evidence: a description of guidelines for doctor-patient communication. Medical Education 41, 138-45.

- $\quad$ Wullink M, Schrojenstein Lantman - de Valk HMJ van \& Dinant GJ (2005) Zorg voor mensen met een verstandelijke beperking. Programma Individuele Nascholing. Dutch College of General Practitioners (NHG), Utrecht, the Netherlands.

- $\quad$ Wullink M, Schrojenstein Lantman - de Valk HMJ van, Akker M van den, Metsemakers JFM \& Dinant GJ (2006) Improving transfer of care for people with intellectual disability to general practice: development of a guideline. Journal of Policy and Practice in Intellectual Disabilities 4, 241-7.

Zantinge EM, Verhaak PF, de Bakker DH, Kerssens JJ, van der Meer K \& Bensing JM (2007) The workload of general practitioners does not affect their awareness of patients' psychological problems. Patient Education and Counseling 67, 93-9. 

Chapter 9

General discussion 



\section{General discussion}

This chapter discusses the main results, strengths and limitations of the studies on which this thesis is based, and presents recommendations for research, policy and practice.

\section{Main findings}

Part 1 - The prevalence of people with intellectual disabilities (ID)

Using a unique combination of the databases of ID care facilities, electronic GP databases and a laborious manual identification method in general practices allowed us to establish a good estimate of the numbers of people with ID in the Netherlands: 111,750 persons, corresponding to a prevalence of $0.7 \%$. This is about the same as the figure reported in a study from 1986 (Maas et al., 1988), which found a prevalence of people with ID in the Netherlands of $0.75 \%$, even though we included all age groups, persons living in ID care facilities and those living with relatives, as well as those who were not included in ID care services records but were identified in GP databases. Westerinen et al. (2007) used eight national health and social benefit registers to update the prevalence of people with ID in Finland, which has a health care system comparable to that in the Netherlands (POMONA, 2009). The prevalence they found was $0.7 \%$, which is also in good agreement with our results.

\section{Part 2 - Transfer of health care}

Based on the comments of the participants to our Transfer of Care Guideline study, we developed an instrument to facilitate the transfer of care process, the first instrument of its kind in the Netherlands, which we made available via the Internet. Over the past few years, however, the Guideline has not been frequently downloaded, though the transfer process is still going on. This means that more attention is needed for the implementation of the Guideline.

Research in the countries which were front-runners in the shift from residential care to community care for people with ID has found that their health improved after the transfer of care, as reported by Cooper et al. (2006) and Lennox et al. (2007). Studies using the C21st Health Check (Glasgow U.A.P., 2001) and the Comprehensive Health Assessment Program (CHAP, Lennox et al., 2007) reported benefits in 
terms of health outcomes: the problems of underdiagnosis decreased and health promotion was stimulated (Cooper et al., 2006).

\section{Part 3 - Autonomy of people with ID}

Participatory research among people with ID proved to be feasible, and useful results were obtained. However, active participation by people with ID in decisions about their health is rare. Cumella (2008) evaluated the implementation of Valuing People and reported that consumer choice as regards public services is only practised by people with mild/moderate ID. The health care workers of Centre of Developmental Disability Health Victoria (CDDHV), who use specific tools and training sessions, reported positive supporting results, e.g. Personal Health Record (PHR). On the other hand, it is not easy to support people with ID in exercising autonomy if the health care workers only see clients with complex problems.

GPs, people with ID and their support workers can improve triadic communication by emphasizing this specific form of communication. People with ID who participated as research partners in our study appreciated the opportunity to express their communication preferences. This is in agreement with Abma et al. (2009), who reported about people with ID sharing decision-making with professionals.

\section{Strengths and Limitations}

People with ID performed an active role in our studies. They were not only interviewed, but also acted as research partners, which meant that they participated in research as members of the community and they were able to act autonomously.

The research method we chose for our quantitative study was carefully designed. The use of more than one database resulted in a reliable estimate of the numbers of people with ID in the Netherlands, including even those who did not use any ID care. This estimate can be used by governmental and other organisations in planning health care policy and the provision of supported accommodations.

The Transfer of Care Guideline can be used by all parties involved in the process of people with ID moving from residential care facilities to supported accommodations in the community. On the other hand, we found it difficult to recruit participants to test the Guideline. This small number of participants is a limitation of the study, and the same problem has been reported in the literature. Fortunately, people with ID 
appreciate the opportunity to act as research participants in interviews, and also as research partners, as we found when designing a communication preferences list.

We recruited interested health care workers to comment on the draft Guideline during three conferences. Their comments were based on their experiences of transfer of care. Managers of residential care facilities concluded in their comments that it was the IDPs who should make the first contact with GPs, because they were better able to identify the problems to be solved. GPs, on the other hand, can use our Programme for Individual Postgraduate Education (PIN) to prepare themselves for consultations with people with ID.

Thorough qualitative research into people with ID is not yet possible. Medical Ethics Committees and legal representatives were reluctant to give permission to audiotape or videotape focus group meetings with people with ID, so verbatim transcription was not allowed. In our experience, member check was also impossible, which is why we used participant check as an alternative.

\section{Recommendations for research, policy and practice}

It is important to monitor changes in the numbers of people with ID, both those living in the community in supported accommodations or with relatives and those in residential care facilities, as health care planning needs this regularly updated information. Furthermore, updates of prevalence and appropriate health care are in urgent need of one unique ICPC code for all persons with ID. This would also facilitate the development of an appropriate interdisciplinary chain of health care. Dissemination and implementation research has shown that merely creating a new instrument for appropriate health care is not enough (Grol et al., 2005; Grol \& Wensing, 1994). A pioneering role could be given to the Netherlands Organisation for Health Research and Development (ZonMw), which might initiate future studies on the implementation of recently developed instruments.

There are about 8000 GPs in the Netherlands, and almost every GP has patients with ID registered with their practice. Until now, GPs have been free to choose their subjects for post-graduate education, and even though the influx of people with ID into general practice is now increasing, post-graduate training programmes mostly lack subjects related to health care for these people. This lack of attention for the health problems of people with ID is also seen in the basic medical school curriculum and in GP training courses. The Dutch College of 
General Practitioners (NHG) should use various methods and more than one regular promotion campaign to ensure that GPs take part in the PIN on Medical care for people with ID (Wullink et al., 2005). In addition, more post-graduate education programmes on ID health care should be developed, in cooperation with ID experts.

Patient participation is an important issue in the ZonMw research programmes. Like us, ZonMw is of the opinion that the lifelong personal experiences of people with ID can very well be used in research. Further research is needed on the best ways to introduce people with ID as research partners, not only in health-related studies, but also in studies on aspects of care and care provision. In addition, studies ought to look into ways to improve the support for people with ID to help them exercise autonomy. Attitudes of health care workers are not always supportive of the exercise of autonomy (Jones et al., 2008). Studies should examine how both people with ID and health care workers can improve in this respect and can be made responsible for the autonomy skills of themselves and of the people with ID. The design of qualitative studies involving people with ID also needs further research: a debate should be started to draw up rules for audio taping or video taping focus group meetings involving people with ID, and experiments with the use of member check for people with ID should be developed. Finally, there is a need to improve communication during consultations. A communication manual could be developed with the help of people with ID who act as research partners, while specific attention should be given to triadic communication (i.e. communication between doctor and patient in the presence of an ID-support worker).

For years, Arduin, a large centre for supported living in the south-west of the Netherlands, has been promoting the importance of emancipation and empowerment for people with ID. In November 2008, the centre started the 'Academy for Quality of Life', concentrating the permanent education of people with ID and all health care workers. Twice a year, the academy offers a programme to all interested persons (Arduin, 2009). This initiative deserves implementation on a larger scale, and should be supported by an annual training budget for each person.

People with ID have the same right to live in an optimised situation as people without ID. Whereas people without ID can exercise autonomy every day, people with ID need support in exercising theirs. Support paradigm is not just a word, it is work! 


\section{References}

Abma TA, Nierse CJ \& Widdershoven GAM (2009) Patients as partners in responsive research: methological notions for collaborations in mixed research teams. Qualitative Health Research 19, 401-15.

- $\quad$ Arduin. Retrieved April 2, 2009 from http://www.arduin.nl/cliënten/leren.

- $\quad$ Cooper SA, Morrison J, Melville C, Finlayson J, Allan L, Martin G \& Robinson N (2006) Improving the health of people with intellectual disabilities: outcomes of a health screening programme after 1 year. Journal of Intellectual Disability Research 5o, 667-77.

- Cumella S (2008) New public management and public services for people with intellectual disability: a review of the implementation of Valuing People in England. Journal of Policy and Practice in Intellectual Disabilities 5, 178-86.

- $\quad$ Glasgow UAP (2001) The C21st Health Check. University of Glasgow, Glasgow.

- Grol R \& Wensing M (1994) Implementatie. Effectieve verbetering van de patiëntenzorg. Elsevier, Maarssen, the Netherlands.

- $\quad$ Grol R, Wensing M \& Eccles M (2005) Improving patient care. The implementation of change in clinical practice Elsevier, Edinburgh.

- Jones J, Ouellette-Kuntz H, Vilela T \& Brown H (2008) Attitudes of community developmental services agency staff towards issues of inclusion for individuals with intellectual disabilities. Journal of Policy and Practice in Intellectual Disabilities 5, 219-26.

- Lennox N, Bain C, Rey-Conde T, Purdie D, Bush R \& Pandeya N (2007) Effects of a comprehensive health assessment programme for Australian adults with intellectual disability: a cluster randomized trial. International Journal of Epidemiology 36, 139-46.

- $\quad$ Maas JMAM, Serail S \& Janssen AJM (1988) Frequentieonderzoek geestelijk gehandicapten 1986. IVA, Tilburg, the Netherlands.

- $\quad$ POMONA. Retrieved May, 23, 2009 from www.pomonaproject.org.

- Westerinen H, Kaski M, Virta L, Almqvist F \& Iavanainen M (2007) Prevalence of intellectual disability: a comprehensive study based on national registers. Journal of Intellectual Disability Research 51, 715-25.

- Wullink M, Schrojenstein Lantman - de Valk HMJ van, Dinant GJ. (2005) Zorg voor mensen met een verstandelijke beperking. Programma Individuele Nascholing (PIN). Dutch College of General Practitioners (NHG), Utrecht, the Netherlands. 

Summary 



\section{Summary}

At the moment, in the 1990s, the Dutch government accepted the view that people with ID should be included in the community, everyday life of people with intellectual disability (ID) and the organisation of their care changed. The whole chain of health care from residential care to primary care had to be adapted. Both ID-physicians (IDPs) and general practitioners (GPs) have to be prepared for these relatively new aspects of health care. People with ID who live in the community became members of that community and try to live autonomously.

In line with the change, this thesis focuses on three themes:

1. The prevalence of people with ID

The aim was to determine the prevalence of people with ID in the Netherlands.

2. Transfer of health care

The first aim was to assess what support was needed to ensure a smooth transfer of the health care process of people with ID from residential care facilities to supported accommodations in the community. The second study concerned the development of a postgraduate training programme 'Care for people with ID' for GPs.

3. Autonomy of people with ID

The first aim was to find out from the literature how people with ID can exercise autonomy in relation to health. Further, the contributions of physicians and consultants in supporting the autonomy of people with ID were studied. Finally, the preferences of people with ID as regards communication with their physicians were investigated.

Because of the policy change, residential care facilities should be closed and thousands of people with ID moved to supported accommodations in the community. After this change, the need for a new estimate of the number of people with ID was felt. In Chapter 2, the question 'How many people with ID can be found in (part of) the Netherlands?' was described. Our research group 'Health care for people with ID' performed a calculation of people with ID in the province of Limburg. Data bases of ID care facilities and general practices (Family Practices Registration Network - RNH) were used to identify as much as possible persons with ID. By using this combination, the prevalence of ID appeared to be between $0,64 \%$ and $0,70 \%$. 
Based on the Limburg data from chapter 2, in Chapter 3 the prevalence of ID in the Netherlands was extrapolated. The lowest and highest estimation of prevalence of ID was calculated. A good estimation of prevalence of ID in the Netherlands was $0.7 \%$ (111 750 persons). Other assumptions yielded 0.54-0.64\%. Compared to 1988, there has been a slight decrease in the prevalence of ID. All age groups, persons living in ID care facilities and those living with relatives, as well as those who were not included in ID care services records, but were identified in GP databases, were included.

A Transfer of ID Care Guideline was developped and tested to create a smooth transfer of medical care from IDPs to GPs. In Chapter 4, the elements and the barriers of both the draft and the definitive Guideline were reported. IDPs and GPs made feasible working agreements about handing over patient files with problem list and history and about arrangements of out-of-hours house calls and practice visits, medication delivery and paramedical treatments. Solutions for barriers were suggested. More attention is needed for the implementation of the Guideline, because the transfer process is still going on.

In Chapter 5 the development of an individual (electronical) education for GPs titled 'Care for people with ID' was decribed. The programme is part of the series 'Programma Individuele Nascholing' (PIN, Programme Individual Education). The preliminary form of the PIN, a practicebased postgraduate course was evaluated in GPs education groups. The main themes of the PIN were described in six cases: presentation of complaints, physician-patient communication, co-morbidity of people with ID and cooperation between GPs and medical specialists, including the ID-physician. Subjects and cases with the highest prevalence of complaints and syndromes in daily practical care of people with ID were used. GPs who use our PIN are well prepared for consultations with people with ID.

Since the 1990s, autonomy has become an important issue for people with ID. Based on searches in Cochrane, Medline and PsycINFO, the following aspects of autonomy: self-determination, independence, selfregulation and self-realisation were studied. In Chapter 6 the answer on the question 'How do people with ID exercise autonomy in relation to health?' was described. Out of 791 articles, 39 met our criteria. Promoting autonomy and exercising autonomy in relation to health has rarely been an issue in the literature. By using specific tools and training sessions, positive results could be reported. 
In Chapter 7 the results of the study question 'During consultations, do physicians and consultants support the autonomy of people with intellectual disability (ID) in relation to health?' are described. In an Australian ID specialist consultation centre, the Centre for Developmental Disability Health Victoria (CDDHV, Australia), which was established after closing down of the residential care facilities in the 1980 , staff was interviewed about the support they can give to people with ID in exercising autonomy in relation to health. They all supported people with mild to moderate ID to act autonomously with regard to choice making and decisions about their health. CDDHV only works with referred clients, which means often clients with complex problems. Supporting autonomy was difficult for the staff, but positive experiences were reported by using specific tools, for example Personal Health Records and training sessions.

People with ID express dissatisfaction about doctor-patient communication and express their preferences about this communication. Therefore, people with ID developed together with the researcher a preference list for communication with their GP's. The similarities and differences between these communication preferences and professional criteria for doctor-patient communication of GPs were studied. In Chapter 8, the results of the comparison were described. Eight preferences for doctor-patient communication were formulated by people with ID and six of them were also formulated in the criteria of GPs. Additional requirements to improve doctor-patient communication were described and specific attention was given to triadic communication (doctor - patient with ID - support worker).

In Chapter 9 the strenghts and weaknesses of the studies were discussed, recommendations were suggested and conclusions were described. The good estimation of prevalence can be used by the government and ID care organisations and institutions. Monitoring the changes in prevalence is useful for health care planning in the future. A unique ICPC (International Classification of Primary Care) for people with ID should be helpful in prevalence studies.

In this thesis, two newly developed instruments were described and studied, i.e. the Transfer of Care Guideline and the individual education for GPs (PIN). More attention to the dissemination and implementation of these new instruments could be helpful to spread the instruments on a larger scale, because moving of people with ID is still going on. A good transfer of care process can improve health of people with ID. And, GPs 
can use the course to improve their health care for people with ID, specificly for relatively unknown complaints.

Active participation of people with ID in studies (as a research partner or as a research participant) is not easy because of restrictions. For example, during our qualitative communication preferences study, audio taping of the focusgroup meeting of people with ID was not permitted by their legal representatives. Therefore, qualitative studies are almost impossible. Better research should be possible if people with ID, support workers and relatives participated on a larger scale in studies and if restrictions were decreased. Exercising autonomy in relation to health among people with ID was not frequently found in the literature. However, positive results are reported by using specific tools and training skills. People with ID appreciate to be involved in studies, because that is a situation to exercise their autonomy.

Based on the 3 themes of this thesis, the conclusion can be that inclusion of people with ID in the community is not yet a fact. People with ID appreciate to exercise autonomy, but they need help and skills to do so. Support workers also need help and skills to exercise their new role in supporting people with ID who live in the community. An annual training budget for each person with ID and for the persons that support them is needed, so autonomy can be exercised. 
Samenvatting 



\section{Samenvatting}

In de jaren 90 groeide ook in Nederland, hoewel later dan in enkele andere landen, het besef dat mensen met een verstandelijke beperking recht hebben op een volwaardige plaats in de maatschappij (Inclusie). Dat resulteerde in een geleidelijke beleidswijziging waarbij regering en maatschappelijke organisaties ernaar gingen streven om grote instellingen af te bouwen en mensen met een verstandelijke beperking de mogelijkheid te geven om in de wijk te gaan wonen. Deze beleidswijziging had consequenties voor het leven van mensen met een verstandelijke beperking en ook voor de organisatie van hun medische zorg.

In dit proefschrift worden drie thema's besproken die gerelateerd zijn aan de beschreven beleidsverandering:

1. De prevalentie van verstandelijke beperking in Nederland

De onderzoeksvraag was hoeveel mensen met een verstandelijke beperking in Nederland verblijven.

2. Zorgoverdracht

De eerste onderzoeksvraag richtte zich op de vraag welke ondersteuning nodig is om het overgangsproces van medische zorg van instellingen voor mensen met een verstandelijke beperking naar woningen met ondersteuning in de wijk goed te laten verlopen. Het accent lag op de overdracht van zorg van artsen voor mensen met een verstandelijke beperking naar huisartsen in de wijk waar mensen met een verstandelijke beperking gingen wonen. Vervolgens werd onderzoek gedaan naar het ontwikkelen van een nascholingsprogramma voor huisartsen om ze goed voor te bereiden op de instroom van meer mensen met een verstandelijke beperking in hun praktijken.

3. Autonomie in relatie tot gezondheid van mensen met een verstandelijke beperking

In een literatuurstudie werd allereerst bekeken hoe mensen met een verstandelijke beperking autonomie ten aanzien van hun gezondheid in de praktijk brengen. Daarna werd een onderzoeksvraag uitgewerkt om te achterhalen hoe artsen en therapeuten mensen met een verstandelijke beperking ondersteunen bij het uitvoeren van die autonomie. Tenslotte werd uitgezocht welke communicatie mensen met een verstandelijke beperking wensen als ze voor een consult bij hun huisarts komen. 
De Nederlandse regering wilde voor verdere beleidsvoornemens beschikken over een recente berekening van het aantal mensen met een verstandelijke beperking in Nederland. De onderzoeksgroep 'Gezondheid voor mensen met een verstandelijke beperking' van de vakgroep Huisartsgeneeskunde van de Maastricht University heeft aantallen mensen met een verstandelijke beperking bepaald. In Hoofdstuk 2 is beschreven, hoe databestanden van zorgverleners in de provincie Limburg en het Registratie Net Huisartspraktijken (RNH) van de Maastricht University werden gebruikt om zo veel mogelijk mensen met een verstandelijke beperking te identificeren. Door deze databestanden te combineren konden ook mensen met een verstandelijke beperking die geen zorg voor mensen met een verstandelijke beperking gebruiken worden geïdentificeerd. De prevalentie van mensen met een verstandelijke beperking in Limburg bleek tussen 0,64 en 0,70\% te liggen.

Met de gevonden data uit de provincie Limburg werd een geëxtrapoleerde schatting voor Nederland gemaakt. In Hoofdstuk 3 wordt hierop ingegaan. Ook wordt beargumenteerd waarom, uit twee gehanteerde scenario's (hoge en lage schatting) de hoogste werd gekozen. Op basis van dit onderzoek kan gesteld worden dat 111750 mensen met een verstandelijke beperking in Nederland wonen (prevalentie $0,7 \%$ ). Schattingen op basis van andere aannames resulteren in een prevalentie van $0,54-0,64 \%$. Vergeleken met het vorige prevalentie onderzoek in Nederland (1988), is de prevalentie ongeveer gelijk gebleven, terwijl in het huidige onderzoek alle leeftijdsgroepen zijn geïncludeerd en gegevens van huisartsen werden gebruikt. Regelmatige updates van prevalentiedata zijn nodig om een goede planning van zorg voor mensen met een verstandelijke beperking te kunnen maken.

Mensen met een verstandelijke beperking verhuizen van instellingen naar woningen in de wijk, soms dichtbij en soms veraf van de instelling. Als gevolg daarvan dient de medische zorg anders te worden ingericht. Mensen met een verstandelijke beperking worden ingeschreven bij de huisartsen van de wijk waar ze gaan wonen en artsen van de instellingen krijgen een andere rol. Om de overdracht van zorg goed te laten verlopen werd een Richtlijn voor Zorgoverdracht ontwikkeld en getest. Dit proces wordt in Hoofdstuk 4 beschreven. In de richtlijn worden praktische afspraken voor managers, artsen voor mensen met een verstandelijke beperking (AVGs), huisartsen en hun assistenten, en begeleiders geformuleerd. Meer aandacht voor implementatie van de Richtlijn is gewenst. 
Door de verhuizingen naar kleinschalige woonvoorzieningen krijgen huisartsen te maken met meer mensen met een verstandelijke beperking in hun praktijk en gerelateerde complexere medische problemen. Om de huisarts goed toe te rusten voor deze taak werd in samenwerking met het Nederlands Huisartsen Genootschap (NHG) en de Nederlandse Vereniging voor Artsen voor mensen met een Verstandelijke Beperking (NVAVG) een nascholing voor huisartsen ontwikkeld. Het nascholingsboekje is onderdeel van de serie 'Programma Individuele Nascholing' (PIN) en is ook elektronisch te raadplegen. Het ontwikkelingsproces van de PIN 'Zorg voor mensen met een verstandelijke beperking' is beschreven in Hoofdstuk 5. Er is een keuze gemaakt voor zes casus, die klachten en syndromen met een hoge prevalentie vertegenwoordigen. Verder komen aan de orde: presentatie van klachten, arts-patient communicatie, co-morbiditeit en samenwerking tussen huisartsen, specialisten en artsen voor mensen met een verstandelijke beperking. Huisartsen kunnen zich door bestudering van de PIN goed voorbereiden op de zorg voor mensen met een verstandelijke beperking.

Normalisatie, participatie en inclusie in de maatschappij bepalen al jaren het beleid voor ondersteuning aan mensen met een verstandelijke beperking. In die maatschappij gelden rechten en plichten, bijvoorbeeld recht op autonomie. De onderzoeksvraag van het literatuur review in Hoofdstuk 6 was: 'Hoe brengen mensen met een verstandelijke beperking autonomie in relatie tot gezondheid in de praktijk?'. Uit de literatuur over gezondheid, gezondheidsethiek en zorg voor mensen met een verstandelijke beperking werd een definitie van autonomie gekozen. Autonomie in relatie tot gezondheid blijkt geen belangrijk onderwerp te zijn Slechts 39 (van 791) artikelen werden gevonden waarin mensen met een verstandelijke beperking een actieve rol spelen betreffende autonomie. Wel blijkt dat specifieke hulpmiddelen en scholing een positief effect hebben op het uitvoeren van autonomie in relatie tot gezondheid door mensen met een verstandelijke beperking.

Vervolgens werd onderzocht hoe autonomie in praktijk wordt gebracht. Het Centre for Developmental Disability Health Victoria (CDDHV, Australië) is een gespecialiseerd centrum voor zorg aan mensen met een verstandelijke beperking. Het centrum werd opgericht om deskundigheid te behouden na het sluiten van de instituten in de jaren 8o. Huisartsen en psychiaters kunnen gebruik maken van de deskundigheden van de staf bij het oplossen van complexe problemen van mensen met een verstandelijke beperking. De staf werd geïnterviewd over de mogelijkheden en onmogelijkheden van het ondersteunen van 
mensen met een verstandelijke beperking tijdens consulten betreffende autonomie in relatie tot gezondheid. Autonomie van mensen met een verstandelijke beperking werd beperkt gezien, want verwezen cliënten zijn mensen met ernstige problemen. In Hoofdstuk 7 worden wel positieve ervaringen beschreven bij mensen met een lichte tot matige verstandelijke beperking, bij het gebruik van speciale hulpmiddelen voor deze mensen (Personal Health Record) en na het volgen van scholingen.

Omdat mensen met een verstandelijke beperking klachten uiten over de communicatie met hun arts werd aan een aantal mensen met een verstandelijke beperking gevraagd, hun wensen ten aanzien van communicatie met een arts tijdens een consult onder woorden te brengen. Hun acht wensen zijn beschreven in Hoofdstuk 8 en vergeleken met de communicatiecriteria van huisartsen zoals die aan bod komen tijdens de huisartsopleiding. Zes van de acht wensen kwamen overeen met de criteria en gewenste aanvullingen om de arts patiënt communicatie te verbeteren werden geformuleerd. De communicatie tussen arts - patiënt met een verstandelijke beperking begeleider werd daarbij expliciet als aanvulling genoemd, omdat mensen met een verstandelijke beperking vaak samen met hun begeleider naar de huisarts gaan.

In Hoofdstuk 9 wordt de sterkte-zwakte analyse van het gehele onderzoek besproken, en worden aanbevelingen gedaan en conclusies getrokken. De goed onderbouwde prevalentie van verstandelijke beperking kan voorlopig door regering en instellingen worden gebruikt. Als er een specifieke ICPC code (International Classification of Primary Care) voor mensen met een verstandelijke beperking zou komen, dan zal het in de toekomst gemakkelijker zijn om prevalentie-onderzoek te doen.

Tijdens studies beschreven in dit proefschrift zijn bruikbare instrumenten ontwikkeld, namelijk de Richtlijn voor Zorgoverdracht en de nascholing 'Zorg voor mensen met een verstandelijke beperking'. Het op grotere schaal gebruiken van deze instrumenten kan worden bevorderd door disseminatie en implementatie studies te laten volgen op de nu afgeronde ontwikkelings- en testfase. Het is te verwachten dat huisartsen door nascholing adequate zorg aan mensen met een verstandelijke beperking kunnen geven bij ziektebeelden die tot nu toe weinig in de praktijk voorkomen.

Onderzoek doen waarbij mensen met een verstandelijke beperking zijn betrokken is niet eenvoudig vanwege de vereiste instemming die veelal niet van de persoon zelf mag komen. Het maken van audio-opnames van 
een groepsgesprek in het kader van kwalitatief onderzoek wordt daardoor zo goed als onmogelijk. Door grotere deelname aan onderzoek van mensen met een verstandelijke beperking, maar vooral ook door begeleiders en familieleden kan een beter onderzoeksresultaat worden bewerkstelligd. Uitvoeren van autonomie in relatie tot gezondheid door mensen met een verstandelijke beperking komt niet frequent voor. Echter, positieve ontwikkelingen werden gemeld door gebruik te maken van specifieke hulpmiddelen en trainingen. Mensen met een verstandelijke beperking waarderen een actieve rol als onderzoeks-partner, omdat die rol mede uitdrukking geeft aan hun autonomie.

Er moet nog het nodige werk verzet worden om mensen met een verstandelijke beperking een volwaardige plaats in de maatschappij (Inclusie) te laten innemen. Mensen met een verstandelijke beperking wensen autonomie en hebben hiervoor steun en scholing nodig. Het leven in de maatschappij vergt immers andere vaardigheden dan het wonen in een instelling. Een jaarlijks scholingsbudget voor mensen met een verstandelijke beperking en hun ondersteuners faciliteert naar verwachting de gewenste uitbreiding van autonomie. 



\section{List of publications}





\section{List of publications}

2001: Wullink M, Stoffers HEJH \& Kuipers H. A primary care walking exercise program for patients with intermittent claudication. Medicine and Science in Sports and Exercise 33, 1629-34.

2002: Schrojenstein Lantman-de Valk, HMJ van, Heurn-Nijsten EWA van \& Wullink $M$. Mensen met een verstandelijke beperking in Nederland Prevalentie onderzoek. Universiteit Maastricht, Maastricht.

2003: Wullink Magda, Henny van Schrojenstein Lantman-de Valk, Marjan van den Akker, Job Metsemakers \& Geert-Jan Dinant. Overdracht van zorg naar de huisarts voor mensen met een verstandelijke beperking die in de wijk (gaan) wonen. Universiteit Maastricht, Maastricht.

2003: Wullink M, Schrojenstein Lantman - de Valk HMJ van, Metsemakers JFM \& Dinant GJ Overdracht van zorg naar de huisarts voor mensen met een verstandelijke beperking die in de wijk (gaan) wonen [Transfer of ID Care Guideline].

2004: Schrojenstein Lantman - de Valk HMJ van, Wierik MJM te, Akker M van den, Wullink M, Schellevis FG, Dinant GJ \& Metsemakers JFM. Morbidity and health-care use in people with intellectual disabilities in general practice: first results of a survey in the Netherlands. Journal of Policy and Practice in Intellectual Disabilities 1, 107-9.

2004: Vugt HC van, Schrojenstein Lantman - de Valk HMJ van, Heurn EWA van, Wullink M, Metsemakers JFM \& Dinant GJ. Medisch Contact 59,1903-5.

2004: Ewals F \& Wullink M Zorg voor gezondheid. In: Onderzoek over grenzen. Thematische rapportages en beschouwingen naar aanleiding van het $12^{\text {de }}$ IASSID congres, Montpellier 2004. Kersten M \& Flikweert D (Red.). Utrecht: NGBZ en LKNG/NIZW, ISBN 9077292098.

2005: Bartelink MEL, Wullink M, Stoffers HEJH \& Hoes AW. Walking exercise in patients with intermittent claudication not well implemented in Dutch primary care. European Journal of General Practice 11, 27-8.

2005: Magda Wullink \& Henny Lantman. Naar een nieuwe huisdokter. Universiteit Maastricht, Maastricht. ISBN 9080987611/9789080987616. 2005: Magda Wullink, Henny van Schrojenstein Lantman - de Valk \& Geert Jan Dinant. Zorg voor mensen met een verstandelijke beperking (PIN Programma Individuele Nascholing). Nederlands Huisartsen Genootschap, Utrecht. ISBN 9057932016.

2005: Schrojenstein Lantman - de Valk HMJ van, Akker M van den, Wullink M, Schellevis FG, Metsemakers JFM \& Dinant GJ. Gezondheidsproblemen van mensen met verstandelijke beperkingen in 
de huisartpraktijk. Nederlands Tijdschrift voor de Zorg aan mensen met verstandelijke beperkingen 31, 250-60.

2006: Schrojenstein Lantman-de Valk, HMJ van, Wullink M, Akker M van den, Heurn-Nijsten EWA van, Metsemakers JFM \& Dinant GJ. The prevalence of intellectual disability in Limburg, the Netherlands. Journal of Intellectual Disability Research 50, 61-8.

2007: Wullink M, Schrojenstein Lantman-de Valk, HMJ van, Dinant GJ \& Metsemakers JFM. Prevalence of people with intellectual disability in the Netherlands. Journal of Intellectual Disability Research 51, 511-9.

2007: Wullink M, Schrojenstein Lantman-de Valk HMJ van, Akker M van den, Metsemakers JFM \& Dinant GJ. Improving transfer of care to general practice for people with intellectual disabilities: development of a guideline. Journal of Policy and Practice in Intellectual Disabilities 4, 241-7.

2009: Wullink M, Widdershoven $G$, Schrojenstein Lantman-de Valk, $H$ van, Dinant GJ \& Metsemakers J. Autonomy in relation to health among people with intellectual disability: a literature review. Journal of Intellectual Disability Research 53, 816-26.

2009: Wullink M, Veldhuijzen $W$, Schrojenstein Lantman-de Valk, HMJ van, Metsemakers JFM \& Dinant GJ. Doctor-patient communication with people with intellectual disability. BMC Family Practice 10, 82.

2009: Wullink M, Schrojenstein Lantman-de Valk, HMJ van, Davis R, Widdershoven GAM, Metsemakers JFM \& Dinant GJ. Supporting the autonomy of people with intellectual disability in relation to health: contributions of physicians and consultants in Victoria (Australia). Submitted. 
Dankwoord 



\section{Dankwoord}

De onderzoeken zijn afgerond. Het proefschrift is gedrukt. Mijn nieuwsgierigheid is bevredigd. Ik weet wat onderzoek doen kan inhouden. Veel data verzamelen en deze tot een handzaam geheel omvormen. Inspirerende interviews met mensen met een verstandelijke beperking en hun ondersteuners. Proberen oplossingen te bedenken voor problemen die aangegeven zijn door zowel huisartsen als mensen met een verstandelijke beperking.

Persoonlijk sluit ik een periode van 9 jaar halftijds onderzoek af. Zaken die sluimerend aanwezig waren, zijn voor mij uitgekristalliseerd: ik wil creatief en innovatief bezig blijven. Ook wil ik werken in een omgeving waarin ik naast mijn verstand ook mijn gevoel kan inzetten. Gelukkig bieden mijn eigen bedrijven, die ik de afgelopen jaren heb kunnen opbouwen, daarvoor een goede mogelijkheid.

De onderzoeken beschreven in dit proefschrift waren onmogelijk zonder de bijdrage van mensen met een verstandelijke beperking. Hen dank ik hartelijk voor de interviews, focusgroepsdiscussies, ZonMw vergaderingen e.d. en hun ondersteuners voor de hulp bij het uitvoeren van de onderzoeken. Artsen voor mensen met een verstandelijke beperking en huisartsen die hebben deelgenomen aan de onderzoeken wil ik bedanken voor hun inbreng.

Mijn promotoren, Geert-Jan Dinant en Job Metsemakers, en mijn copromotor Henny van Schrojenstein Lantman - de Valk wil ik hartelijk bedanken voor hun begeleiding. Ik heb veel geleerd de afgelopen jaren. De kneepjes van het vak hebben jullie me bijgebracht. Maar ik ben ook blij dat we nu klaar zijn. Ik heb in de projectgroep meer geleerd over de scherpe kanten van mijn karakter dan ik op dat moment graag wilde en ik heb het idee dat dat wederzijds is geweest. Ondanks de problemen die wij hebben gehad rond financiën en communicatie, ben ik blij met wat wij met elkaar hebben bereikt.

Bernadette Zinzen - Turkenburg, Antje Ritter en Karin Aretz. Jullie weten hoe je een onderzoek moet opzetten, zodat de data na binnenkomst gemakkelijk in SPSS zijn in te voeren en te verwerken. Karin had altijd suggesties in de opzetfase van het onderzoek die goud waard waren. Bernadette, bedankt voor al die interviews met mensen met een verstandelijke beperking. Wij hebben dankbaar gebruik gemaakt van jouw ervaringen. Antje en Bernadette, met jullie ging ik op 
pad om congressen te houden op drie plaatsen in Nederland. De voorbereidingen waren in goede handen bij Antje. De uitvoering is prima verlopen dankzij de inzet van Antje, Bernadette en stagestudent Mireille Knulst.

Digitale ondersteuning is een vereiste. Marga van der Aa en Jim Tatipata hebben de afgelopen jaren gezorgd voor goed materiaal om mee te werken en handige tips om het tempo erin te houden. Dank voor jullie 'digital support'.

Kamergenoten zijn onmisbaar. Jaren heb ik met Piet Portegijs en Arian Plat een kamer gedeeld, regelmatig aangevuld met mijn onderzoeksassistente of studenten. We hebben veel gelachen, ergernissen besproken, interesse in elkaar gedeeld, techneuten-dingen besproken, zeppelins opgelaten en de meest energiezuinige methode bedacht en ingevoerd om de kamer koel te houden bij zomerse hitte. Kortom, we deelden lief en leed. Ik heb ervan genoten.

Ine, officieel secretaresse maar ook gastvrouw van Huisartsgeneeskunde. Ze doet haar werk, voor mij eigenlijk niet merkbaar. Maar Ine heeft nog een officieuze rol, die ze met verve vervult. Je mag haar schouder gebruiken als het water je boven de lippen stijgt. Je mag uithuilen en uitrazen. Ine luistert, haalt een glas water voor je en zorgt ervoor dat je met een beter humeur weer aan je werk gaat. Ik vind dit een heel belangrijke rol.

Gezond en fit blijven tijdens de promotie tropenjaren is een must. De dagelijkse wandeling met collega's tijdens de lunchpauze heeft daar zeker aan bijgedragen. Susanne Hanssen, Frits Ruijters, Karin Aretz en Ria Lumeij, we hebben heel wat zwanen en eenden groot zien worden en de vijver vol met vis zien geraken.

Jarenlang heb ik met vrienden en familie over mijn proefschrift gesproken. Ik heb alle wandelingen, weekendjes, gezamenlijke etentjes, (zeldzame) zeildagen, bezoek aan filmhuis en theater zeer gewaardeerd. Laten we vooral doorgaan met deze activiteiten. En het onderwerp van gesprek ligt niet vast! 
Curriculum vitae 



\section{Curriculum vitae}

Magda Wullink werd geboren op een binnenvaartschip dat op 2 juli 1952 in de haven van Leiden lag. In 1971 behaalde zij het diploma HBS-B aan de Prins Bernhard HBS te IJmuiden. Aansluitend volgde zij de opleiding Geneeskunde aan de Erasmus Universiteit te Rotterdam. Na het behalen van het Kandidaatsdiploma in 1974 ging ze een jaar werken in een instelling voor mensen met een verstandelijke beperking te Schaarsbergen. In 1977 behaalde zij het diploma Diëtetiek aan De Schutse te Nijmegen. Vervolgens heeft ze jaren gewerkt als docent anatomie/fysiologie aan inservice-A verpleegkunde opleidingen en aan de Haagse Hogeschool. Tegelijkertijd werkte ze als diëtist in een verzorgingshuis te Utrecht. In 1993 besloot ze haar banen op te zeggen en de voltijdse studie Gezondheidswetenschappen - specialisatie Bewegingswetenschappen aan de Universiteit Maastricht te gaan volgen. Het afstudeeronderzoek 'Looptraining voor patiënten met claudicatio intermittens (etalagebenen)' werd met veel plezier opgezet en uitgevoerd onder de bezielende leiding van Harm Kuipers en Jelle Stoffers. Het onderzoek heeft geresulteerd in een internationale publicatie. Om ook wat beleg op de boterham te hebben, werkte ze tijdens de studie als freelance docent anatomie/fysiologie aan een opleiding voor natuurgeneeskundig therapeuten in Arnhem. In 1998 behaalde zij het diploma Gezondheidswetenschappen (cum laude).

Vanaf 1998 werkte ze twee jaar als onderzoeker bij de staf Radiologie van het Academisch Ziekenhuis Utrecht aan het opzetten van een RCT naar niet-invasieve behandelmethoden voor patiënten met claudicatio intermittens. Het betrof een samenwerkingsproject met de capaciteitsgroep Huisartsgeneeskunde van de Universiteit Maastricht. Helaas werd het project als een implementatieprobleem ervaren en werd subsidie voor het project afgewezen.

Eind 2000 werd ze als onderzoeker aangenomen bij de onderzoeksgroep 'Gezondheidszorg voor mensen met een verstandelijke beperking' van de capaciteitsgroep Huisartsgeneeskunde van de Universiteit Maastricht om twee projecten uit te voeren. Tevens heeft ze een individuele nascholing voor huisartsen (PIN) gemaakt en een door de eigen groep gemaakt wetenschappelijk rapport vertaalt in gemakkelijk leesbare taal voor mensen met een verstandelijke beperking. Begin 2001 werd afgesproken met haar begeleiders Geert-Jan Dinant, Job Metsemakers en Henny Lantman om de projecten tot een proefschrift te bewerken. In 
juni 2005 was het geld bij de onderzoeksgroep op en heeft ze besloten om in haar eigen tijd artikelen te schrijven.

Sinds 2006 heeft ze samen met een collega (arts) een eigen bedrijf in Arnhem. Ze verzorgen lessen anatomie, fysiologie en pathologie voor natuurgeneeskundig therapeuten. Haar tweede bedrijf is in de opstartfase. Samen met twee collega's gaat ze trainingen Diagrammatisch Denken uitvoeren met als doel om gezondheid te bevorderen en ziekte te voorkomen bij werknemers in het midden- en kleinbedrijf. 